\title{
Bdired by:
}

Bonomo A.

Corona-Cabrera, V.

Norman-Acevedo, $=$

Sosa-Varela, J.C.

\section{CONSUMER \\ GULURAL \\ SUUDIES}



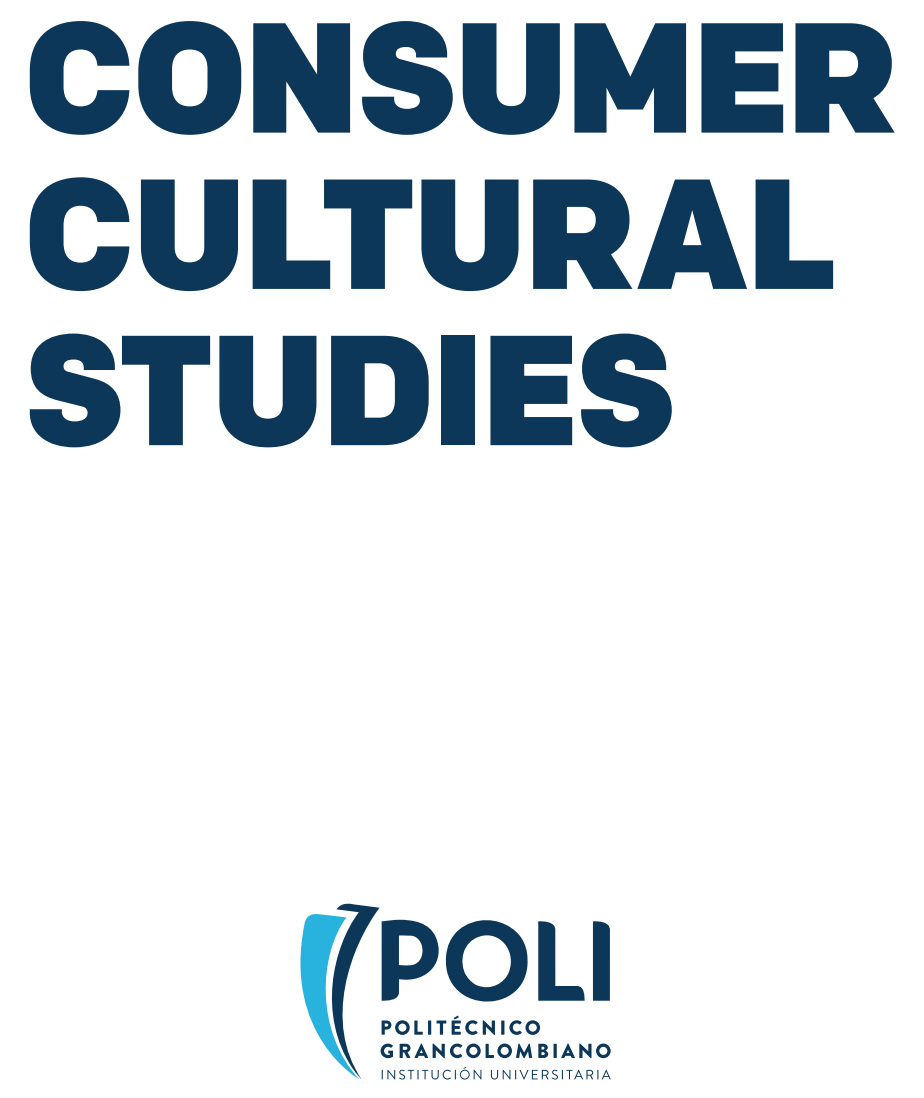


\section{POLI \\ POLITÉCNICO \\ GRANCOLOMBIANO \\ INSTITUCIÓN UNIVERSITARIA}

(C) Institución Universitaria Politécnico Grancolombiano

\section{CONSUMER CULTURAL STUDIES}

ISBN 978-958-5544-25-3

E-ISBN 978-958-5544-26-0

E-Book ISBN 978-958-5544-27-7

Editorial Politécnico Grancolombiano

Calle 61 No. 7 - 66

Tel: 7455555, Ext. 1516

Bogotá, Colombia

\section{General editor}

Carlos Eduardo Daza Orozco

\section{Scientific Editors}

Adriana Bonomo, Violeta Corona Cabrera,

Eduardo Norman-Acevedo, Juan Carlos Sosa Varela

\section{Authors:}

Adriana Bonomo, Arthur Asa Berger,

Byung-Joon CHOI, Diana Giraldo-López, Eduardo

Norman-Acevedo, Iván Alonso Montoya Restrepo, Juan Carlos Sosa Varela, Luz Alexandra Montoya

Restrepo, Oscar Robayo-Pinzon, Sandra Rojas

Berrío, Tetiana Dubovyk, Violeta Corona Cabrera

\section{Publishing Leader}

Eduardo Norman Acevedo

\section{Publishing Production Analyst \\ Carlos Eduardo Daza Orozco}

\section{Copy Editing}

Hernán Darío Cadena

\section{Electronic Design and Layout}

Nelson Rocha Sánchez

\section{Photography}

Designed by Pressfoto / Freepik

\section{Printing}

Xpress Estudio Gráfico y Digital S.A.S.

\section{How to reference this book?}

Bonomo, A., Corona-Cabrera, V., Norman-Acevedo, E., Sosa-Varela, J.C. (2019). Consumer culture studies. Bogotá, Colombia: Institución Universitaria Politécnico Grancolombiano.

Printed in Colombia
Consumer Cultural Studies / Adriana Bonomo, Arthur Asa Berger Byung-Joon CHOI ; Diana Giraldo-López ; Eduardo Norman-Acevedo; Iván Alonso Montoya Restrepo; Juan Carlos Sosa Varela; Luz Alexandra Montoya Restrepo; Oscar Robayo-Pinzon; Sandra Rojas Berrío; Tetiana Dubovyk; Violeta Corona Cabrera.

Scientific editors: Adriana Bonomo; Violeta Corona Cabrera; Eduardo Norman-Acevedo; Juan Carlos Sosa Varela; General editor: Carlos Eduardo Daza Orozco - Bogotá D.C.: Editorial Politécnico Grancolombiano., 2019.

132 p. : il. ; $17 \times 24 \mathrm{~cm}$

Includes bibliographical references.

ISBN 978-958-5544-25-3

E-ISBN 978-958-5544-26-0

E-Book ISBN 978-958-5544-27-7

Consumer behavior 2. Marketing 3. Consumers - studies 4. Marketing research I. Adriana Bonomo II. Violeta Corona Cabrera III. Eduardo Norman-Acevedo IV. Juan Carlos Sosa Varela V. Institución Universitaria Politécnico Grancolombiano VI. Tít.

SCDD 658.8343 C758

Co-BoIUP

Sistema Nacional de Bibliotecas - SISNAB

Institución Universitaria Politécnico Grancolombiano.

Total or partial reproduction of this work is not allowed, nor its incorporation to an information system or any kind of handling in any existing or still in existent form or media, without prior written consent by the Publishing Department of Institución Universitaria Politécnico Grancolombiano.

For scientific and academic purposes, Institución Universitaria Politécnico Grancolombiano grants the following Creative Commons licensing for the content of the works: Attribution - Non-Commercial - No Derivative - Share-Alike.

The content of this publication may be quoted or reproduced with academic purposes only if the source or origin is indicated.

The opinions expressed herein are the sole respon-sibility of the author(s) and shall not be considered institutional stances".

This book is the result of a research process and has been assessed by blind peers, it complies with selec-tivity, temporality, normality and availability criteria.

The Publishing Department of Institución Universitaria Politécnico Grancolombiano is a member of Asociacion de Editoriales Universitarias de Colombia (ASEUC). 


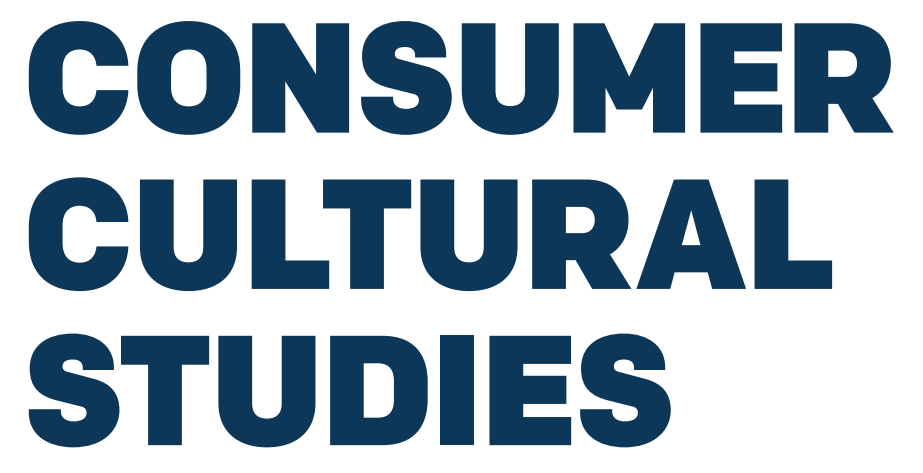

Edited by:

Bonomo, A.

Corona-Cabrera, V.

Norman-Acevedo, E.

Sosa-Varela, J.C. 


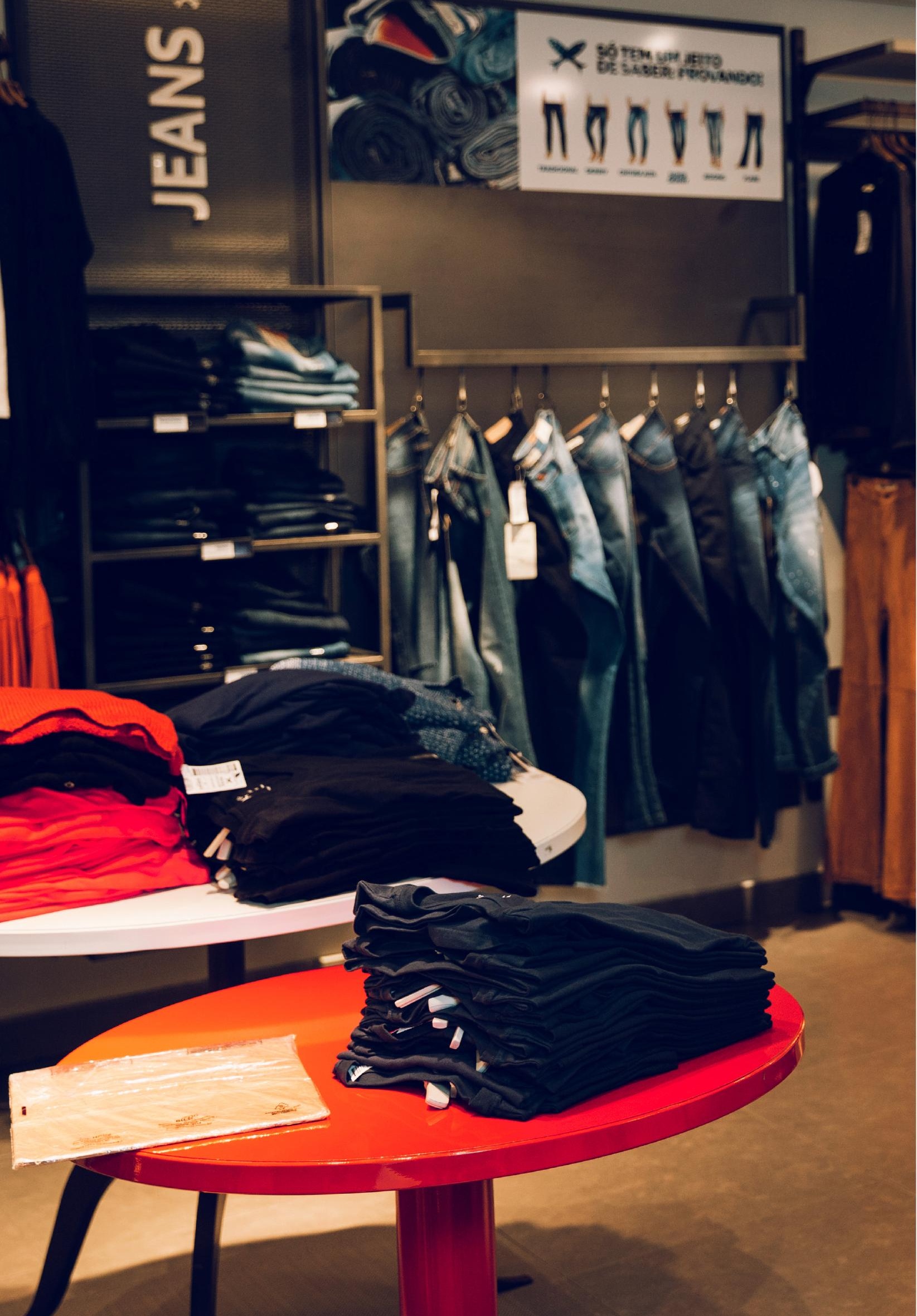




\section{CONTENTS}

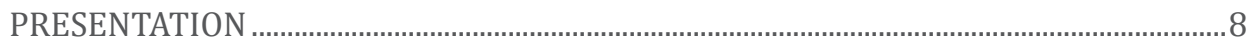

\section{CHAPTER 1}

CONSUMER CULTURE STUDIES, A GLANCE AT THE LITERATURE'S

CONTRIBUTIONS TO THE CONCEPT ….........................................................................

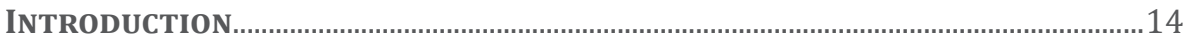

Defining the area of study and time period ..................................................................

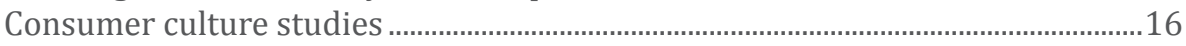

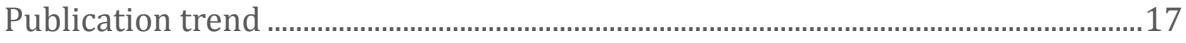

Type of text according to publication format ............................................................. 18

STUDY CONCEPT AND ASSOCIATED VARIABLES ........................................................ 19

Methodology introduced by the texts reviewed ............................................................24

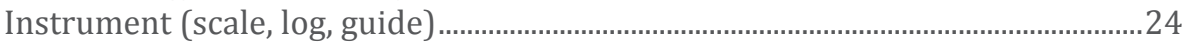

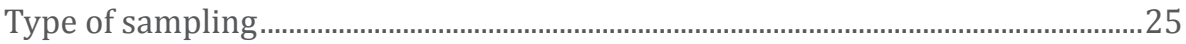

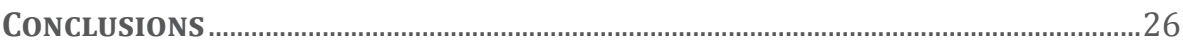

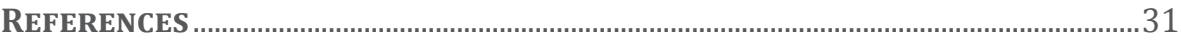

\section{CHAPTER 2}

CONSUMER DECISION PROCESS EXPLORATION:

LUXURY FASHION PRODUCTS IN BOGOTÁ ...................................................................... 41

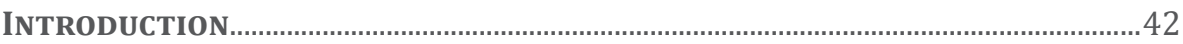

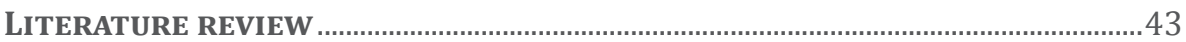

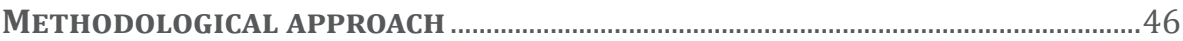

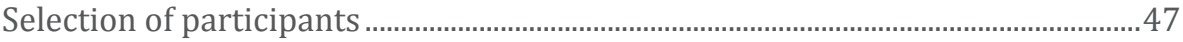

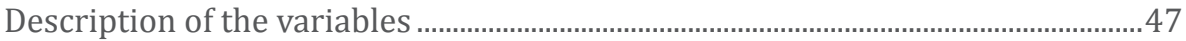

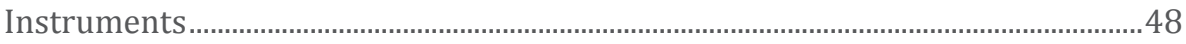

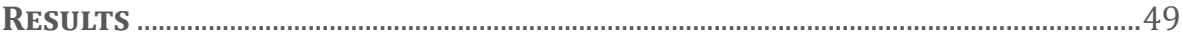

Analysis system for processing information ..................................................................49

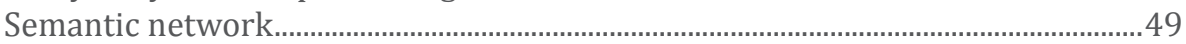

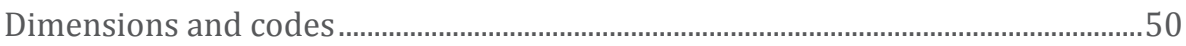

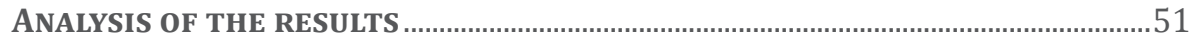

Schematic of the purchase decision process ....................................................................

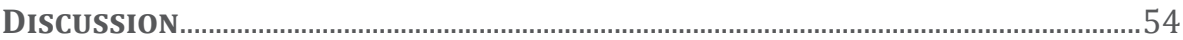

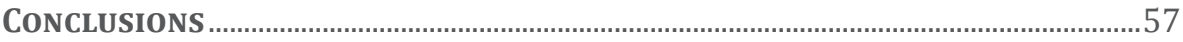

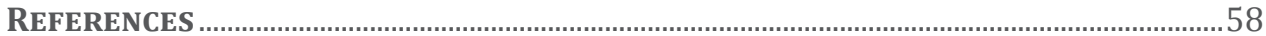




\section{CHAPTER 3}

INTERNET MARKETING COMMUNICATIONS

OF TRADE ENTERPRISES IN UKRAINE

METHOD

RESULTS

REFERENCES

\section{CHAPTER 4}

SIX MARKETING TYPOLOGIES IN SEARCH OF A CUSTOMER (WITH APOLOGIES TO LUIGI PIRANDELLO)

INTRODUCTION

The VALS (Values and Life Styles) Typology.....

THE CLARITAS TYPOLOGY

These sixty-six categories and their subcategories are shown below:

GRID-GROUP THEORY

IN DEFENCE OF SHOPPING

REFERENCES

\section{CHAPTER 5}

THE RELATION BETWEEN CULTURE AND PSYCHOLOGICAL

PROCESSES OF CONSUMERS: ATTRIBUTES-CONSEQUENCES-VALUES

LINKAGES VARIATIONS

MEANS-END THEORY IN CROSS-CULTURAL CONTEXTS.

DYNAMIC APPROACH TO CULTURAL ORIENTATION

IN STYLES OF THINKING

MethodologY

General Study Design

Participants

Priming Manipulations

Measurement of MEC Linkages.

RESULTS

Quantitative Variations in A-C and C-V Linkages.....................................................100

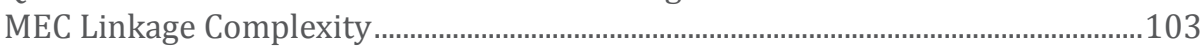

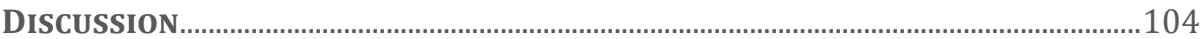

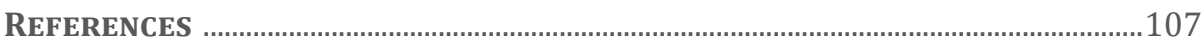

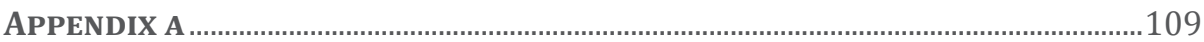

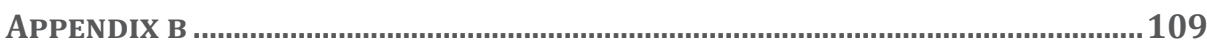


CHAPTER 6

MARKETING RESEARCH PROCESSES. A PERSPECTIVE OF THE FUTURE

FROM A QUALITATIVE VIEW

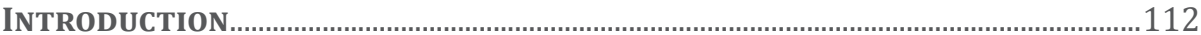

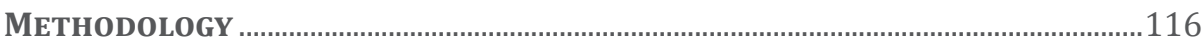

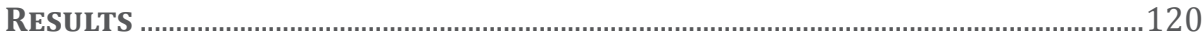

Marketing Bibliometrics Analysis According to Research Focus .............................120

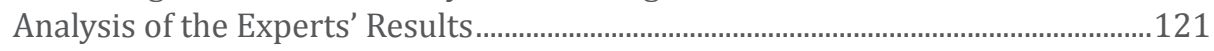

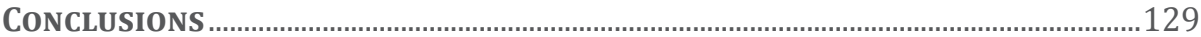

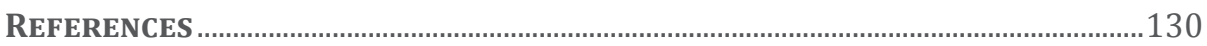




\section{PRESENTATION}

\section{Eduardo Norman Acevedo}

Institución Universitaria Politécnico Grancolombiano

Publishing Leader

Marketing -as a social discipline that outlines cultural traits- involves a series of new social players in constant change who affix new concepts to the construction of the culture of consumption, its evolution and behavior.

Understanding this and reaching an improved and complete holistic vision of the factors that affect consumers' purchase decisions (Rehman, 2017) and their influence on marketing as a social phenomenon results in a field that has been and must be explored from the outskirts in scientific papers, such as the structured review "Consumer culture theory: Development, critique, application and prospects" by Arnould, Press, Salminen, \& Tillotson (2019) who validate the need to research and disseminate findings in this area of knowledge in a book that provides a rigorous literature update due to the fact that it proposes interesting journeys through different approaches in order to understand consumption culture's studies.

Based on that exploration, the work herein examines trends in studies of interest identifying relevant theoretical concepts to understand this phenomenon, as follows: 1. Consumer buying behavior ${ }^{1}$, aimed at improving understanding of consumers' behavioral intentions and explaining the way in which the purchase intention is formed, as well as analyzing decision-making processes regarding a tangible and intangible product; 2. Market segments, with its corresponding segmentation tools to visualize demographic, lifestyle and behavioral traits depending on geographical areas of residence; 3. Cross-cultural ${ }^{2}$, as a meaningful predictor of the perceived social usefulness between market variables and its co-creation and crowdsourcing activities; 4. Emerging markets ${ }^{3}$, which explores strategic orientation of the market according to characteristics of quick growth and industrialization. 5. Mobile/online shopping ${ }^{4}$, an inquiry into the behavior of purchase decisions based on channels or digital media positioning. Finally, and prominently, some elements of Ethical consumption ${ }^{5}$ are formulated, from which a arises a concerning lack of meaningful relationship between well-being evaluative scales and ethics and sustainability dimensions that integrate consumption practices.

1. Faletar, Kovačić, \& Cerjak (2018); Kimixay, Cheng, \& Liu (2019); Swain \& Dhurkari (2018).

2. Ammar, Garbout, \& Trigui (2018); Elghannam, Arroyo, Eldesouky, \& Mesias (2018)

3. Guo, Kulviwat, Zhu, \& Wang (2019)

4. Kimixay et al. (2019)

5. Ganglmair-Wooliscroft \& Wooliscroft (2019), Moraes, Carrigan, Bosangit, Ferreira, \& McGrath (2017), Papaoikonomou \& Alarcón (2017), Zollo, Yoon, Rialti, \& Ciappei (2018) 
This collaborative publishing project was built following those trends; it embraced the participation of diverse international authors, whose perception, rationale and research development helped signify the interest and need for an in-depth approach in consumer cultural studies to provide perspectives to tackle the market's influence over popular culture, its diverse identity resources and intersections between influential analytical categories, such as surroundings, organizations and circulation and distribution of tangible and intangible products.

From a mixed methodology, the book highlights five important development areas: neuromarketing and nano marketing, research on sensory marketing, social networks and Internet analysis, ethnographies and different forms of interactive interviews. In their execution, all of the above share different quantitative techniques of different segmentation models such as The Values, Attitudes and Lifestyles (VALS) (Jeong, Yoo, \& Heo, 2011; Sirtautiene \& Sirtautas, 2009; Steenkamp \& Ter Hofstede, 2002) or Claritas typology (Brenes \& Hernandez Rivero, 2018; Fernandez-Hernandez, Leon, Aranã, \& Diaz-Pere, 2016); and in terms of qualitative techniques, they determine relationships between consumers' knowledge and purchase habits, associated through: sensory and neurological conditions, social network strategies and specific phenomena (Simpson, Bretherton, \& Vere, 2012) that lead to the configuration of a scientific anthropo-marketing, which gives us an in-depth analysis of data and interpretations on possible predictions for assertive decision-making.

The development of this publication adds diverse components that lay out the possibility of analyzing consumers' cultural phenomenon, from: understanding of the variables that intervene in the purchase decision-making process from several geographic locations, even when the market is subject to globalized rationales; reviewing local phenomena from intercultural contexts that sketch behaviors associated with the consumer; consumption of luxury items and the argumentation towards its selection; to the emerging collective -and individual- axiology of the market, which exceeds the interests to build a map of commercial factors that operate on an offline, while adapting to the continuous changes in consumers' behavior and personality traits.

This work introduces a comparison between different marketing strategies and what it takes to increase the intention of sustainable purchases, cognitive styles of concentrations, cultural norms and market forces between unique and distant societies with implications that -mainly- respond to the brand, supported by the influence of surroundings, emotions, acknowledgement and self-esteem. With the understanding that even when they are related to purchasing power and cognitive processing styles -in function of the change of self-concept induced by auto-perceptive manipulation- may affect decisions at the moment of the purchase or consumption. 
Finally, "Cultural Studies of the Consumer" goes deep into the commercial factors that operate in the network and that are constantly updated to respond to meaningful user experiences, invigorating information search processes and agile, easy and assertive purchase opportunities and choices.

\section{References:}

Ammar, O., Garbout, S., \& Trigui, I. T. (2018). Co-design and chronic regulatory focus: A cross-cultural study and suggestions for future e-marketing practices (B. T. M.A., J. R., K. Y., \& N. A., Eds.). 3rd International Conference on Digital Economy, ICDEc 2018, Vol. 325, pp. 28-47. https://doi. org/10.1007/978-3-319-97749-2_3

Arnould, E., Press, M., Salminen, E., \& Tillotson, J. S. (2019). Consumer culture theory: Development, critique, application and prospects. Foundations and Trends in Accounting, 12(2), 80166. https://doi.org/10.1561/1700000052

Brenes, M. D. C. R., \& Hernández Rivero, V. M. (2018). The incorporation and use of ICT in early childhood education. A study on infrastructure, teaching methods and teacher training in Andalusia . Pixel-Bit, Revista de Medios y Educacion, (52), 81-96. https://doi.org/10.12795/ pixelbit.2018.i52.06

Chekima, B., Chekima, S., Syed Khalid Wafa, S. A. W., Igaua, O. A., \& Sondoh, S. L. (2016). Sustainable consumption: The effects of knowledge, cultural values, environmental advertising, and demographics. International Journal of Sustainable Development and World Ecology, 23(2), 210-220. https://doi.org/10.1080/13504509.2015.1114043

Elghannam, A., Arroyo, J., Eldesouky, A., \& Mesias, F. J. (2018). A cross-cultural consumers' perspective on social media-based short food supply chains. British Food Journal, 120(10), 22102221. https://doi.org/10.1108/BFJ-11-2017-0633

Faletar, I., Kovačić, D., \& Cerjak, M. (2018). Buying behaviour of organic vegetables consumers in Croatia. Agriculturae Conspectus Scientificus, 83(3), 213-218. Retrieved from https://www. scopus.com/inward/record.uri?eid=2-s2.0-85056350919\&partnerID=40\& md5=588cdf2659b4ebcfab3f01382f5fa948

Fernández-Hernández, C., León, C. J., Aranã, J. E., \& Díaz-Pére, F. (2016). Market segmentation, activities and environmental behaviour in rural tourism. Tourism Economics, 22(5), 1033-1054. https://doi.org/10.5367/te.2015.0476

Ganglmair-Wooliscroft, A., \& Wooliscroft, B. (2019). Well-Being and Everyday Ethical Consumption. Journal of Happiness Studies, 20(1), 141-163. https://doi.org/10.1007/s10902-017-9944-0

Guo, C., Kulviwat, S., Zhu, J., \& Wang, Y. J. (2019). Competing in an emerging market: antecedents and consequences of market orientation and the role of environmental factors. Journal of Strategic Marketing, 27(3), 248-267. https://doi.org/10.1080/0965254X.2017.1411386

Jeong, N., Yoo, Y., \& Heo, T.-Y. (2011). Market segmentation strategies for future telecommunications services. Portland International Center for Management of Engineering and Technology - Technology Management in the Energy-Smart World, PICMET'11. Retrieved from 
https://www.scopus.com/inward/record.uri?eid=2-s2.0-80053380188\&partnerID=40\&md5=54b1350714afd377159c0838039d4aa6

Kimixay, L., Cheng, L., \& Liu, X. (2019). An empirical study to understand the effect of email marketing on Consumer's online buying behavior in a developing country. 3rd International Conference on Management Engineering, Software Engineering and Service Sciences, ICMSS 2019, 179-183. https://doi.org/10.1145/3312662.3312669

Li, M., Zhang, H., Xiao, H., \& Chen, Y. (2015). A grid-group analysis of tourism motivation. International Journal of Tourism Research, 17(1), 35-44. https://doi.org/10.1002/jtr.1963

Moraes, C., Carrigan, M., Bosangit, C., Ferreira, C., \& McGrath, M. (2017). Understanding Ethical Luxury Consumption Through Practice Theories: A Study of Fine Jewellery Purchases. Journal of Business Ethics, 145(3), 525-543. https://doi.org/10.1007/s10551-015-2893-9

Papaoikonomou, E., \& Alarcón, A. (2017). Revisiting Consumer Empowerment: An Exploration of Ethical Consumption Communities. Journal of Macromarketing, 37(1), 40-56. https://doi. org/10.1177/0276146715619653

Rehman, V. (2017). Looking through the Glass of Indian Culture: Consumer Behaviour in Modern and Postmodern Era. Global Business Review, 18(3_suppl), S19-S37. https://doi. org/10.1177/0972150917693139

Simpson, K., Bretherton, P., \& Vere, G. D. (2012). Lifestyle market segmentation, small business entrepreneurs, and the New Zealand wine tourism industry. In Hospitality, Tourism, and Lifestyle Concepts: Implications for Quality Management and Customer Satisfaction (pp. 157-188). https://doi.org/10.1300/J162v05n02_09

Sirtautiene, D., \& Sirtautas, V. V. (2009). Consumer market segmentation on the base of evaluating TV commercials. Transformations in Business and Economics, 8(2), 150-168. Retrieved from https://www.scopus.com/inward/record.uri?eid=2-s2.0-67650270035\&partnerID=40\&md5=bba05abcf772cbbbdd7239e8e0371c81

Steenkamp, J.-B. E. M., \& Ter Hofstede, F. (2002). International market segmentation: Issues and perspective. International Journal of Research in Marketing, 19(3), 185-213. https://doi. org/10.1016/S0167-8116(02)00076-9

Swain, A. K., \& Dhurkari, R. K. (2018). Shopping goods and consumer buying behavior: An AHP perspective. 2018 International Conference on Computers in Management and Business, ICCMB 2018, 9-13. https://doi.org/10.1145/3232174.3232179

Zaharia, S. (2019). Online Shopping Motives - An Empirical Investigation of Consumer Buying Behavior in Germany's Main Online Retail Segments (N. F.F.-H. \& S. K., Eds.). 6th International Conference on HCI in Business, Government, and Organizations, HCIBGO 2019, Held as Part of the 21st International Conference on Human-Computer Interaction, HCI International 2019, pp. 333-349. https://doi.org/10.1007/978-3-030-22335-9_23

Zollo, L., Yoon, S., Rialti, R., \& Ciappei, C. (2018). Ethical consumption and consumers' decision making: the role of moral intuition. Management Decision, 56(3), 692-710. https://doi. org/10.1108/MD-10-2016-0 


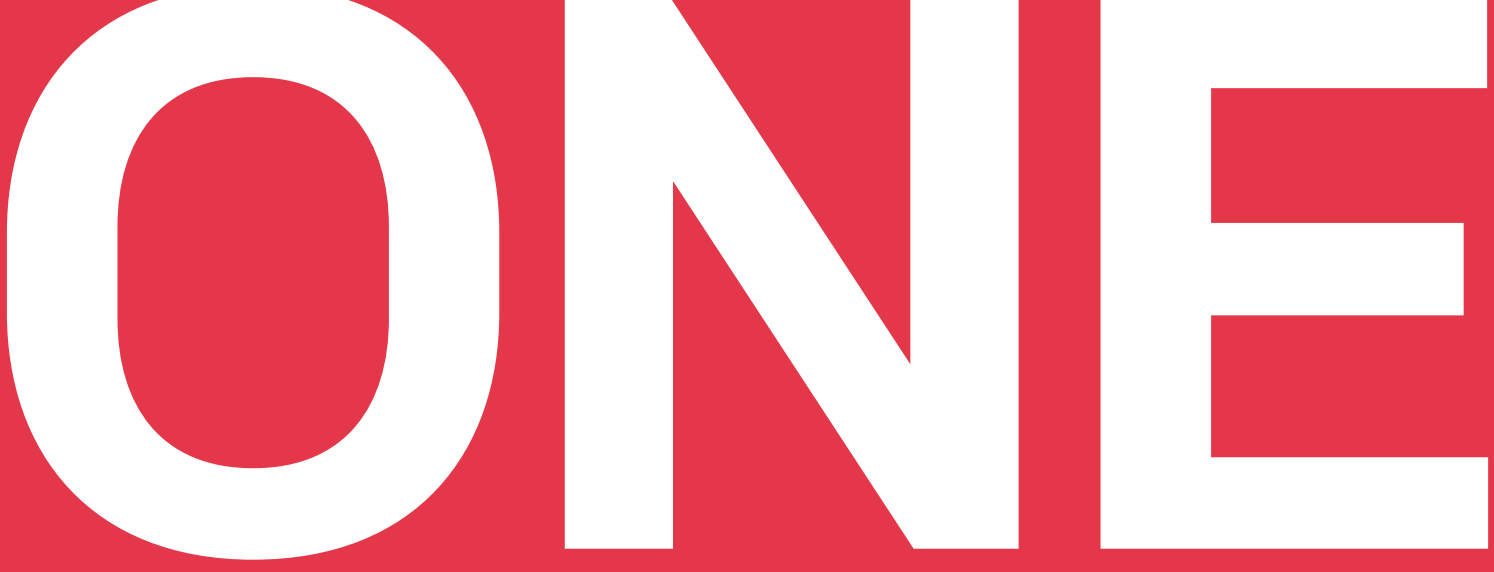

\section{CHAPTER 1 CONSUMER CULTURE STUDIES, A GLANCE AT THE LITERATURE'S CONTRIBUTIONS TO THE CONCEPT}

\section{AUTHORS:}

Eduardo Norman-Acevedo, Ma. Politécnico Grancolombiano Institución Universitaria

Juan Carlos Sosa Varela, PhD. University of Turabo of Puerto Rico

Adriana Bonomo, PhD. (c) Catholic University of Uruguay

Violeta Corona Cabrera, Ma. Pan-American University of Mexico 


\section{INTRODUCTION}

Publishing a book on consumer culture studies originates from the need to review research conducted on this subject. Among the expectations of Politécnico Grancolombiano Institución Universitaria, and as a result of reviews on the subject, this opportunity was identified within scientific literature. This book intends to be useful for readers by identifying international research trends in this field. It also aims to support the decision-making of marketing managers, with respect to consumers, and to have important input that fosters future research.

To do so, the institution introduces the structure of this editorial project, which first identified relevant authors and made an initial call to authors based on an approach to the state of the art by implementing a systematic literature review (SLR) (Kitchenham, 2004). The call made in August 2017 proposed that a select group of authors participate in the project with a chapter of its structure, given that they have indicated their interest in the subject. This proposal received great reception among those invited, including eight articles submitted, from which, after a rigorous selection process, contributions of five chapters were included at the date of publication with participation from international researchers who believed in our project.

Moreover, the project proposed establishing an editorial committee that provides academic support for the proposal. To do so, we sent out a call for academics with a PhD. Juan Carlos Sosa Varela, Chair and Associate Professor, University of Turabo of Puerto Rico, is completing Post-Doctoral Studies (PAG) at the Central American Institute of Business Administration in Alajuela, Costa Rica, PhD in International Business (School of Business Administration), University of Puerto Rico: San Juan and has research interests in international marketing, corporate responsibility, and branding. Lic ${ }^{1}$. Adriana Bonomo, Professor of high dedication at the Catholic University of Uruguay, holds a Doctorate in Business Administration (c) from "Santa Maria De Los Buenos Aires" Catholic University of Argentina, School of Social and Economic Sciences, with interests in Entrepreneurship and Marketing. Violeta Corona Cabrera holds a Master's Degree in Strategic Marketing from Pan-American University and is currently a professor in the Marketing Department at the Pan-American University of Mexico and has interests in market research, strategic planning, and marketing strategy. The institutional contribution is made by Eduardo Norman-Acevedo, Editorial Head and professor at Politécnico Grancolombiano Institución Universitaria. Master's Degree in Strategic Marketing Management and Expert in Communication and Dissemination of Science and Technology at the University of Oviedo, Asturias in Spain.

\footnotetext{
1. T.N.: Academic title used by professionals having a bachelor college degree in different fields.
} 
Within the development of the Master's Program in Marketing at the Politécnico Grancolombiano Institución Universitaria, frequently, expectations are identified in the academic community regarding the appearance of information from various sources, the interest in ensuring quality and its origin. Thus, institutional affiliation to reliable databases like Scopus allows the academic community to consult quality information. For this reason, from the institution, supported by the teaching staff, we started to create review publications, identifying key aspects during the training process of future teachers and hoping to encourage the use of this type of tool that contributes to the quality of production and teaching.

This chapter comprises the different stages used in the SLR, based on the SLR protocol proposed by (Kitchenham, 2004). It evaluates the existing literature in a database such as Scopus, in light of the publication, with a methodology that allows for replication or future review. "The interest in developing a systematic review arises from researchers' need to summarize existing information on knowledge in the marketing field, in a rigorous and impartial manner" (López, Méndez, Paz, \& Arboleda, 2016 p. 11). The goal is to establish a state of the art useful in the academic process of the institution.

The protocol includes systematically recording of the procedure, which enables us to contrast the information at different times to achieve conclusive results (Brereton, Kitchenham, Budgen, Turner, \& Khalil, 2007). The protocol used for this study is constructed from the 13 activities proposed by the aforementioned authors. These activities are divided into three clearly distinguished stages (in the order mentioned): planning, execution, and analysis (López et al., 2016).

"In the planning stage, the specific intention, as well as the approach, must be identified. This process includes writing out the objectives. The strategy considers all perspectives and outlines the development of relevant search strings to obtain the articles necessary for the SLR (Petersen, Feldt, Mujtaba, \& Mattsson, 2008 p. 146). The search query lays out the criteria for selecting the literature and applies inclusion and exclusion criteria using Boolean operators (Cream \& Verbano, 2013).

This chapter documents the process outlined to establish the publication's state of the art regarding consumers, from the Master's Program in Strategic Marketing Management at Politécnico Grancolombiano Institución Universitaria. 
We propose the following methodology for this analysis:

\section{Defining the area of study and time period}

Initially, a developing need was identified in the publication area due to the difficulty of finding media related to publishing consumer culture studies. Thus, we found a thematic opportunity relevant to students.

\section{Consumer culture studies}

In relation to consumers, one of the findings from the previous exercise identified the opportunity to take a closer look at consumer culture studies, finding an interesting number of texts and an emerging interest in this specific topic.

This is how a new exercise is constructed, which gives rise to a new SLR aimed at better understanding this phenomenon in greater depth, proposing a trend within the findings.

Through this procedure, this book identified the interest and relevance in developing this particular publishing project. It sought to again analyze and interpret a new search query that included new interests found in the previous study, and developed a different period of analysis, which yielded an initial equation of 634 texts that were subsequently refined to the database that is covered within this chapter. The result yielded a database of 385 articles devoted to research on consumer culture studies between 2011 and 2018, using the following search query in the Scopus database:

(TITLE-ABS-KEY ("consumer behavior" OR "consumer behavior") AND TITLEABS-KEY (cultur*) AND TITLE-ABS-KEY (marketing)) AND (LIMIT-TO (PUBYEAR, 2018) OR LIMIT-TO (PUBYEAR, 2017) OR LIMIT-TO (PUBYEAR, 2016) OR LIMIT-TO (PUBYEAR, 2015) OR LIMIT-TO (PUBYEAR, 2014) OR LIMIT-TO (PUBYEAR, 2013) OR LIMIT-TO (PUBYEAR, 2012) OR LIMIT-TO (PUBYEAR, 2011)).

For this review, certain variables and aspects of each of the texts analyzed were considered: purpose, marketing variable, hypotheses, instrument and information collection techniques, types of sampling, research, and information processing, results, and the country or population involved. 


\section{Publication trend}

Figure 1. Publication in Scopus, in accordance with the review.

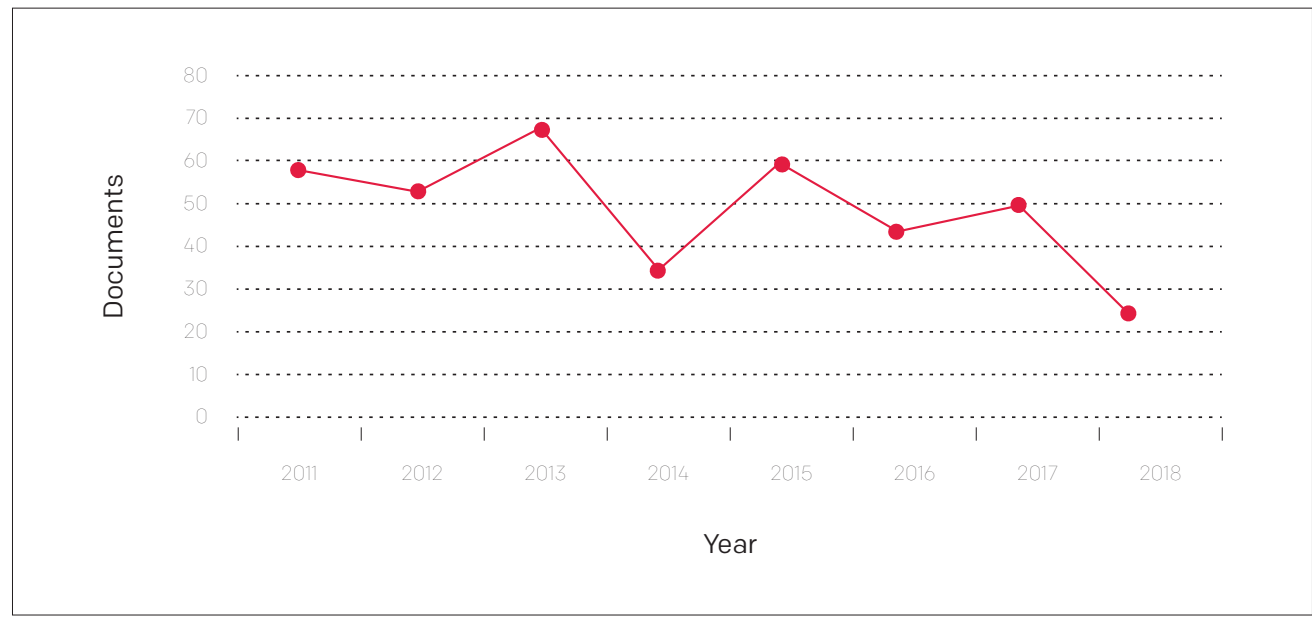

Source: Scopus.

It should first be noted that the research on consumer culture studies has remained an active and interesting topic, as it is seen as a publication trend, and is stable during the years of the review, with increased interest in 2013, remaining constant until 2017. We identified that, as of the date of the review, in publications for the current year, two publication periods are still missing, which explains the decreasing trend in 2018 as shown in Figure 1.

Below, the main publishers interested in the subject are shown.

\section{Source}

Asia Pacific Journal of Marketing and Logistics

British Food Journal 11

\begin{tabular}{l|l} 
International Marketing Review & 10
\end{tabular}

\begin{tabular}{l|l} 
Journal of Islamic Marketing & 10 \\
\hline
\end{tabular}

\begin{tabular}{l|l} 
European Journal of Marketing & 8
\end{tabular}

Journal of Business Research $\quad 8$

\begin{tabular}{l|l} 
Journal of Global Fashion Marketing & 8
\end{tabular}

\begin{tabular}{l|l} 
Journal of Consumer Marketing & 7
\end{tabular}

Table 1. Source: Scopus 
From this information, we can identify the means most interested in the subject analyzed, the different citation opportunities of greater relevance to select means of disseminating this trend, and the review of topics relevant to consumer culture studies for future studies.

\begin{tabular}{|l|c|}
\hline Language & Texts \\
\hline English & 378 \\
\hline Chinese & 2 \\
\hline Russian & 2 \\
\hline French & 1 \\
\hline German & 1 \\
\hline Spanish & 1 \\
\hline
\end{tabular}

Table 2. Source: Scopus

I $\mathrm{n}$ addition, we found that the predominant language in the journals consulted was English and that the country with the most case studies was the United States with 109 texts, followed by the United Kingdom with 49. This was one of the main reasons for deciding to publish the book in English, to have the widest visibility possible.

\section{Type of text according to publication format}

\begin{tabular}{|l|c|}
\hline Type of publication & Texts \\
\hline Article & 262 \\
\hline Book Chapter & 30 \\
\hline Conference Paper & 29 \\
\hline Book & 25 \\
\hline Conference Review & 15 \\
\hline Review & 12 \\
\hline Editorial & 6 \\
\hline News Article & 4 \\
\hline Letter & 1 \\
\hline
\end{tabular}

Table 3 Source: Scopus

Unlike the first study conducted, for this new analysis, all forms of publication were included in the search, to obtain a broader view. 
Regarding how they are circulated, we identified that $68.1 \%$ of the texts are published in scientific articles, which matches the publication trend in the marketing field overall, where $76.11 \%$ are published in this manner, which indicates a behavior similar to other forms of publication such as books where this percentage is only $6.5 \%$, compared to 7.18\% in books for marketing. This confirms the need to publish more in-depth data, justifying this book's publication.

\section{STUDY CONCEPT AND ASSOCIATED VARIABLES}

From the results analysis generated by the SLR, some main concepts were identified, which allow us to visualize the literature's progress.

\begin{tabular}{|l|c|}
\hline Study concept and associated variables & Text \\
\hline Big data analysis & 2 \\
\hline Co-creation & 2 \\
\hline Consumer behavior & 207 \\
\hline Consumer behavior; Consumer buying behavior; Cross-cultural & 1 \\
\hline Consumer behavior; Cross-cultural & 3 \\
\hline Consumer behavior; Cross-cultural; Mobile/online shopping & 1 \\
\hline Consumer behavior; Emerging markets; Cross-cultural & 1 \\
\hline Consumer behavior; Emerging markets; Mobile/online shopping & 1 \\
\hline Consumer behavior; Ethical consumption \& sustainability; Literature review & 1 \\
\hline Consumer behavior; Literature review & 2 \\
\hline Consumer behavior; Market segments & 3 \\
\hline $\begin{array}{l}\text { Consumer behavior; Market segments; Ethical consumption } \\
\text { \& sustainability; Cross-cultural }\end{array}$ & 2 \\
\hline Consumer behavior; Market segments; Mobile/online shopping & 1 \\
\hline Consumer behavior; Mobile/online shopping & 2 \\
\hline Consumer behavior; Mobile/online shopping; Cross-cultural & 5 \\
\hline Consumer behavior; Sustainable consumption & 1 \\
\hline Consumer buying behavior & 2 \\
\hline Consumer culture theory & 2 \\
\hline
\end{tabular}




\section{Study concept and associated variables}

Consumer culture theory; Consumer buying behavior

Consumer culture theory; Market segments

Cross-cultural

Cross-cultural; Market segments

Cross-cultural; Mobile/online shopping

Emerging markets

Ethical consumption \& sustainability

Ethical consumption \& sustainability; Cross-cultural

\begin{tabular}{|l|c|}
\hline Literature review & 1 \\
\hline Market segments & 10 \\
\hline Mobile/online shopping & 19 \\
\hline Mobile/online shopping; Cross-cultural & 1 \\
\hline Mobile/online shopping; Emerging markets & 1 \\
\hline Mobile/online shopping; Market segments & 1 \\
\hline Packaging & 1 \\
\hline Packaging, Sustainable consumption & 1 \\
\hline Practices of social innovation & 7 \\
\hline Practices of social innovation; Co-creation; Mobile/online shopping & 7 \\
\hline Practices of social innovation; Co-creation; & 7 \\
\hline Mobile/online shopping; Literature review & \\
\hline Practices of social innovation; Consumer buying behavior & 1 \\
\hline Practices of social innovation; Cross-cultural & 1 \\
\hline Practices of social innovation; Market segments & 353 \\
\hline Practices of social innovation; Mobile/online shopping & 1 \\
\hline Practices of social innovation; Mobile/online shopping & 2 \\
\hline Total, general & 1 \\
\hline
\end{tabular}

Table 3. Source: Created by the authors. 
With the consumer culture studies SLR, the great importance of analyzing consumer behavior is identified, where an interest in understanding this phenomenon occupies great part of the literature. From Table 3, we find 231 articles having this concept as their main motivation. It is worth mentioning two previous review articles regarding this particular topic from the works consulted. The first article (Kaufmann, Loureiro, Basile, \& Vrontis, 2012) explains the various stages of the evolution of the relationship between consumers and brands. The second conceptualization proposes a new pattern of segmentation and categorization of brand consumers and their respective behaviors derived from the different stages of development of the consumer-brand relationship integrating cultural aspects that lead to new segmentation patterns and socially responsible marketing. The second article (Al-Hyari, Alnsour, Al-Weshah, \& Haffar, 2012), related to understanding the concept from a religious perspective, gives researchers an opportunity to recognize the concept from a marketing/management perspective.

Within the SLR, there are 13 articles directly related to the topic of consumer culture Theory. These reviews raise five essential theoretical issues in basic and applied fields of study. The first suggests a detailed analysis of the processes and consequences of activities during use (Penz \& Stöttinger, 2015). The second explains activity meaning and actor motivations (Mitchell \& Imrie, 2011). The third predicts (shapes) what actions and results will occur and the impacts of attempts to influence before, during, and after getting involved (Granot, Alejandro, \& Russell, 2014). Finally, controlling or influencing beliefs, attitudes, behaviors, and assessments (Woodside, 2017). One of the most interesting articles is that of Ladik, Carrillat, and Tadajewski (2015), who argue that Belk's study within the theory of consumer culture is significant for the whole discipline, regardless of the paradigmatic position. The research presented aims to demonstrate that the article by Belk (1988) is possibly among the most influential articles ever published in JCR on the subject.

We can see a trend within the literature on consumer behavior toward studies associated with mobile/online shopping. The findings reflect similarities between markets, but also differences, related to consumers' motivation in using augmented reality systems to support their decision to buy online. It also suggests the need for retailers to consider online shopping to improve their success using the Internet (Swamp, Rese, \& Baier, 2017; Zendehdel, Paim, \& Delafrooz, 2016). For Hagag, Clark, and Wheeler (2015), there are several cultural frameworks, but they are not based on consumer behavior, whether online or offline. They consider this to be an opportunity in this area of research.

The term practices of social innovation is included in 27 texts, of which articles such as The effect on medical tourism of spreading cultural content online (Hong, Kwak, \& Kwak, 2016), which considers understanding the effect of consumer search behavior 
in the worldwide circulation of medical tourism. Another study suggests that consumers are moving from electronic channels to mobile channels and consider the effect of these technological innovations in retail environments from a cognitive perspective, where studies are limited (Swamp \& Priporas, 2016), which becomes a research opportunity. Additionally, Abou-Elgheit (2013) analyzes the enormous digital business environment in China for e-commerce, digital marketing, consumer behavior, IT outsourcing, software development, and innovation. The analysis reveals vast opportunities in China's digital social business that takes advantage of the collaborative culture for businesses and individual consumers. Finally, the study A cross-country study of consumer innovativeness and technological service innovation argues that the results of a multi-group structural equation modeling show that the relationship between consumer innovation capacity and attitude toward innovation varies in three dimensions: perceived novelty, perceived value, and perceived risk.

When reviewing the term Big Data analysis, the obtained bibliographic results yielded a limited number of texts, which could signify a research opportunity. In the research study big data and consumer behavior: imminent opportunities, Hofacker, Malthouse, and Sultan (2016) suggest that big data has the potential to broaden our understanding of each stage of the consumer decision-making process. While the field has traditionally progressed using first a theory followed by experimentation, it now appears that the nature of the feedback cycle between theory and results may change with the use of this technique. In another article Design and implementation of hadoop-based customer marketing big data processing system, Liu (Liu, 2016) argues that reliability and validity can be analyzed to determine the data collected, checking its correlation analysis, and the hypothesis model of regression analysis to obtain accurate marketing.

Co-creation is also a strong trend within publication, with more than 16 articles including this term within the SLR, and at least 14 of them are associated with the topic of consumer behavior. From the review, it is worth highlighting a study on the agricultural consumption of products that states in its findings that the quality of the product is the client's key motivator. Price is not a significant barrier in purchasing as long as the customer feels included (Murphy, 2011). Most of the texts related to this topic are included in proceedings and cover topics alluding to the effects of the policy of disseminating information about products, interactivity of social networks, and online consumer behavior, strategies to establish service-focused designs based on consumers and their degrees of involvement, the influence on general attitudes of sustainability and the congruence of values in consumer behavior among others ("International Conference on Information Systems, ICIS 2012, Volume 1," 2012; 2011; Volume 2," 2012; 2012, Volume 3," 2012, Volume 4," 2012; 2012, Volume 5," 2011; 2012, Volume 5," 2012). 
The growth of the term cross-cultural is present in 37 reviewed texts, involving concepts such as ethical consumption and sustainability (Yen, Wang, \& Yang, 2017). Another text consulted contributes decisively to group decision-making and joint decisions in segments that have not been widely researched: intercultural problems in emerging markets, emotions, and consumer misconduct (Cohen, Prayag, \& Moital, 2014). Another relevant text suggests a positive relationship between intrinsic religiosity and the belief that questionable consumer activities are not ethical. However, extrinsic religiosity does not affect consumer opinions about the ethics of consumer practices (Patwardhan, Keith, \& Vitell, 2012). The literature review showed a trend toward purchasing ethical foods (organic foods, fair trade products, and locally grown products), suggesting that this phenomenon can do more harm than good in the long term, in terms of the environment, nutrition, and health (Popa, Draghici, Popa, \& Niculita, 2011).

In relation to studying the relationship between culture and gender roles in the purchase and consumption of products, a book called Gender, culture, and consumer behavior is highlighted (Otnes \& Zayer, 2012). It offers innovative research on gender and consumer behavior with topics relevant to psychology, marketing, advertising, sociology, women's studies, and cultural studies. Another relevant study on gender shows how women go from being a wife in a consanguineous family in Nigeria, which they describe as patriarchal, to transforming their role in a nuclear family in the United Kingdom, a society to which they attribute gender equality (Lindridge, Peñaloza, \& Worlu, 2016). In the research study Gender: As a purchasing decision variable and a research at Karamanoglu Mehmetbey University (Alagöz \& Burucuoglu, 2011), they attempt to explain the term gender in several categories and study its effects (like a subclass of personal factors) in buying behavior.

Finally, the cultural concept is provided by articles from the SLR that indicate the term consumer buying behavior, which highlights a study on the characteristics of country of origin ( $\mathrm{COO}$ ) products and seeks to understand the effects of these types of products between subnational cultural consumers, which is relevant given the increasing ethnic diversity of consumer markets (Shoham, Segev, \& Gavish, 2017). It is also worth noting a modeling of consumer buying behavior using the Z-Number concept (Shoham et al., 2017). In the study by Shoham et al. (2017), the concept of Z number is applied to handle uncertainties when analyzing consumer buying behavior. This concept is also related to another empirical study conducted with Korean American families in relation to values, attitudes, and behaviors related to fashion. In this study, two roles of fashion were identified in relation to the process of family assimilation. It refers to a strong relationship between the values of parents and children in the Korean American families interviewed (Lee \& Lee, 2015). 


\section{Methodology introduced by the texts reviewed.}

\begin{tabular}{|l|c|}
\hline Methodology & Number of texts \\
\hline Causal & 5 \\
\hline Descriptive & 3 \\
\hline Exploratory & 17 \\
\hline Mixed & 2 \\
\hline Qualitative & 318 \\
\hline Quantitative & 8 \\
\hline Total, general & $\mathbf{3 5 3}$ \\
\hline
\end{tabular}

Table 4 Source: created by the authors

The analysis of the methodologies used by these studies outlines a propensity for qualitative research in the knowledge area. Studies have a tendency toward empiricism.

Most of the documented research studies are studies aimed at describing a phenomenon. Only eight documents use quantitative methodologies and only two use mixed methodologies, which identifies an opportunity to conduct multidisciplinary research with experts in other knowledge areas.

\section{Instrument (scale, log, guide)}

\begin{tabular}{|l|c|}
\hline Instrument & Number of texts \\
\hline Guide & 18 \\
\hline Literature review & 7 \\
\hline Log & 158 \\
\hline Survey & 130 \\
\hline Scale & 40 \\
\hline Total, general & $\mathbf{3 5 3}$ \\
\hline
\end{tabular}

Table 5 Source: created by the authors

The instrument configuration is distributed between scales, logs, and guides, being logs as one of the most used instruments, followed by surveys, which accounts for the previously related methodologies. 


\section{Type of sampling}

\begin{tabular}{|l|c|}
\hline Sample type & Number of texts \\
\hline $\begin{array}{l}\text { Convenience } \\
\text { sampling }\end{array}$ & 4 \\
\hline Critical reading & 34 \\
\hline Observation & 249 \\
\hline Sampling & 10 \\
\hline $\begin{array}{l}\text { Simple Random } \\
\text { sample }\end{array}$ & 56 \\
\hline Total, general & $\mathbf{3 5 3}$ \\
\hline
\end{tabular}

Table 6 Source: created by the authors

In the previous table, the different types of information collection are connected. The various mechanisms used by the researcher to collect and record the information were taken from the SLR.

The technique is focused on the methodology. For some of the texts, there may be different information collection techniques, but for this analysis, the most relevant one was selected according to the method. 


\section{CONCLUSIONS}

This book's contributions can be very useful in identifying research opportunities, as well as being a useful tool for constructing basic concepts for future research.

The chapters proposed for this publication suggest an approach to some of these theoretical models identified within the SLR. Next, we will describe the common points found within the theoretical models that introduce the different chapters to guide readers on the relevance of their reading and opportunities to make progress in the state of the art of the topics.

Chapter 2:

EXPLORATION OF THE CONSUMER DECISION PROCESS: LUXURY FASHION PRODUCTS IN BOGOTÁ.

\section{Authors:}

Oscar Robayo-Pinzon PhD. (c)

Politécnico Grancolombiano Institución Universitaria

Bachelor's degree in psychology and Master's degree in consumer psychology from Konrad Lorenz University, and researches in the areas of consumer behavior, decisionmaking models, and brand choice patterns.

\section{Sandra Rojas-Berrío PhD.}

Assistant Professor, School of Economic Sciences, National University of Colombia.

\section{Diana Giraldo-López MS.}

Politécnico Grancolombiano Institución Universitaria

Professional in Business Administration with emphasis in Finances and Master in Strategic Marketing Management at the Institución Universitaria Politécnico Grancolombiano; with 10 years of experience in commercial area, marketing, customer loyalty, and sales channels.

This chapter is the product of a research that presents the results as a suggestion for marketing managers in this sector. It identifies the need to improve their marketing strategies, focusing on what their target audience is looking for. This research is the first to analyze the decision process in buying luxury fashion products in the city of Bogotá through the use of in-depth interviews. It shows potential given the thematic con- 
cordance found in nine texts within the database. One of the studies considered in the review is Digitalization, luxury fashion and "Chineseness": The influence of the Chinese context for luxury brands and the online luxury consumers experience (Rovai, 2018). This study proposes an understanding of the emerging problems arising from the Chinese consumer market, which influence the strategy of digitalization of luxury brands in China. This allows us to make a direct comparison to this chapter, with user experiences from two different social contexts. This study suggests the need to expand the result of the very limited research on the subject. This finding from the SLR indicates the potential for readers to compare the appreciation of luxury in two places as diverse as Bogotá and China using the cross-cultural concept.

Within the referenced studies, there is also concurrence with texts on fashion marketing strategies, a phenomenon that was also studied in Mexico (Rajagopal \& Rajagopal, 2017; Rajagopal, 2011). In Italy, generally, this is covered by S. Kim, Shimizu, and Donvito (2016); specifically in the city of Florence, by the authors Aiello, Donvito, Grazzini, and Petrucci (2016); in Korea, by Read and Lee (2015); in China, by Read and Lee (2015), which may be a complement to another study, Fashion phenomenon in postmodern marketing applications and effects on the marketing components proposed by (Aksu, Pektaș, \& Eseoğlu, 2011), which is complementary by researching the effects of the phenomenon of fashion on understanding marketing and applications in marketing components. As an alternative, the Istanbul Shopping Fest project is suggested, which aims to turn Istanbul into a shopping center as a global brand, primarily for European countries and Central Asia, and for other neighboring countries; not only using clothing and fashion products but also the distinctive values of clothing and food as cultural and tourist values. Finally, the article: The impact of country of origin and ethnocentrism as major dimensions in consumer purchasing behavior in fashion industry examines the impact of the $\mathrm{COO}$ and ethnocentrism on consumer purchasing behavior in the fashion industry, specifically in the fabric industry written by Abedniya and Zaeim (2011).

For Chapter 3:

INTERNET MARKETING COMMUNICATIONS OF TRADE ENTERPRISES IN UKRAINE.

\section{Author:}

Tetiana Dubovyk Grand PhD (Economics)

Professor, Department of Marketing and Advertising

Kyiv National University of Trade and Economics

Kyiv, Ukraine 
This chapter covers the study of the transformation of the Ukrainian economy as whole, activities by specific groups of commercial companies, and trends in the development of Internet marketing communications (InMC), from the concepts of consumer behavior, market segments, and mobile/online shopping's perspective. It is precisely relevant to the proposed publication because it considers the overlap of these concepts with at least 50 texts in the SLR. This chapter discusses overlap with six texts that deal with the concept of marketing communications. The analysis of Trade Enterprises is explained in the article How consumer mindsets in ethnic Chinese societies affect the intention to buy Fair Trade products: The mediating and moderating roles of moral identity (Yen et al., 2017) and in the article Strategies for trade sales in a changing Asian business culture (Leach, Liu, \& Pelton, 2011). Another important text for the Market Communication concept is Cross-Cultural Consumer Behavior: Use of Local Language for Market Communication-A Study in Region Friuli Venetia Giulia (Italy) (Rosa, Sillani, \& Vasciaveo, 2017). Another article that stands out from the SLR is Psychological, economic and social efficiency of advertising in modern marketing communications by Lebedev (2015). Its results from experimental studies on emotional assessments of commercial and social advertisements in altered states of consciousness and by people with mental pathologies are presented. Finally, it analyzes the correlations between consumers' personal characteristics and their assessments of commercial offers under different marketing communications. The communication phenomenon is also analyzed from the concept of consumer behavior in texts by Dogerlioglu-Demir and Tansuhaj (2011a, 2011b). The mediating and moderating roles of moral identity in the communication of products (Yen et al., 2017).

\title{
Chapter 4:
}

SIX MARKETING TYPOLOGIES IN SEARCH OF A CUSTOMER (WITH APOLOGIES TO LUIGI PIRANDELLO)

Author:

\author{
Arthur Asa Berger, PhD \\ Professor Emeritus \\ Broadcast and Electronic Communication Arts \\ San Francisco State University
}

In analyzing two of the most popular marketing typologies, the VALS 1 and 2 typology and the Claritas typology, the possible use of a third typology that could complement the benefits of the first two is suggested. The author argues that these typologies have certain shortcomings and suggests a third typology called grid-group that considers the existence of four lifestyles (consumer cultures) that oppose each other but shape 
consumer preferences for community members. The concept discussed in this chapter synthesizes another publication by the author, Ads, Fads, and Consumer Culture (Berger, 2011), other texts identified that refer to the VALS typology are: (Chang, 2011, 2013; Fornerino, Jolibert, Sánchez, \& Zhang, 2011; Karami, Olfati, \& Dubinsky, 2017; J. Kim \& Kim, 2014; Ogden \& Cheng, 2011; Raij \& Riekki, 2012). Regarding grid-group analysis, by (Li, Zhang, Xiao, \& Chen, 2015). Another relevant text within the SLR is: A typology of internet users based on comparative affective states: Evidence from eight countries (Christodoulides, Michaelidou, \& Siamagka, 2013), whose study proposes the distinction of affective typologies based on the intentions of Internet users, which uses comparable samples from four Western and four East Asian countries. The chapter fits into the publication through the concepts of cross-cultural and consumer behavior, some texts relevant in the review are presented in this chapter, such as the one considered in Cultural persuasive affordances in advergaming design across cultures: A conceptual model (Wanick, Ranchhod, \& Wills, 2015) introduces a conceptual framework with the integration of cultural persuasion opportunities that could be considered in studies that involve persuasion, play, branding, and intercultural consumer behavior. Also, the results of another study whose findings suggest that attitudes toward materialism directly affect consumer behavior, and therefore marketing strategy (Moore \& Berger, 2015). In addition, some studies address the concept of lifestyles (Popa et al., 2011; Grybovych, Lankford, \& Lankford, 2013), and more recently (Muralidharan \& Xue, 2016).

\section{Chapter 5:}

THE RELATION BETWEENCULTUREAND PSYCHOLOGICAL PROCESSES OF CONSUMERS: ATTRIBUTES-CONSEQUENCES-VALUES LINKAGES VARIATIONS.

Author:

\section{Byung-Joon CHOI PHD. in Marketing CNU.}

Assistant Professor of Marketing

European Business School Paris

This chapter argues that primary consumers with holistic thinking consider broader connections between the key perceptive elements of the series of means and ends, providing support for the dynamics of culture-specific thinking styles, such as the driver of cultural variations, in consumers' cognitive complexity during the decision-making process. Important marketing perspectives arise from the results of this empirical multicultural study. The decision-making process concept is developed by (Pantano et al., 2017; Razzaque \& Chaudhry, 2013). This chapter, framed within the concepts 
of consumer behavior, emerging markets, and cross-cultural, is associated with 36 texts from the review conducted, and is similar to the concept in the article Hispanic marketing: A cultural perspective (Korzenny \& Korzenny, 2012), and it can be interpreted from the studies of consumers' responses to CSR in a cross-cultural setting (Karaosman, Morales-Alonso, \& Grijalvo, 2015). Cross-cultural research in international marketing: clearing up some of the confusion (from Mooij, 2015). Students' attitudes to marketing communications: Cross-cultural aspects (Romanova \& Noskova, 2015), which defines the influence of different elements of the culture model (cultural values, elements of material, and institutional environment) in the attitudes of Russian and Chinese students toward marketing communications.

We end external contributions with Chapter 6:

MARKETING RESEARCH PROCESSES. A PERSPECTIVE OF THE FUTURE FROM A QUALITATIVE VIEW.

Authors:

\section{Luz Alexandra Montoya-Restrepo PhD.}

Associate Professor, School of Mining, National University of Colombia.

\section{Iván Alonso Montoya Restrepo PhD.}

Associate Professor, School of Agricultural Sciences, National University of Colombia

\section{Sandra Rojas-Berrío PhD.}

Assistant Professor, School of Economic Sciences, National University of Colombia.

The research will focus on the future as a discipline highly associated with sensory and neurological studies, produced with social networking strategies, and aimed at describing specific phenomena with an ethnographic focus, which will develop a new scientific anthropology-marketing, associated with the concepts of social innovation practices, co-creation, and consumer behavior. It is directly related to 17 texts from the literature review, particularly highlighting its similarity with the article Reinventing the Role of Consumer Research in Today's Open Innovation Ecosystem (Moskowitz \& Saguy, 2013), which suggests contributions to science through consumer Research (CR). The text indicates the need to apply open innovation principles and promote innovation focused on the consumer, proposing the use of social networking strategies. It also suggests the potential identification of seven paradigm changes regarding consumers' roles and how to interact with them. Other elements suggested by the authors of this chapter, such as 
new consumer needs or unsatisfied needs or those that can be better managed, are also explored by authors from the SLR, including (Roozmand et al., 2011; Koo \& Le, 2014; Cova, Kozinets, \& Shankar, 2012). Also, the issue of purchasing decision-making mechanisms are explored by (Berčík, Horská, Gálová, \& Margianti, 2016; Hofacker et al., 2016). Articles regarding product use or utilization are also identified. We find developments related to market research in articles by (Akturan, Tezcan, \& Vignolles, 2011; Allen, Byon, \& Drane, 2011; Atkinson, Nelson, \& Rademacher, 2015; Chekima, Khalid Wafa, Igau, \& Chekima, 2015; Cohen et al., 2014; Feinberg, 2012; Ferguson \& Phau, 2012; Hernando \& Campo, 2017; Morhart, Malär, Guèvremont, Girardin, \& Grohmann, 2013; Opoku, 2012; Pennington, 2015; Pocol \& Bolboacă, 2013; Rehman, 2017; Robson, Pitt, \& Wallstrom, 2013; Sadikoglu, 2017; Shavitt, Jiang, \& Cho, 2016; Shin, 2012; Shoham et al., 2017; Tifferet \& Herstein, 2012; Wróblewski, Dacko-Pikiewicz, \& Cuyler, 2017).

\section{REFERENCES}

Abedniya, A., \& Zaeim, M. N. (2011). The impact of country of origin and ethnocentrism as major dimensions in consumer purchasing behavior in fashion industry. European Journal of Economics, Finance and Administrative Sciences, (33), 222-232. Retrieved from https://www. scopus.com/inward/record.uri?eid=2-s2.0-79959705358 \&partnerID=40\&md5=65d410c2f6dca85fc7aed3229438e6e0

Abou-Elgheit, E. (2013). The digital Guanxi: China's digital business in light of recent transformation. 2013 International Conference on Information Society, i-Society 2013, 200-206. Retrieved from https://www.scopus.com/inward/record.uri?eid=2-s2.0-84890834571\&partnerID=40\&md5=eb238daa040d81963b5a378da21b9fbc

Aiello, G., Donvito, R., Grazzini, L., \& Petrucci, E. (2016). The relationship between the territory and fashion events: The case of Florence and Pitti Immagine fashion fairs. Journal of Global Fashion Marketing, 7(3), 150-165. https://doi.org/10.1080/20932685.2016.1166714

Aksu, M., Pektaş, G. O. E., \& Eseoğlu, M. (2011). Fashion phenomenon in postmodern marketing applications and effects on the marketing components. 7th International Strategic Management Conference, 24, 325-339. https://doi.org/10.1016/j.sbspro.2011.09.126

Akturan, U., Tezcan, N., \& Vignolles, A. (2011). Segmenting young adults through their consumption styles: A cross-cultural study. Young Consumers, 12(4), 348-360. https://doi. org/10.1108/17473611111185896

Al-Hyari, K., Alnsour, M., Al-Weshah, G., \& Haffar, M. (2012). Religious beliefs and consumer behaviour: From loyalty to boycotts. Journal of Islamic Marketing, 3(2), 155-174. https://doi. org/10.1108/17590831211232564

Alagöz, S. B., \& Burucuoglu, M. (2011). Gender: As a purchasing decision variable and a research at Karamanoglu Mehmetbey University. European Journal of Economics, Finance and Administrative Sciences, (39), 94-100. Retrieved from https://www.scopus.com/inward/record. uri?eid=2-s2.0-80054806694\&partnerID=40\&md5=2ecb971c4ff7c588e12945c1cf86b0b3 
Allen, J. T., Byon, K. K., \& Drane, D. D. (2011). International students' sport spectator behavior: Socialization and cultural expression. In Social and Psychological Issues in Sports (pp. 191-216). Retrieved from https://www.scopus.com/inward/record.uri?eid=2-s2.0-84896567134\&part-

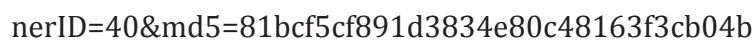

Atkinson, L., Nelson, M. R., \& Rademacher, M. A. (2015). A Humanistic approach to understanding child consumer socialization in US homes. Journal of Children and Media, 9(1), 95-112. https://doi.org/10.1080/17482798.2015.997106

Belk, R. (1988). Possessions and the Extended Self. Journal of Consumer Research, 15(2), 139-168. https://doi.org/10.1086/209154

Berčík, J., Horská, E., Gálová, J., \& Margianti, E. S. (2016). Consumer neuroscience in practice: The impact of store atmosphere on consumer behavior. Periodica Polytechnica Social and Management Sciences, 24(2), 96-101. https://doi.org/10.3311/PPso.8715

Berger, A. A. (2011). Ads, Fads, and Consumer Culture. Advertising's Impact on American Character and Society, p. 258. Retrieved from http://books.google.com/books?id=5B8yXtjEsbkC\&printsec=frontcover \&dq=intitle:Ads+Fads+and+Consumer+Culture \&hl=\&cd=1\&source=gbs api\%5Cnpapers3://publication/uuid/D6565543-930B-4D13-BB83-AD8D404C6BED

Brereton, P., Kitchenham, B. A., Budgen, D., Turner, M., \& Khalil, M. (2007). Lessons from applying the systematic literature review process within the software engineering domain. Journal of Systems and Software, 80(4), 571-583. https://doi.org/10.1016/j.jss.2006.07.009

Chang, E. C. (2011). Consumer market segmentation in China. In Handbook of Contemporary Marketing in China: Theories and Practices (pp. 185-208). Retrieved from https://www.scopus.com/ inward/record.uri?eid=2-s2.0-84896169791\&partnerID=40\&md5=f6ff991a5a6249797deae6dd5db631f5

Chang, E. C. (2013). Consumer market segmentation in China. In Handbook of Contemporary Marketing in China: Theories and Practices (pp. 185-208). Retrieved from https://www.scopus.com/inward/record.uri?eid=2-s2.0-84896234070\&partnerID=40\&md5=ea5826ccacca456128799f8c53b6b991

Chekima, B., Khalid Wafa, S. A. W. S., Igau, O. A., \& Chekima, S. (2015). Determinant factors of consumers' green purchase intention: The moderating role of environmental advertising. Asian Social Science, 11(10), 318-329. https://doi.org/10.5539/ass.v11n10p318

Christodoulides, G., Michaelidou, N., \& Siamagka, N. T. (2013). A typology of internet users based on comparative affective states: Evidence from eight countries. European Journal of Marketing, 47(1), 153-173. https://doi.org/10.1108/03090561311285493

Cohen, S. A., Prayag, G., \& Moital, M. (2014). Consumer behaviour in tourism: Concepts, influences and opportunities. Current Issues in Tourism, 17(10), 872-909. https://doi.org/10.1080/136 83500.2013.850064

Cova, B., Kozinets, R. V, \& Shankar, A. (2012). Consumer tribes. In Consumer Tribes. https://doi. org/10.4324/9780080549743

Crema, M., \& Verbano, C. (2013). Guidelines for overcoming hospital managerial challenges: A systematic literature review. Therapeutics and Clinical Risk Management, 9(1), 427-441. https:// doi.org/10.2147/TCRM.S54178 
de Mooij, M. (2015). Cross-cultural research in international marketing: clearing up some of the confusion. International Marketing Review, 32(6), 646-662. https://doi.org/10.1108/IMR12-2014-0376

Dogerlioglu-Demir, K., \& Tansuhaj, P. (2011a). Global vs local brand perceptions among Thais and Turks. Asia Pacific Journal of Marketing and Logistics, 23(5), 667-683. https://doi. org/10.1108/13555851111183084

Dogerlioglu-Demir, K., \& Tansuhaj, P. (2011b). Global vs local brand perceptions among Thais and Turks. Asia Pacific Journal of Marketing and Logistics, 23(5), 667-683. https://doi. org/10.1108/13555851111183084

Feinberg, F. M. (2012). Mediation analysis and categorical variables: Some further frontiers. Journal of Consumer Psychology, 22(4), 595-598. https://doi.org/10.1016/j.jcps.2012.03.007

Ferguson, G., \& Phau, I. (2012). A cross-national investigation of university students' complaining behaviour and attitudes to complaining. Journal of International Education in Business, 5(1), 50-70. https://doi.org/10.1108/18363261211261755

Fornerino, M., Jolibert, A., Sánchez, C. M., \& Zhang, M. (2011). Do values or goals better explain intent? A cross-national comparison. Journal of Business Research, 64(5), 490-496. https:// doi.org/10.1016/j.jbusres.2010.03.007

Granot, E., Alejandro, T. B., \& Russell, L. T. M. (2014). A socio-marketing analysis of the concept of cute and its consumer culture implications. Journal of Consumer Culture, 14(1), 66-87. https://doi.org/10.1177/1469540513485274

Grybovych, O., Lankford, J., \& Lankford, S. (2013). Motivations of wine travelers in rural Northeast Iowa. International Journal of Wine Business Research, 25(4), 285-309. https://doi. org/10.1108/IJWBR-07-2012-0023

Hagag, W., Clark, L., \& Wheeler, C. (2015). A framework for understanding the website preferences of Egyptian online travel consumers. International Journal of Culture, Tourism, and Hospitality Research, 9(1), 68-82. https://doi.org/10.1108/IJCTHR-03-2013-0008

Hernando, E., \& Campo, S. (2017). An artist's perceived value: Development of a measurement scale. International Journal of Arts Management, 19(3), 33-47. Retrieved from https:// www.scopus.com/inward/record.uri?eid=2-s2.0-85028940500\&partnerID=40\&md5=f486327941aadc4b97da4ad0db8171a1

Hofacker, C. F., Malthouse, E. C., \& Sultan, F. (2016). Big Data and consumer behavior: imminent opportunities. Journal of Consumer Marketing, 33(2), 89-97. https://doi.org/10.1108/JCM04-2015-1399

Hong, J.-W., Kwak, Y.-S., \& Kwak, Y.-S. (2016). The effect of diffusion of online culture content on medical tourism: Analysis of keyword. International Journal of Database Theory and Application, 9(11), 293-304. https://doi.org/10.14257/ijdta.2016.9.11.26

International Conference on Information Systems, ICIS 2012, Volume 1. (2012). International Conference on Information Systems, ICIS 2012, 1. Retrieved from https://www. scopus.com/inward/record.uri?eid=2-s2.0-84886536369\&partnerID=40\&md5=9ad75527585a4798835d4fbb73864ebf 
International Conference on Information Systems, ICIS 2012, Volume 2. (2011). 32nd International Conference on Information System 2011, ICIS 2011, 2. Retrieved from https://www. scopus.com/inward/record.uri?eid=2-s2.0-84884643093\&partnerID=40\&md5=27 fade6ac3f03a37cb6cf606f1c7b775

International Conference on Information Systems, ICIS 2012, Volume 2. (2012). International Conference on Information Systems, ICIS 2012, 2. Retrieved from https://www.scopus.com/inward/record.uri?eid=2-s2.0-84886483941\&partnerID=40\&md5=6cd9bfdd6a2af8d9c158ec51172c5a42

International Conference on Information Systems, ICIS 2012, Volume 3. (2012). International Conference on Information Systems, ICIS 2012, 3. Retrieved from https://www.scopus.com/ inward/record.uri?eid=2-s2.0-84886470101\&partnerID=40\&md5=7f51e14982a32277bb87f17300c42c60

International Conference on Information Systems, ICIS 2012, Volume 4. (2012). International Conference on Information Systems, ICIS 2012, 4. Retrieved from https://www.scopus. com/inward/record.uri?eid=2-s2.0-84886483021\&partnerID=40\&md5=70b50ba9af00fc697b1ff4ef4921fad6

International Conference on Information Systems, ICIS 2012, Volume 5. (2011). 32nd International Conference on Information System 2011, ICIS 2011, 5. Retrieved from https://www. scopus.com/inward/record.uri?eid=2-s2.0-84884667362\&partnerID=40\&md5=e103cbe40f0093afbd6072db2985328e

International Conference on Information Systems, ICIS 2012, Volume 5. (2012). International Conference on Information Systems, ICIS 2012, 5. Retrieved from https://www.scopus.com/ inward/record.uri?eid=2-s2.0-84886550717\&partnerID=40\&md5=2441a03d215ae7a1b04bc5151531cada

Karami, M., Olfati, O., \& Dubinsky, A. J. (2017). Key cultural values underlying consumers' buying behaviour: a study in an Iranian context. Journal of Islamic Marketing, 8(2), 289-308. https:// doi.org/10.1108/JIMA-06-2015-0039

Karaosman, H., Morales-Alonso, G., \& Grijalvo, M. (2015). Consumers' responses to CSR in a cross-cultural setting. Cogent Business and Management, 2(1). https://doi.org/10.1080/233 11975.2015.1052916

Kaufmann, H. R., Loureiro, S. M. C., Basile, G., \& Vrontis, D. (2012). The increasing dynamics between consumers, social groups and brands. Qualitative Market Research, 15(4), 404-419. https://doi.org/10.1108/13522751211257088

Kim, J., \& Kim, J.-E. (2014). Making customer engagement fun: Customer-salesperson interaction in luxury fashion retailing. Journal of Fashion Marketing and Management, 18(2), 133-144. https://doi.org/10.1108/JFMM-04-2013-0050

Kim, S., Shimizu, A., \& Donvito, R. (2016). Italian fashion case study. Journal of Global Fashion Marketing, 7(3), 147-149. https://doi.org/10.1080/20932685.2016.1166711

Kitchenham, B. (2004). Procedures for performing systematic reviews. Keele, UK, Keele University, 33(TR/SE-0401), 28. https://doi.org/10.1.1.122.3308 
Koo, F. K., \& Le, H. (2014). Understanding culture, motivation, and ethnic consumer behavior. In Handbook of Research on Effective Marketing in Contemporary Globalism (pp. 47-65). https://doi.org/10.4018/978-1-4666-6220-9.ch003

Korzenny, F., \& Korzenny, B. A. (2012). Hispanic marketing: A cultural perspective. In Hispanic Marketing: A Cultural Perspective. https://doi.org/10.4324/9780080478357

Ladik, D., Carrillat, F., \& Tadajewski, M. (2015). Belk's (1988) "possessions and the extended self" revisited. Journal of Historical Research in Marketing, 7(2), 184-207. https://doi. org/10.1108/JHRM-06-2014-0018

Leach, M. P., Liu, A. H., \& Pelton, L. E. (2011). Strategies for trade sales in a changing asian business culture. Journal of Marketing Channels, 18(3), 217-239. https://doi.org/10.108 0/1046669X.2011.584299

Lebedev, A. N. (2015). Psychological, economic and social efficiency of advertising in modern marketing communications. Psikhologicheskii Zhurnal, 36(2), 5-19. Retrieved from https://www.scopus.com/inward/record.uri?eid=2-s2.0-84958690119\&partnerID=40\&md5=baabac2b72eccc885c09a87af73f1897

Lee, J., \& Lee, Y.-J. (2015). Acculturation for fashion consumer behavior: A case of Korean-American families. Journal of Global Fashion Marketing, 6(4), 278-291. https://doi.org/10.108 $0 / 20932685.2015 .1070683$

Li, M., Zhang, H., Xiao, H., \& Chen, Y. (2015). A grid-group analysis of tourism motivation. International Journal of Tourism Research, 17(1), 35-44. https://doi.org/10.1002/jtr.1963

Lim, H., Yoo, E.-H., \& Park, M. (2018). Warehouse rental market segmentation using spatial profile regression. Journal of Transport Geography, 73, 64-74. https://doi.org/10.1016/j. jtrangeo.2018.10.007

Lindridge, A., Peñaloza, L., \& Worlu, O. (2016). Agency and empowerment in consumption in relation to a patriarchal bargain: The case of Nigerian immigrant women in the UK. European Journal of Marketing, 50(9-10), 1652-1671. https://doi.org/10.1108/EJM-07-2011-0365

Liu, Y. (2016). Design and implementation of hadoop-based customer marketing big data processing system. International Journal of Database Theory and Application, 9(12), 331-340. https://doi.org/10.14257/ijdta.2016.9.12.29

López, A., Méndez, D., Paz, A., \& Arboleda, H. (2016). Desarrollo e Instrumentación de un Proceso de Vigilancia Tecnológica basado en Protocolos de Revisión Sistemática de la Literatura. Development and Implementation of a Technology Surveillance Process Based on Systematic Literature Review Protocols., 27(4), 155-164. https://doi.org/10.4067/S071807642016000400017

Maciejewski, G., Mokrysz, S., \& Wróblewski, Ł. (2019). Segmentation of coffee consumers using sustainable values: Cluster analysis on the Polish coffee market. Sustainability (Switzerland), 11(3). https://doi.org/10.3390/su11030613

Mitchell, C., \& Imrie, B. C. (2011). Consumer tribes: Membership, consumption and building loyalty. Asia Pacific Journal of Marketing and Logistics, 23(1), 39-56. https://doi. org/10.1108/13555851111099989 
Moore, K. A., \& Berger, P. D. (2015). Materialism and consumer behavior: Differences in types of materialism among different cultures. Indian Journal of Marketing, 45(1), 9-18. https://doi. org/10.17010/ijom/2015/v45/i1/79995

Morhart, F., Malär, L., Guèvremont, A., Girardin, F., \& Grohmann, B. (2013). Brand authenticity: An integrative framework and measurement scale. Journal of Consumer Psychology, 25(2), 200-218. https://doi.org/10.1016/j.jcps.2014.11.006

Moskowitz, H. R., \& Saguy, I. S. (2013). Reinventing the Role of Consumer Research in Today's Open Innovation Ecosystem. Critical Reviews in Food Science and Nutrition, 53(7), 682-693. https://doi.org/10.1080/10408398.2010.538093

Muralidharan, S., \& Xue, F. (2016). Personal networks as a precursor to a green future: a study of "green" consumer socialization among young millennials from India and China. Young Consumers, 17(3), 226-242. https://doi.org/10.1108/YC-03-2016-00586

Murphy, A. J. (2011). Farmers' markets as retail spaces. International Journal of Retail and Distribution Management, 39(8), 582-597. https://doi.org/10.1108/09590551111148668

Ogden, H., \& Cheng, S. (2011). Cultural dimensions and materialism: Comparing canada and china. Asia Pacific Journal of Marketing and Logistics, 23(4), 431-447. https://doi. org/10.1108/13555851111165011

Opoku, R. (2012). Young Saudi adults and peer group purchase influence: A preliminary investigation. Young Consumers, 13(2), 176-187. https://doi.org/10.1108/17473611211233549

Otnes, C. C., \& Zayer, L. T. (2012). Gender, culture, and consumer behavior. In Gender, Culture, and Consumer Behavior. https://doi.org/10.4324/9780203127575

Pantano, E., \& Priporas, C.-V. (2016). The effect of mobile retailing on consumers' purchasing experiences: A dynamic perspective. Computers in Human Behavior, 61, 548-555. https:// doi.org/10.1016/j.chb.2016.03.071

Pantano, E., Rese, A., \& Baier, D. (2017). Enhancing the online decision-making process by using augmented reality: A two country comparison of youth markets. Journal of Retailing and Consumer Services, 38, 81-95. https://doi.org/10.1016/j.jretconser.2017.05.011

Patwardhan, A. M., Keith, M. E., \& Vitell, S. J. (2012). Religiosity, Attitude Toward Business, and Ethical Beliefs: Hispanic Consumers in the United States. Journal of Business Ethics, 110(1), 61-70. https://doi.org/10.1007/s10551-011-1147-8

Pennington, R. (2015). Branding cultural analogues in virtual communities. In Strategic E-Commerce Systems and Tools for Competing in the Digital Marketplace (pp. 117-138). https:// doi.org/10.4018/978-1-4666-8133-0.ch006

Penz, E., \& Stöttinger, B. (2015). Consuming "European": Capturing homogeneity and heterogeneity in consumer culture of five European countries. European Journal of International Management, 9(3), 326-341. https://doi.org/10.1504/EJIM.2015.069162

Petersen, K., Feldt, R., Mujtaba, S., \& Mattsson, M. (2008). Systematic Mapping Studies in Software Engineering. 12Th International Conference on Evaluation and Assessment in Software Engineering, 17, 10. https://doi.org/10.1142/S0218194007003112 
Pocol, C. B., \& Bolboacă, S. D. (2013). Perceptions and trends related to the consumption of honey: A case study of North-West Romania. International Journal of Consumer Studies, 37(6), 642-649. https://doi.org/10.1111/ijcs.12046

Popa, A., Draghici, M., Popa, M., \& Niculita, P. (2011). Consumer choice and food policy. A literature review. Journal of Environmental Protection and Ecology, 12(2), 708-717. Retrieved from https://www.scopus.com/inward/record.uri?eid=2-s2.0-79960773213\&partnerID=40\&md5=a0be01a11af54f067609714dbe94077d

Raij, T. T., \& Riekki, T. J. J. (2012). Poor supplementary motor area activation differentiates auditory verbal hallucination from imagining the hallucination. NeuroImage: Clinical, 1(1), 75-80. https://doi.org/10.1016/j.nicl.2012.09.007

Rajagopal. (2011). Consumer culture and purchase intentions toward fashion apparel in Mexico. Journal of Database Marketing and Customer Strategy Management, 18(4), 286-307. https:// doi.org/10.1057/dbm.2011.33

Rajagopal, \& Rajagopal, A. (2017). Brand competition, peer influence, and purchase intentions towards fashion apparel in Mexico. International Journal of Business Excellence, 12(3), 386-412. https://doi.org/10.1504/IJBEX.2017.084455

Razzaque, M. A., \& Chaudhry, S. N. (2013). Religiosity and Muslim consumers' decision-making process in a non-Muslim society. Journal of Islamic Marketing, 4(2), 198-217. https://doi. org/10.1108/17590831311329313

Rehman, V. (2017). Looking through the Glass of Indian Culture: Consumer Behaviour in Modern and Postmodern Era. Global Business Review, 18(3_suppl), S19-S37. https://doi. org/10.1177/0972150917693139

Robson, K., Pitt, L., \& Wallstrom, A. (2013). Creative market segmentation: Understanding the bugs in consumer behavior. Journal of Public Affairs, 13(2), 218-223. https://doi.org/10.1002/ pa.1477

Romanova, I. M., \& Noskova, E. V. (2015). Students' attitude to the marketing communications: Cross-cultural aspects. Journal of Advanced Research in Law and Economics, 6(1), 177-185. https://doi.org/10.14505/jarle.v6.1(11).20

Roozmand, 0., Ghasem-Aghaee, N., Hofstede, G. J., Nematbakhsh, M. A., Baraani, A., \& Verwaart, T. (2011). Agent-based modeling of consumer decision making process based on power distance and personality. Knowledge-Based Systems, 24(7), 1075-1095. https://doi.org/10.1016/j.knosys.2011.05.001

Rosa, F., Sillani, S., \& Vasciaveo, M. (2017). Cross-Cultural Consumer Behavior: Use of Local Language for Market Communication-A Study in Region Friuli Venetia Giulia (Italy). Journal of Food Products Marketing, 23(6), 621-648. https://doi.org/10.1080/10454446.2015.1048029

Rovai, S. (2018). Digitalisation, luxury fashion and "Chineseness": The influence of the Chinese context for luxury brands and the online luxury consumers experience. Journal of Global Fashion Marketing, 9(2), 116-128. https://doi.org/10.1080/20932685.2018.1435294

Sadikoglu, G. (2017). Modeling of Consumer Buying Behaviour Using Z-Number Concept. Intelligent Automation and Soft Computing, pp. 1-5. https://doi.org/10.1080/10798587.2017.1327159 
Shavitt, S., Jiang, D., \& Cho, H. (2016). Stratification and segmentation: Social class in consumer behavior. Journal of Consumer Psychology, 26(4), 583-593. https://doi.org/10.1016/j. jcps.2016.08.005

Shin, D.-H. (2012). Cross-analysis of usability and aesthetic in smart devices: What influences users' preferences? Cross Cultural Management, 19(4), 563-587. https://doi. org/10.1108/13527601211270020

Shoham, A., Segev, S., \& Gavish, Y. (2017). The effect of acculturation and ethnic identification on consumer disidentification and consumption: An investigation of U.S. Hispanics. Journal of Consumer Behaviour, 16(5), 403-412. https://doi.org/10.1002/cb.1640

Steenkamp, J.-B. E. M., \& Ter Hofstede, F. (2002). International market segmentation: Issues and perspective. International Journal of Research in Marketing, 19(3), 185-213. https://doi. org/10.1016/S0167-8116(02)00076-9

Tifferet, S., \& Herstein, R. (2012). Need for cognition as a predictor of store brand preferences. EuroMed Journal of Business, 7(1), 54-65. https://doi.org/10.1108/14502191211225374

Wanick, V., Ranchhod, A., \& Wills, G. (2015). Cultural persuasive affordances in advergaming design across cultures: A conceptual model. 19th International Academic Mindtrek Conference, AcademicMindTrek 2015, 63-68. https://doi.org/10.1145/2818187.2818293

Woodside, A. G. (2017). Solving the core theoretical issues in consumer behavior in tourism. Advances in Culture, Tourism and Hospitality Research, Vol. 13, pp. 141-168. https://doi. org/10.1108/S1871-317320170000013008

Wróblewski, Ł., Dacko-Pikiewicz, Z., \& Cuyler, A. C. (2017). The European union consumer behaviour in the festivals market in Poland . Polish Journal of Management Studies, 16(2), 302314. https://doi.org/10.17512/pjms.2017.16.2.26

Yen, G.-F., Wang, R.-Y., \& Yang, H.-T. (2017). How consumer mindsets in ethnic Chinese societies affect the intention to buy Fair Trade products: The mediating and moderating roles of moral identity. Asia Pacific Journal of Marketing and Logistics, 29(3), 553-568. https://doi. org/10.1108/APJML-06-2016-0107

Zendehdel, M., Paim, L. H., \& Delafrooz, N. (2016). The moderating effect of culture on the construct factor of perceived risk towards online shopping behaviour. Cogent Business and Management, 3(1). https://doi.org/10.1080/23311975.2016.1223390 


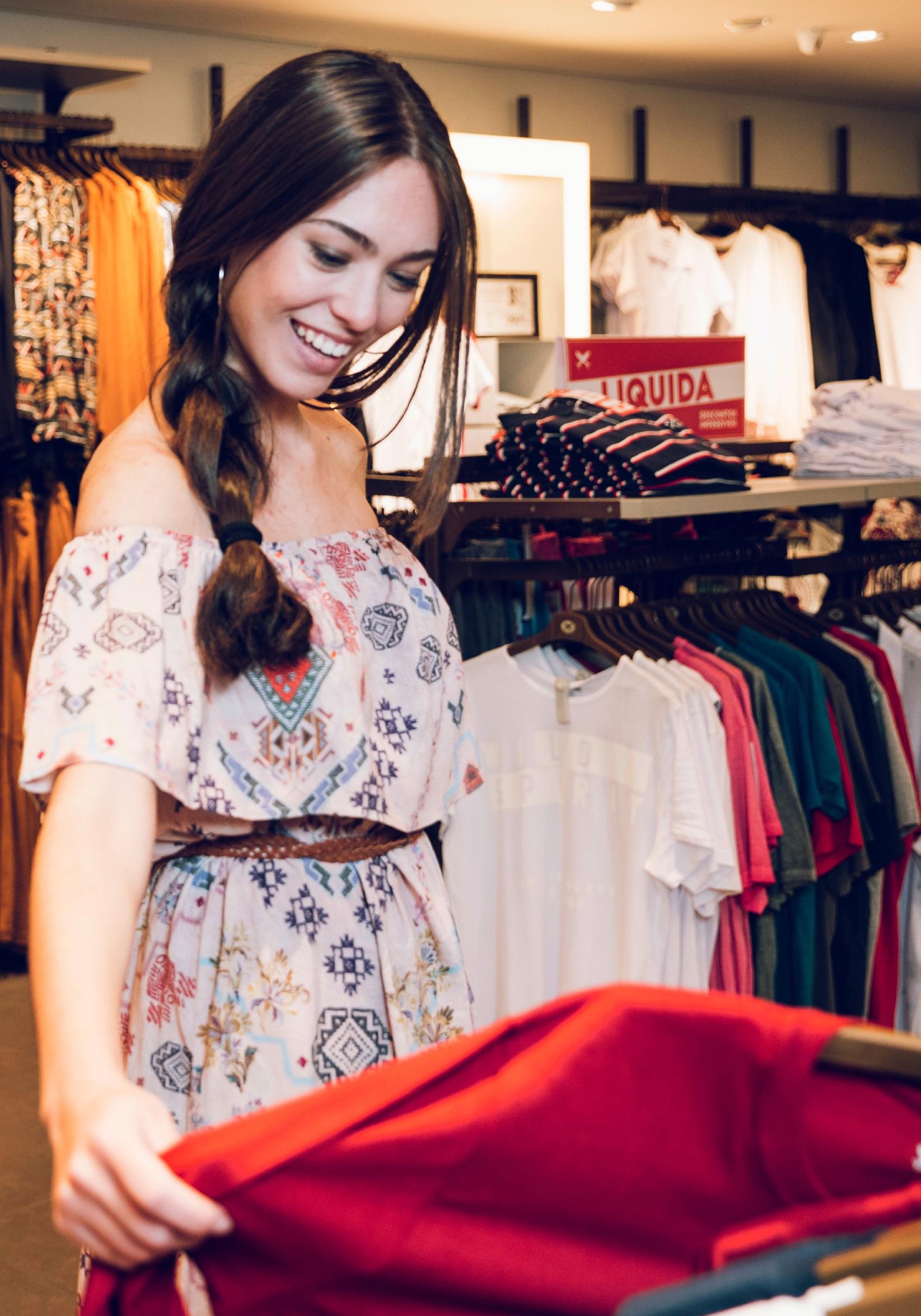





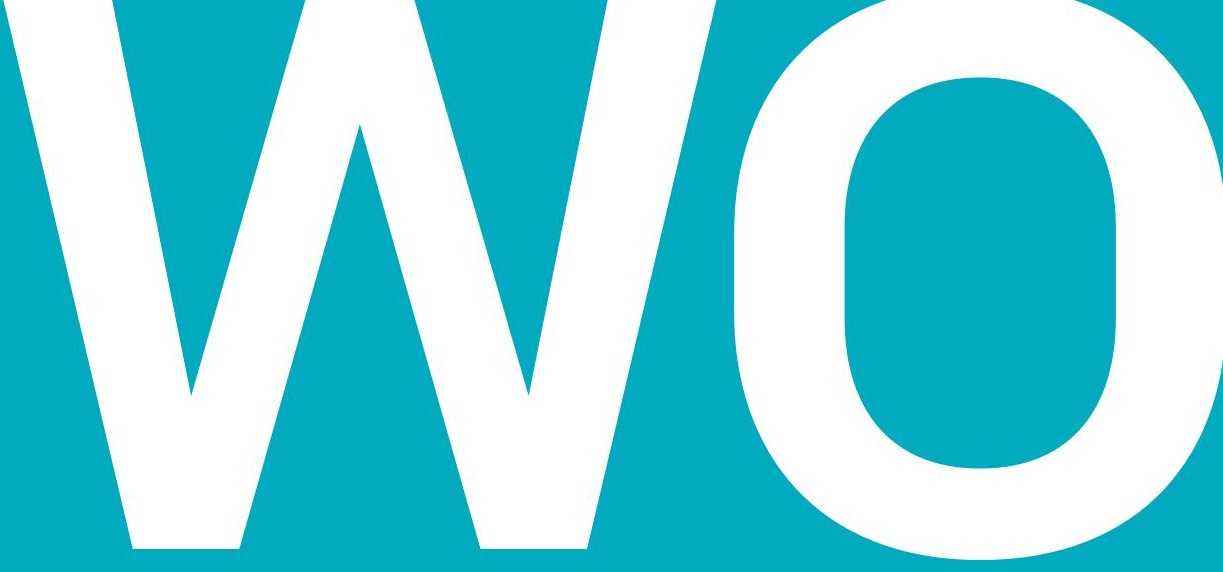

\section{CHAPTER 2 \\ CONSUMER DECISION PROCESS EXPLORATION: LUXURY FASHION PRODUCTS IN BOGOTÁ}

AUTHORS:

Oscar Robayo-Pinzon, PhD. (c)

Politécnico Grancolombiano Institución Universitaria Bachelor's degree in psychology and Master's degree in consumer psychology from Universidad Konrad Lorenz, and researches in the areas of consumer behavior, decision-making models, and brand choice patterns.

Sandra Rojas-Berrío, PhD. Assistant professor, School of Economic Sciences, Universidad Nacional de Colombia.

Diana Giraldo-López, MS.

Politécnico Grancolombiano Institución Universitaria Professional in Business Administration with emphasis in Finances and Master's in Strategic Marketing Management at the Institución Universitaria Politécnico Grancolombiano; with 10 years of experience in commercial area, marketing, customer loyalty, and sales channels. 


\section{INTRODUCTION}

This research aims to explore the factors that are part of the decision process for purchasing luxury fashion products in the city of Bogota (Colombia). The variables of influence that arise from the previous literature (product display, technological accessibility, representation of status, brand perception, lifestyle, association with well-being and wealth, association with delight, motivation of the consumer, authenticity of the product, and cost-benefit ratio) were explored as part of 10 in-depth interviews with people between ages of 25 and 45 who live in strata 5 and 6 in Bogota, Colombia. The validity of the interviews is observed in the verification of concepts with previous research, the quality of the data collected, and, therefore, with the condition of the dependence, credibility, and transferability of these data. The main variables that affect the decision process for purchasing luxury fashion products are the brand, exclusivity, distinction, and their relationship with the positive emotions generated in the consumer. The results of this research suggest how to improve their marketing strategies, focusing on what their target public looks for. This research is the first to analyze the decision process for purchasing luxury fashion products in the city of Bogota by using in-depth interviews.

Well-being and the access to certain goods have been associated with luxury over the years because, since the beginning, these have been associated with the elites (Varsha, et al., 2015; Atwal and Williams, 2009); however, this concept has evolved such that the demand for this type of product is no longer exclusive to developed countries, and developing countries currently represent millions of dollars for this industry (Truong and McColl, 2011).

As a result, luxury goods are no longer exclusive to the elite. The different brands that are representative of those goods have been forced to produce more accessible product lines to meet market demand and that are aimed at giving customers with less purchasing power access to these brands, thus meeting their psychological needs (Sulehri, et al., 2011). These needs are matched to fashion trends, which in turn generate social standards that strengthen the increase in the demand for this type of product (Levy and Luedicke, 2013; Summer, et al., 2006).

Consequently, this research demonstrates the importance of the purchase decision process as a fundamental variable for analyzing the development of the market of luxury fashion goods (Li, et al., 2012).

Considering that there are several studies on this topic in countries with conditions similar to those of Colombia, each country has singularities that correspond to the cultural development and idiosyncrasies of each population. This is therefore expected to 
serve as a basis for the development of marketing strategies and merchandising directed to this type of consumer in a growing market such as that of Colombia (Hung, et al., 2011; Lozano, 2014; Summer, et al., 2006).

Therefore, the goal of this research is to understand the different variables that are involved in the decision process for purchasing luxury fashion products in the city of Bogota. This understanding is expected to be achieved through the identification of the factors that encourage the consumer to buy luxury fashion products, the study of the variables involved in the decision process for purchasing luxury fashion goods and their influence in the decision process of consumers, the categorization of the factors according to their level of relevance, and the establishment of the criteria on which the decision process for purchasing luxury fashion products is based.

\section{LITERATURE REVIEW}

The consumer behavior that leads to the purchase of luxury products is perceived differently in developed countries compared to developing countries (Leung, et al., 2015). Considering that it is a highly competitive market where brands constantly enter, trying to position themselves as differentiated luxury products. This generates the question of how brands come into play in the positioning process, in a scenario in which consumers are driven to demand this type of product (Giovanini, et al., 2015).

Here is where different factors gain importance, such as the display of goods, which also has an impact on the intention to purchase them, which makes it possible to analyze the consumer behaviors of this type of product (Huddleston, et al., 2015). Other factors are the desire for luxury brands, how these are perceived and represent a measure of achievement for consumers, and how these psychologically affect consumers, becoming synonymous with status and a symbol of achievement (McFerran, et al., 2014).

In addition to these factors, the environment in which the market is presently being developed should be analyzed. Due to technology and the accessibility of different brands and collections, it is necessary to develop a globalized strategy that will make it possible to reach different markets and produce the expected impact, especially when the goods must be specific and differentiated and have unique features, as is the case with luxury goods (Simmers, et al., 2014).

That is precisely why the need arises to analyze more than just the market trends and to perform an in-depth analysis of the factors involved in the intention to purchase luxury goods, such as lifestyle and how it affects consumer behavior as well as its relationship with the types of products demanded (Pan, et al., 2014). For example, the case 
of luxury underwear indicates that lifestyle and personal style influence the intention to purchase these goods, in addition to factors such as perception of value, brand concept, and self-image of the consumer; in this case, these factors are used as motivators for creating market demand for this type of product (Hume and Mills, 2013).

Thus, in addition to brand, country of origin has positioned itself as a factor in the purchase decision process to such a degree that there are countries that have already positioned themselves as manufacturers of luxury goods. Therefore, country of origin has become a relevant criterion in the decision process for purchasing luxury goods (Godey, et al., 2012). It has been found that, for consumers, the origin of the goods is directly associated with the level of quality and that this attribute therefore impacts the willingness to pay, which will vary according to the brand and the consumer's perception of the product (Seidenfuss, et al., 2010).

In fact, the operations managers of different brands, in their search for knowing their consumers and their behavior, analyze the response of consumers to their manufacturing practices and production because there is a confirmed interest in knowing what type of labor practices are applied in the production of the products consumed (Aiello, et al., 2009). This causes the phenomenon of ethnocentrism because it is clear that the relationship of the brand and its origin is also relevant to the consumer; therefore, it is a factor within consumer behavior and directly affects the purchase decision process (Javalgi, et al., 2005).

Another factor, and perhaps one of the most important, is purchasing power because it directly influences the purchase decision process. In this process, the intention to purchase becomes increasingly sophisticated; not only does the perception of brand value have an effect, but other factors are also included, such as exclusivity, design, trend, and others that determine the intention to purchase and to pay a higher price for this type of product (Li, et al., 2013).

All of these factors lead to exploring how brands have a psychological impact and how these are part of the purchase decision process, in addition to how the acquisition of this type of product is mainly related to behavioral factors that respond to the search for social approval, the constant search for self-image improvement, and the creation of a prestigious image that is associated with well-being and wealth (Abdolvand and Reihani, 2013).

In turn, these factors are related to a hedonistic concept in which the acquisition of luxury goods is associated with delight, the feeling generated from the purchase. The constant purchase of these goods leads to another factor, the obsolescence of fashion, because, based on trends, consumers generate unmet needs that are covered with constant 
change and innovation (Miller, 2013). This has led to a steady growth in the worldwide figures of this market that is primarily based on options for increasing self-esteem, which is related to the purchase of goods and what the purchase represents for the person and his or her environment (Truong and McColl, 2011).

Furthermore, another factor of influence emerges in which the main motivation develops through the encouragement to follow reference groups, based on the case of some societies that seek to imitate others. This generates a motivation to demand the same class of goods and to develop an appearance that is similar to that of the reference image ( $\mathrm{Li}$ and $\mathrm{Su}, 2007$ ), to the extent that in the constant search for uniqueness, a vintage trend, which intends to revive old fashions, has emerged. Even luxury fashion houses lean toward seeking models from other decades to meet the demand created by this type of product (Cervellon, et al., 2012).

It should also be noted that another phenomenon that has a direct impact on the purchase of luxury goods is the effect of the replicas of this class of products, emphasizing that the type of consumer changes because, even if they experience the same motivations as the habitual consumer of luxury goods, their socio-economic level is different and, therefore, they accept goods of similar appearance but at a lower cost (Hanzaee and Jalalian, 2012). For this reason, it is established that there is a direct relationship between the perception of pleasure through shopping, based on materialism, and brand value, in which culture also has an important role in the purchase decision process. (Shukla, 2012).

Consequently, the impact of the brand on social networks should also be analyzed as part of a globalized culture in which the corresponding measurement needs to be applied to the intention to purchase luxury goods. This intention is directly associated with the index of satisfaction perceived by the consumer who accesses this type of goods (Jin, 2012), considering that the index of satisfaction responds not only to the brand acquired but also to the consumer's association with the brand, including its production process, raw materials, origin, and other characteristics.

In addition, the luxury items market is linked to other factors such as price competition, global supply, and the high volatility of demand due to the socio-economic conditions of the consumer. Therefore, in cases of currency crises, this market is directly affected because, when luxury is not perceived as a primary need, these items can be displaced by the consumption of highly durable goods that are associated with lower costs and priority needs (Bruce and Daly, 2011).

It should be noted that, in a socio-economic environment that changes constantly, in which each economy at a global level has a different dynamic and therefore consum- 
er behavior is also different, there is also a constant process of adaptation to the changes of each economy. This adaptation affects the purchase decision process, starting with the purchase intention, which is determined by the perception of the consumer, and depending on whether the consumer considers the purchase essential or not, it may be replaced even by replicas that represent a lower cost and generate the same psychological sensation (Sulehri, et al., 2011)

Based on this scenario, the impact on brand perception generated by counterfeits can also be analyzed; by associating brands and luxury with uniqueness and the ownership of goods that are seemingly identical but far more affordable in price, the concept of exclusivity would substantially disappear. With the passage of time, however, it has been found that brands still retain their strength and prestige despite the emergence of replicas and counterfeits of their goods (Hieke, 2010)

Nonetheless, it is important to increase consumer awareness of the impacts of the demand for counterfeits in the market because, even if the brand is unaffected, the impact of this phenomenon is transferred to production processes. The reason is that poor work conditions are generated for manufacturers, which, in their search to maintain the competitiveness of their goods, reduce production costs, starting with human capital (Phau, et al., 2009).

In the case of imitations, the useful life of the product is less important in the intention to purchase. The reason is that the preference of the consumer is the product, regardless of whether it is a replica, because the interest in the product is its similarity with the original item and also the price comparison, in which the cost-benefit relationship is greater for consumers, provided that they acquire what they are looking for at a lower cost (Zaichkowsky and Nia, 2000).

As a result, companies have had to focus on the development of the value chain and the development of sell strategies for goods to analyze the behavior and attitudes of consumers and also the influence of how goods are distributed, with the goods' accessibility to the public being essential within the aspects that constitute the purchase decision process (Cang, et al., 2009).

\section{METHODOLOGICAL APPROACH}

Given that the interest is in understanding the psychological variables involved in the decision to purchase luxury goods, this research takes a qualitative approach. Although the behavior of the luxury goods market has been extensively studied, the psychological dimension that supports it has been reduced to the feeling of well-being associated with 
this type of product, and the variables that influence the decision-making process have not been examined in-depth (Leung, et al., 2015).

Qualitative research is designed to understand and analyze phenomena to explore them from the perspective of those who participate in such research in a natural environment and in relation to the context. Thus, for the information obtained to be valid, the population must be understood and the knowledge gained in the responses must be transferred, in addition to that which is perceived through other types of language (Zhan and He, 2012). The scope of this investigation is limited to the population of the city of Bogotá, and the analyzed segment is consumers, both men and women, between ages of 25 and 45 from strata 5 and 6, from whom the information corresponding to the factors that are involved in the purchase process of luxury fashion goods was obtained. Data analysis was performed using the Atlas.ti tool, applying the corresponding coding, on which the amount of information needed was based, for its quantification and analysis in regard to the factors and criteria most noted in the transcripts of the interviews conducted (Corbin, et al., 2008).

The objective of this research is to understand the different variables involved in the decision process for purchasing luxury fashion goods in the city of Bogota, and therefore, this study is exploratory in nature (Creswell, 2013). This research is conducted through the application of in-depth interviews that allow a qualitative analysis that demonstrates how and why the purchase decision of this type of product is made (Bryman, 2006). From this analysis, the information is collected and coded according to dependency, credibility, auditability, and transferability, based on the equivalence of the results obtained with those from previous research on the same subject (Zhan and He, 2012).

\section{Selection of participants}

The sample selected for the study consists of 10 people (men and women) located in the city of Bogota, given that this is the basis of the study, from strata 5 and 6, ranging from 25 to 45 years of age; considering that these factors have been used in similar studies in other countries (Truong and McColl, 2011; Simmers et al., 2014; Wernerfelt and Cervellon, 2012). Also the persons were habitual consumers of luxury goods. An ethics code was used to establish that the personal data of the participants are confidential and that any other additional information is only used for investigative purposes. To enrich the research, only consumers of this type of product are considered.

\section{Description of the variables}

Given the literature reviewed, the variables to examine are determinants of the decision and the influence of the environment in the context of the purchase of luxury goods, goods, or services. 


\begin{tabular}{|c|c|c|}
\hline CATEGORY & INQUIRY THEMES & AUTHORS \\
\hline \multirow{4}{*}{ Context of the product } & Product display & (Huddleston, et al., 2015) \\
\hline & Technological accessibility & (Simmers, et al., 2014) \\
\hline & Representation of status & (McFerran, et al., 2014) \\
\hline & Cultural Characteristics & (Shukla, 2012) \\
\hline \multirow{3}{*}{ Fashion awareness } & Exclusivity & (Summer, et al., 2006) \\
\hline & Design & (Li, et al., 2013) \\
\hline & Trends & (Pan, et al., 2014) \\
\hline Achievement measures & Consumption desire & (McFerran, et al., 2014) \\
\hline Conception of the brand & Self-image of the Consumer & (Hume \& Mills, 2013) \\
\hline Product origin & Brand perception & (Seidenfuss, et al., 2010) \\
\hline \multirow{4}{*}{ Consumer behavior } & Lifestyle & (Pan, et al., 2014) \\
\hline & $\begin{array}{l}\text { Association with well-being } \\
\text { and wealth }\end{array}$ & (Abdolvand \& Reihani, 2013) \\
\hline & Association with delight & (Miller, 2013) \\
\hline & Consumer motivation & (Truong \& McColl, 2011) \\
\hline Product originality & Authenticity of the product & (Hieke, 2010) \\
\hline Importance of the product & Cost-Benefit ratio & (lan, et al., 2009) \\
\hline
\end{tabular}

Table 1. Description of the variables (own elaboration)

\section{Instruments}

To perform our study, in-depth interviews are conducted because doing so allows a more intimate, flexible, and open conversation and exchange of information; the interview is semi-structured, based on a guide with specific questions. However, questions that will help deepen and obtain more information on the desired topics are included, which is crucial importance when explaining the behavior and attitudes of the consumers of luxury goods.

The interview guide includes demographic questions that allowed to set the target in terms of age, gender, and social class; filter questions to determine whether the persons selected are consumers of these types of goods, goods, or services; structural questions that helped detect the degree of knowledge of these types of goods or goods (brands); and questions about expressing feelings regarding the decision-making process to investigate the variables that influence the decision-making process and also about the antecedents (influence) that provide information on the variables that lead the consumer to purchase luxury goods. 


\section{RESULTS}

\section{Analysis system for processing information}

To conduct this research, semi-structured interviews that make the collected data comparable are applied; for this reason, after obtaining the information from the interviews, there is a pre-coding process that makes it possible to analyze the information.

Therefore, the information analysis process begins with the application of the interviews to gather the information, followed by a process of transcription and organization of the information for its subsequent codification, integration, and analysis.

\section{Semantic network}

To demonstrate the existing connection between the main categories evidenced by the study, this study designs the semantic network shown below, in which the main variables involved in the decision process for purchasing luxury fashion goods converge.

This design is based on the information gathered by the in-depth interviews, in which the respondents expressed that the main variable is the brand, and it is supported by endogenous and exogenous variables that lead the decision-making process to focus on the brand of the product. Clearly, this is in response to specific conditions of the product, for example, that the product is consistent with the trends of the market, that it is original and also represents good status in the social environment, and other conditions that are part of the purchase process as a differentiated experience. An example is the shopping environment, which confirms that the setting is also important in the interaction of the brand with the consumer because, through the acquisition of this type of product, it generates positive emotions that help improve the self-image of the consumer; this indicates that most of the factors involved in the purchase decision process are all interrelated.

It should also be added that in a setting that is increasingly conscious of the environmental impact of buying rapid obsolescence goods or those made from fur, variables such as corporate social responsibility (CSR) are involved in the process. This is linked to the level of income, which is directly associated with the capacity to access this type of product. Consequently, if those who have access to this type of product do not require them, then the supply is discouraged. 


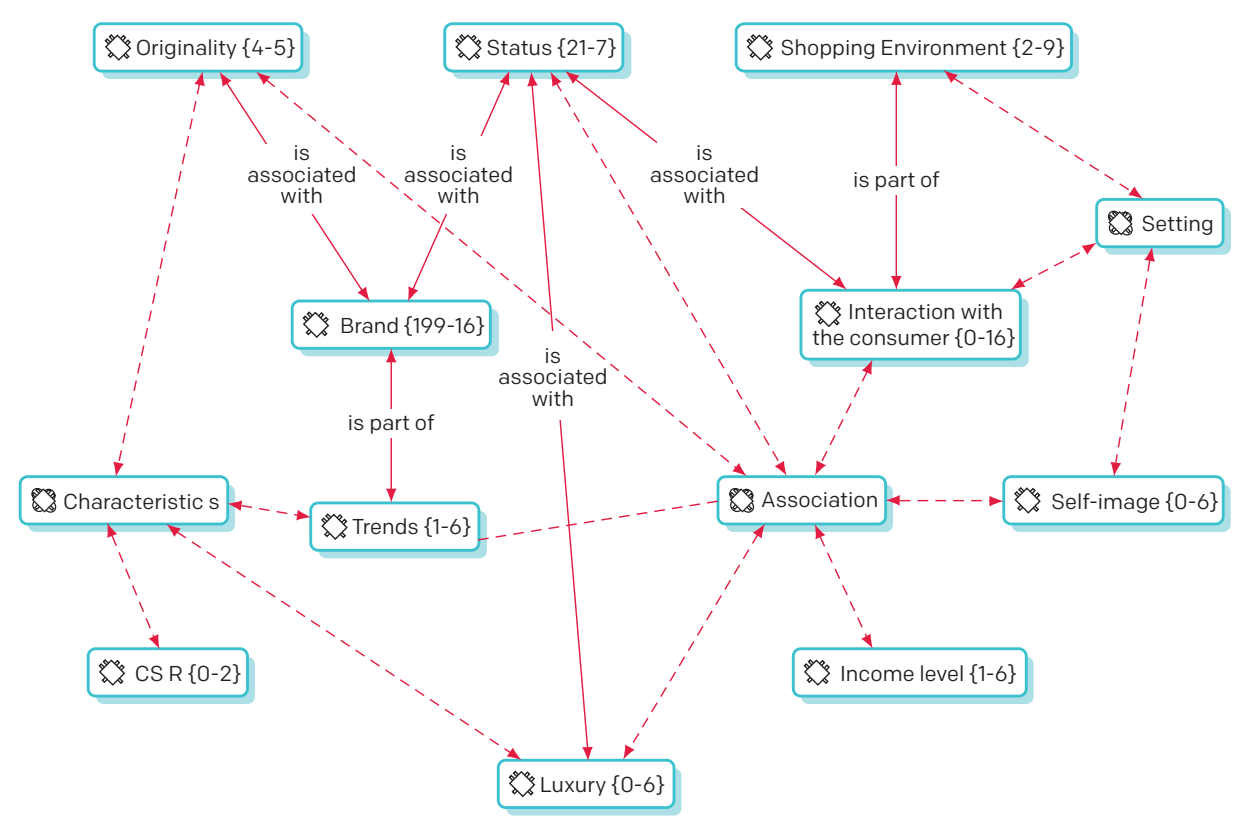

Figure 1. Semantic network (own elaboration)

\section{Dimensions and codes}

Groups corresponding to three macro topics (association, characteristics, and setting) were generated through the codification of the information using ATLAS.ti, and based on these topics, the following dimensions were generated:

- Self-image: This dimension groups the codes that are related to the emotions that arise through accessing luxury goods and contribute to the self-esteem of the consumer.

- Status: In this dimension are the codes that are related to what the purchase of fashion luxury goods represents to the recognition given by the direct customer environment.

- Interaction with the consumer: This dimension groups the codes that are related to how the companies that offer luxury fashion goods relate to consumers and their expectations.

- Luxury: This dimension groups the codes that represent the characteristics and physical and intangible specifications of the product that are associated with luxury.

- Income level: This dimension groups the codes that are associated with the purchasing power and accessibility to this type of product, in addition to those that oppose relating the income level to having access to these goods. 
- Originality: This dimension groups the codes that designate exclusivity and brand distinction with regard to counterfeiting and other types of goods that may distort the value of the product for the consumer.

- Trends: This dimension groups the social, consumer, fashion, and market trends that relate to the demand for fashion luxury goods.

- CSR: This dimension groups the codes related to the awareness of the consumer and of the brands regarding the use of fur and the manufacturing conditions of the goods.

- Shopping environment: This dimension groups the codes that are related to the shopping experience and the environment developed by the brands to provide their consumers a differentiated service model.

\section{ANALYSIS OF THE RESULTS}

The factors that were observed through the codes show how people associate the luxury of the product with the brand, as stated by interviewee 1 (C.P.): "I would think more towards the brand" (P1:50), as well as the association of the brand with recognition and exclusivity, in addition to the conditions of sale and the shopping experience, which are directly related to the value that the consumer is willing to pay, as stated by interviewee 5 (H.C.): "there is a very strong relationship, depending on the design and the brand under consideration" (P6:39). The conditions of sale appeared repeatedly, increasing the density of this dimension above the others, showing that the other variables are components of the brand, and therefore, the brand stood out as the main impact factor in the decision process for purchasing fashion luxury goods in Bogota.

Therefore, in analyzing the interviews, it is found that the decision process for purchasing luxury goods is complex and involves several variables. To conduct this particular study, the following three types of variable groups were generated in the ATLAS. ti software: those related to association (variables that generate a connection between the purchase of luxury goods and emotions, responses from the environment, and distinction), those related to the characteristics (variables that represent the tangible and intangible components of the product), and those related to the setting of the product (variables that represent the characterization of the surroundings and the environment in which the product is presented).

When observing the variables that emerged through the interviewing process, it was found that these do not belong only to a particular type but rather that, in some cases, these are related to each other. Consequently, despite the other factors, it is demonstrated that the brand is what encourages consumers to purchase luxury goods and that 
it is related to the idiosyncrasy of the population, as stated by interviewee 6 (P.R.): "here we are really brand-conscious"(P13:28); and it is supported by variables that constitute the development of the brand, such as distinction and exclusivity. According to interviewee 5 (H.C.), "If I see that it is a good brand and I like it and the brand is exclusive and recognized, I go for it" (P14:23), which in turn is directly associated with the generation of positive emotions in people when they access these goods.

In addition, a long list of components of the purchase decision process originates from these factors. These components materialize through variables such as the setting of the brand, the conditions in which the goods are exhibited and offered, and how the concept of relational marketing is increasingly used to promote sales.

Thus, the brand is tied to the needs of its customers, entering into a process of closeness that establishes a comparative and competitive differentiation of the brand in the mind of the consumer, complemented by a different shopping experience in which consumers find a setting that is designed for their convenience. For this reason, one of the main associations held by the consumer is between the luxury product concept and an environment that is serious, spacious, and organized and that transmits positive sensations that make it possible to focus on the product.

Consequently, the willingness to pay increases because, by accessing this type of product, people buy not only a product but also an entire shopping experience composed of the atmosphere, service, packaging, and the different shopping conditions that may make the purchasing process more pleasurable, as stated by interviewee 2 (L.A.): "spacious environments and environments meant to really influence people to buy the goods" (P10:2). All of these elements are also related to the product perception, which involves variables such as the originality of the product, exclusivity, and the status generated by having access to this type of product.

Accordingly, it is inferred that the purchase of luxury fashion goods is associated with positive emotions such as happiness, satisfaction, and security, among others that were emphasized by the interviewees, for example (C.P.), "the consumption of luxury goods is associated with positive emotions" (P1:20). For this reason, the decision process for purchasing this type of product does not directly depend on the purchasing power of the consumer; although this variable has an impact, it is not the most relevant because some people access these goods through credit cards or consumer finance goods.

Buying these goods responds more to taste for the product and not to the need to have access to them, as stated by interviewee 6 (P.R.): "I think it is more the need than the taste, and wanting to achieve status, more than needing the product" (13:12). 
Everything said up to this point assumes that the variables that correspond to association are the most important and most actively involved in the process of purchasing luxury goods, followed by the factors that correspond to the characteristics, both intrinsic and extrinsic, of the product. These characteristics that correspond to the product mainly include the design, the material, and the differentiation of the product in relation to counterfeits because the increase in the replicas' similarity with the original goods causes their value to be distorted due to the loss of exclusivity.

It should be noted that the characteristics that are most involved in the purchase decision process are the originality of the product, innovation in materials, design, and functionality, provided that these are consistent with the latest trends, without losing the distinctive features of the brand.

In contrast to the above, the variables that comprise the context of the product, despite having less relevance in the purchase process, are used as support for some of the variables of both association and characterization of the product. This may occur because of the atmosphere and presentation of the product; although these variables do not directly affect the purchase process, they are involved in the product perception as part of a differentiated shopping experience, which can complement the persuasion stage that triggers the purchase process of fashion luxury goods.

Specifically, through the findings from the application of the interviews, it was found that the most relevant factor in the purchase process of luxury fashion goods is the brand because of all of its physical components and what it psychologically represents in terms of consumer access to these goods.

Therefore, the criteria that support the decision process for purchasing luxury fashion goods, are the brand, positive emotions, exclusivity, and the status associated with them, as defined by interviewee 6: "Status is the satisfaction from social recognition" (P13:11).

\section{Schematic of the purchase decision proces}

The schematic of the purchase decision process above shows that by analyzing the qualitative data obtained from the interviews and their respective coding, according to the degree of data concentration in the different variables, it is possible to categorize the factors involved in the decision process for purchasing fashion luxury goods, which is based on the lifestyle from which the consumer's needs or desires are triggered. For this reason, the interaction with the customer becomes extremely important in the process because it leads to knowledge of fashion and trends, thus generating an increase in customers' motivation level based on the perception of the product. 


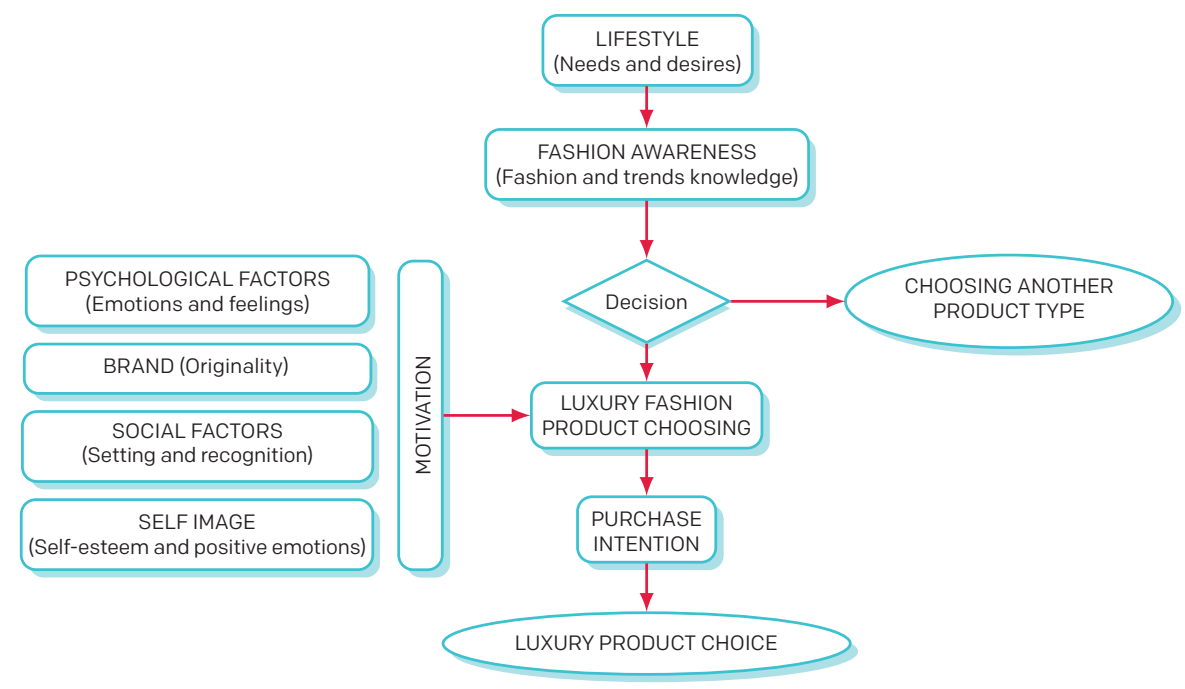

Figure 2. Schematic of the purchase decision process.

Own elaboration from the hermeneutical analysis of the in-depth interviews.

In regard to the psychological factors, motivation responds to the emotions and feelings that the purchase of fashion luxury goods generates in the consumer; regarding the brand, it responds to the image, self-confidence, and satisfaction generated by this type of purchase. The other two factors originate from the brand because the use of luxury fashion goods from socially recognized brands generates the image perceived by the environment and therefore recognition from this environment, which leads to the strengthening of consumers' self-image and, therefore, their self-esteem, through positive emotions as a response to the factors stated above.

It should be noted that this is supported by market trends, in which the main criteria of the purchase decision are based on the brand and all of its components, at the level of presentation, design, service, and associated cost.

\section{DISCUSSION}

The contribution of this research is the description of the decision process for purchasing fashion luxury goods in the city of Bogota; therefore, it serves as a framework for the analysis of this process in other major and intermediate cities nationwide as well as their counterparts in other countries. The reason is that the development of this analysis incorporates the perspectives of the target consumer, in terms of the different factors and attributes of the context, the product, and what the consumer expects to obtain or achieve through the purchase, and also because the process of de- 
veloped countries is different from that of developing countries (Bagheri, 2014). Thus, this research joins the previous bibliographic production as a source for subsequent investigations.

Indeed, the research findings are consistent with those obtained in studies conducted in other countries (Sulehri, et al., 2011; Bagheri, 2014), demonstrating that the shopping environment, the measurements, the differentiated attention, and, in general, the different components of the shopping experience function as inducers to the purchase of the product and affect the consumer perception of the brand through different stimuli, in the same manner in which it has been demonstrated in previous research (Simmers, et al., 2014). It is also demonstrated that the characteristics of the product that influence the consumer are associated with the recognition that these characteristics represent in the direct social environment of the customer as a synonym of status; this factor appears in previous research from countries such as India and Pakistan, representing for their consumers the creation of positive emotions, and providing psychological benefits when they access luxury fashion goods (McFerran, et al., 2014).

It should be noted that at the cultural level, the results differ, even though the economic level in the countries where this type of research was conducted is similar; there is a large discrepancy at the social and cultural level, and for this reason, the defined variables take different values in relation to their environment (Shukla, 2012). Accordingly, it is inferred that the perception of the implicit variables in the purchase decision process is different depending on the country and its culture. An example of this difference is exclusivity, which is assumed as dependent on different factors that mainly respond to the setting in which the investigation is performed (Summer, et al., 2006).

Specifically, to address these types of discrepancies between cultures and the development of their luxury fashion markets, the brands define different product lines that adapt to the specific cultural conditions of the market. In turn, this supports the trend marked by certain brands in some markets compared to others in equal economic and social conditions ( $\mathrm{Li}$ and $\mathrm{Su}, 2007$ ), even when these attempt to standardize the trends on the basis of a constant interaction with the customer to increase the brand attractiveness perceived by the customer (Li, et al., 2013; Kaminakis, et al., 2014).

However, it is found that although the brand is the most influential factor in the decision process for purchasing fashion luxury goods, it must be adjusted according to the social, cultural, consumer, and market conditions; the reason is that, as in a previous research, it is found that the consumer is currently far more aware of fashion and its components. This results in the exigency level that the customer has in regard to offers from the brands available on the market (Pan, et al., 2014). 
Similarly, the product display must be adjusted to the cultural and social conditions of the market, as evidenced in the analysis of the information gathered in this research, because the market determines how the concept of luxury is perceived and associated with the product presentation (Huddleston, et al., 2015).

However, it can be observed that, in fact, the social environment (stratification) has a high influence on the purchase decision process. This finding confirms that lifestyle is directly related to the type of goods demanded (Pan, et al., 2014), in addition to the positive emotions that are reinforced by the purchase of this type of product through the perception of the brand and its collective concept (Hume and Mills, 2013).

This finding contradicts the assertion that one of the relevant factors is purchasing power due to the impact of the demand created by brands on consumers' perception, psychologically impacting them through the association between well-being and the brand, which is the basis for accessing this type of product through credit lines (Abdolvand and Reihani, 2013). For this reason, the consumer accesses the product, even though doing so implies costs related to financing, which means that the desire to spend is greater than the financial variables involved in the purchase process (McFerran, et al., 2014).

Therefore, as evidenced in the analysis conducted through the codification and grouping of codes and their themes, brand perception is one of the strongest incentives of the purchase decision process (Seidenfuss, et al., 2010) because this perception directly triggers the motivation to demand this type of product, in addition to the association with the other variables noted above and those shown in the results of the analysis of this research (Truong and McColl, 2011).

In addition, it is found that consistent with the studies conducted, the acquisition of luxury fashion goods is associated with delight, in which the consumer receives emotional benefits through the purchase of this type of product (Miller, 2013), and that this depends on the authenticity of the product, as stated by interviewee 1: "I feel good about myself buying the original" (P1:13) (Hieke, 2010).

For this reason, the perception of the cost-benefit ratio of those interviewed primarily responds to what the acquisition of fashion luxury goods represents in the perception of their image in their direct environment (Leung, et al., 2015), as interviewee 1 stated, "because people feel more content, safer or more satisfied using something from a luxury brand than from an ordinary brand" (P1:20).

This suggests that the results are not in accordance with the literature review conducted and that they represent a complement to the existing literature. This outcome is obtained from the generation of knowledge through the postulated premises and the 
answers obtained, whose analysis offers a new perspective on the development of the luxury fashion goods market based on the cultural development of a city such as Bogota and, similarly, of the perception of its consumers in regard to the process of purchasing this type of product. This contribution adds value to the existing theory on how consumers perceive the access to luxury fashion goods and the other variables that are involved in the purchase process.

Finally, this research brings a new perspective to the analysis of the purchase decision process, demonstrating that, for the consumer, the product is very important and, even more, the integrity of the supply of luxury fashion goods, which generates demand. Regarding consumer behavior, this research provides a new concept that extends from a purchasing model that is related to purchasing capacity to a model that is more focused on attraction towards positive emotions, strengthening self-image, and response to desires more than to needs.

\section{CONCLUSIONS}

Based on the results presented in the previous section and in contrast to the analysis of the documents consulted, it is demonstrated that even when the decision process for purchasing luxury fashion goods is similar in countries with development conditions that are equal to those of Colombia, this process has some variations; the most representative finding is the importance of the brand, whereas social pressure has less relevance in the purchase decision process (Abdolvand and Reihani, 2013). In Bogota, one of the most cosmopolitan cities in the country, a consumption trend that is mostly driven by fashion trends from world-class brands has been generated. These brands have been entering into one of the most desired markets in recent times for this type of product, based on the rising figures of the sector (McFerran, et al., 2014). It should be added that based on the study conducted, it is observed that the decision process for purchasing luxury fashion goods has a structure that is composed of exogenous and endogenous variables. The endogenous variables are described by consumers as the motivation that makes them acquire this type of product, in addition to psychological factors that contribute to their well-being and self-esteem. Therefore, the endogenous variables are perceived as a component of the lifestyle associated with a differentiated shopping experience. Regarding the exogenous variables, these are described as social as well as consumption and market trends. Additionally, these are determinants in the recognition by the environment and therefore in the representation of status; all of this is associated with the brand and the value perceived through having access to it.

Thus, it can also be concluded that the decision process for purchasing luxury goods in Bogota can be described as a process that, though still composed of internal 
and environment variables, is mostly driven by the positive emotions that are produced in consumers in regard to having access to fashion goods from renowned brands and by the impact that this consumption has on their self-image and on the image of them that the environment perceives.

Consequently, it can be concluded that the criteria that lead consumers to the decision process for purchasing luxury fashion goods are factors that primarily respond to the brand, supported by the influence of the environment, emotions, recognition, and self-esteem, understanding that even when they relate to purchasing power, this type of demand is based more on taste than on the need to access these goods because of the luxury.

Regarding the limitations of this study, the main limitation is the willingness of the people from the defined population to be interviewed due to the time it required. For this reason, in future research, condensing the questions, to reduce the time necessary for the interview and, therefore, to have greater willingness from the base population of the study, is recommended.

Funding details: This work was supported by the Institución Universitaria Politecnico Grancolombiano under Grant number 79843140.

Disclosure statement: We have no conflicts of interest to disclose.

\section{REFERENCES}

Abdolvand, M. and Reihani, N. (2013). "The effect of brand association in psycho-social and psycho-personality antecedents: a conceptual model of conspicuous consumption among youth adults", Research Journal of Applied Sciences, Engineering and Technology, Vol 6 No. 6, pp. 1012-1022.

Aiello, G., Donvito, R., Godey, B., Pederzoli, D., Wiedmann, K.P., Hennigs, O.N., Siebels, O.A. (2009). "Luxury brand and Country of Origin effect: results of an international empirical study", Journal of Marketing Trends, Vol 1 No. 1, pp. 67-75.

Atwal, G. and Williams, A. (2009). "Luxury brand marketing - The experience is everything!", Journal of Brand Management, Vol 16 No. 5, pp. 338-346.

Bagheri, M. (2014). "Luxury consumer behavior in Malaysia: Loud brands vs. quiet brands", Procedia - Social and Behavioral Sciences, Vol 130 No. 1, pp. 316-324.

Bruce, M. and Daly, L. (2011). "Adding value: Challenges for UK apparel supply chain management - a review", Production Planning and Control, Vol 22 No. 3, pp. 210-220.

Bryman, A. (2006). “Integrating quantitative and qualitative research: how is it done?”, Qualitative Research, Vol 6 No. 1, pp. 97-113. 
Cang, P., Wang, S. and Xia, Q. (2009). "Research on the mechanism of retail strategy influencing consumer behavior intention-based on empirical analysis of domestic luxury cosmetics brands", Journal of Donghua University, Vol 26 No. 4, pp. 450-460.

Cervellon, M., Carey, L. and Harms, T. (2012). "Something old, something used: Determinants of women's purchase of vintage fashion vs. second-hand fashion”, International Journal of Retail and Distribution Management, Vol 40 No. 12, pp. 956-974.

Corbin, J. and Strauss, A. (2008), Basics of Qualitative Research: Techniques and Procedures for Developing Grounded Theory, SAGE Publications Inc., Thousand Oaks, CA.

Creswell, J. (2013). “Qualitative, quantitative, and mixed methods approaches”, Research Design, Vol 33 No. 2, pp. 1-26.

Giovanini, S., Xu, Y. and Thomas, J. (2015). "Luxury fashion consumption and Generation Y consumers: Self, brand consciousness, and consumption motivations”, Journal of Fashion Marketing and Management: An International Journal, Vol. 19 No. 1, pp. 22 - 40.

Godey, B., Pederzoli, D., Aiello, G., Donvito, R., Chan, P., Oh, H., Singh, R., Skorobogatykh, I., Tsuchiya J., Weitz, B. (2012). "Brand and country-of-origin effect on consumers' decision to purchase luxury products”, Journal of Business Research, Vol 65 No. 1, pp. 1461-1470.

Hanzaee, K.H., and Jalalian, S. (2012). "Impact of non-price factors on purchase intention counterfeits", Research Journal of Applied Sciences, Engineering and Technology, Vol 4 No. 18, pp. 3313-3322.

Hieke, S. (2010). "Effects of counterfeits on the image of luxury brands: An empirical study from the customer perspective", Journal of Brand Management, Vol 18 No. 2, pp. 159-173.

Huddleston, P., Bridget K., Minahan, S., and Fernandez, R. (2015). "Seeking attention: An eye tracking study of in-store merchandise displays", International Journal of Retail and Distribution Management, Vol. 43, No. 6, pp. 561-574.

Hume, M. and Mills, M. (2013) “Uncovering Victoria's Secret: exploring women's luxury perceptions of intimate apparel and purchasing behaviour", Journal of Fashion Marketing and Management: An International Journal, Vol 17 No. 4. pp. 460-485.

Hung, K, Chen, A., Peng N., Hackley, C., Tiwsakul, R., and Chou, C. (2011) "Antecedents of luxury brand purchase intention", Journal of Product and Brand Management, Vol. 20 No. 6, pp.457 - 467.

Javalgi, R., Khare, V. P., Scherer, R. and Gross, A. (2005). "An application of the consumer ethnocentrism model to French consumers", International Business Review, Vol 14 No. 3, pp. 325-344.

Jin, S. (2012) "The potential of social media for luxury brand management", Marketing Intelligence and Planning, Vol. 30 No. 7, pp.687 - 699.

Kaminakis, K., Karantinou, K. and Boukis, A. (2014). "The mediating role of self-concept discrepancy in the relationship between values and personal based motivation of luxury products consumers", Procedia - Social and Behavioral Sciences, Vol 148 No. 1, 619-624.

Leung, A., Yee, R. and Lo, E. (2015). "Psychological and social factors of fashion consciousness: An empirical study in the luxury fashion market", Research Journal of Textile and Apparel, Vol 19 No. 3, pp. 58-69.

Levy, S. J. and Luedicke, M. K. (2013). “From Marketing Ideology to Branding Ideology”, Journal of Macromarketing, Vol 33 No. 1, pp. 58-66.

Li, G., Li, G., and Kambele, Z. (2012). "Luxury fashion brand consumers in China: Perceived value, fashion lifestyle, and willingness to pay”, Journal of Business Research, Vol 65 No.10, pp. 1516-1522. 
Li, J. and Su, C. (2007). "How face influences consumption: a comparative study of American and Chinese consumers”, International Journal of Market Research, Vol 49 No. 2, pp. 237-256.

Li, N., Robson, A. and Coates, N. (2013) “Chinese consumers' purchasing: impact of value and affect”, Journal of Fashion Marketing and Management: An International Journal, Vol. 17 No. 4, pp.486 - 508.

Lozano, R. (2014), "Marcas de lujo hacen su agosto en un país cada vez más pudiente [Luxury brands make a killing in an increasingly wealthy country]", available at: http://www.eltiempo.com/ economia/empresas/marcas-de-lujo-en-colombia/14427379 (accessed February 20 2016).

McFerran, B., Aquino, K. and Tracy, J. (2014). "Evidence for two facets of pride in consumption: Findings from luxury brands", Journal of Consumer Psychology”, Vol 1 No.1, pp. 1-17.

Miller, K. (2013). "Hedonic customer responses to fast fashion and replicas", Journal of Fashion Marketing and Management: An International Journal, Vol 17 No. 2, pp. 160-174.

Pan, Y., Luo, L., Liu, D., Gao, L., Xu, X., Shen, W., Gao, J. (2014). “How to recommend by online lifestyle tagging (OLT)", International Journal of Information Technology and Decision Making, Vol 13 No. 6, pp. 1183-1209.

Phau I., Sequeira M. and Dix, S. (2009). “Consumers' willingness to knowingly purchase counterfeit products”, Direct Marketing: An International Journal, Vol 3 No. 4, pp. 262-281.

Seidenfuss, K., Kathawala, Y. and Dinnie, K. (2010). "Assembly and component origin effects: an ASEAN consumer perspective", Journal of Consumer Marketing, Vol. 27 No. 6, pp. 488 - 498.

Shukla, P. (2012). "The influence of value perceptions on luxury purchase intentions in developed and emerging markets", International Marketing Review, Vol. 29 No. 6, pp.574 - 596.

Simmers, C., Parker, R., and Schaefer, A. (2014). "The importance of fashion: The Chinese and U.S. Gen Y perspective”, Journal of Global Marketing, Vol 27 No. 2, pp. 94-105.

Sulehri, N., Malik, F., Anjum, N. and Qureshi, W. A. (2011). "Consumer behavior slide down for purchase of luxury brands in Pakistan: A conceptual framework", European Journal of Economics, Finance and Administrative Sciences, Vol 28 No. 1, pp. 189-194.

Summer, T., Belleau, B., and Xu, Y. (2006). "Predicting purchase intention of a controversial luxury apparel product”, Journal of Fashion Marketing and Management: An International Journal, Vol. 10 No. 4, pp. 405 - 419.

Truong, Y. and McColl, R. (2011). "Intrinsic motivations, self-esteem, and luxury goods consumption", Journal of Retailing and Consumer Services, Vol 18 No. 6, pp. 555-561.

Varsha J., Subhadip R., Ashok R. (2015) “Conceptualizing luxury buying behavior: the Indian perspective”, Journal of Product and Brand Management, Vol. 24 No. 3, pp.211 - 228.

Wernerfelt, A. and Cervellon, M. C. (2012). "Knowledge sharing among green fashion communities online: Lessons for the sustainable supply chain”, Journal of Fashion Marketing and Management: An International Journal, Vol. 16 No. 2, pp. 176 - 192.

Zaichkowsky, J. L. and Nia, A. (2000). “Do counterfeits devalue the ownership of luxury brands?”, Journal of Product and Brand Management, Vol. 9 No. 7, pp.485 - 497.

Zhan, L. and He, Y. (2012). "Understanding luxury consumption in China: Consumer perceptions of best-known brands", Journal of Business Research, Vol 65 No. 10, pp. 1452-1460. 


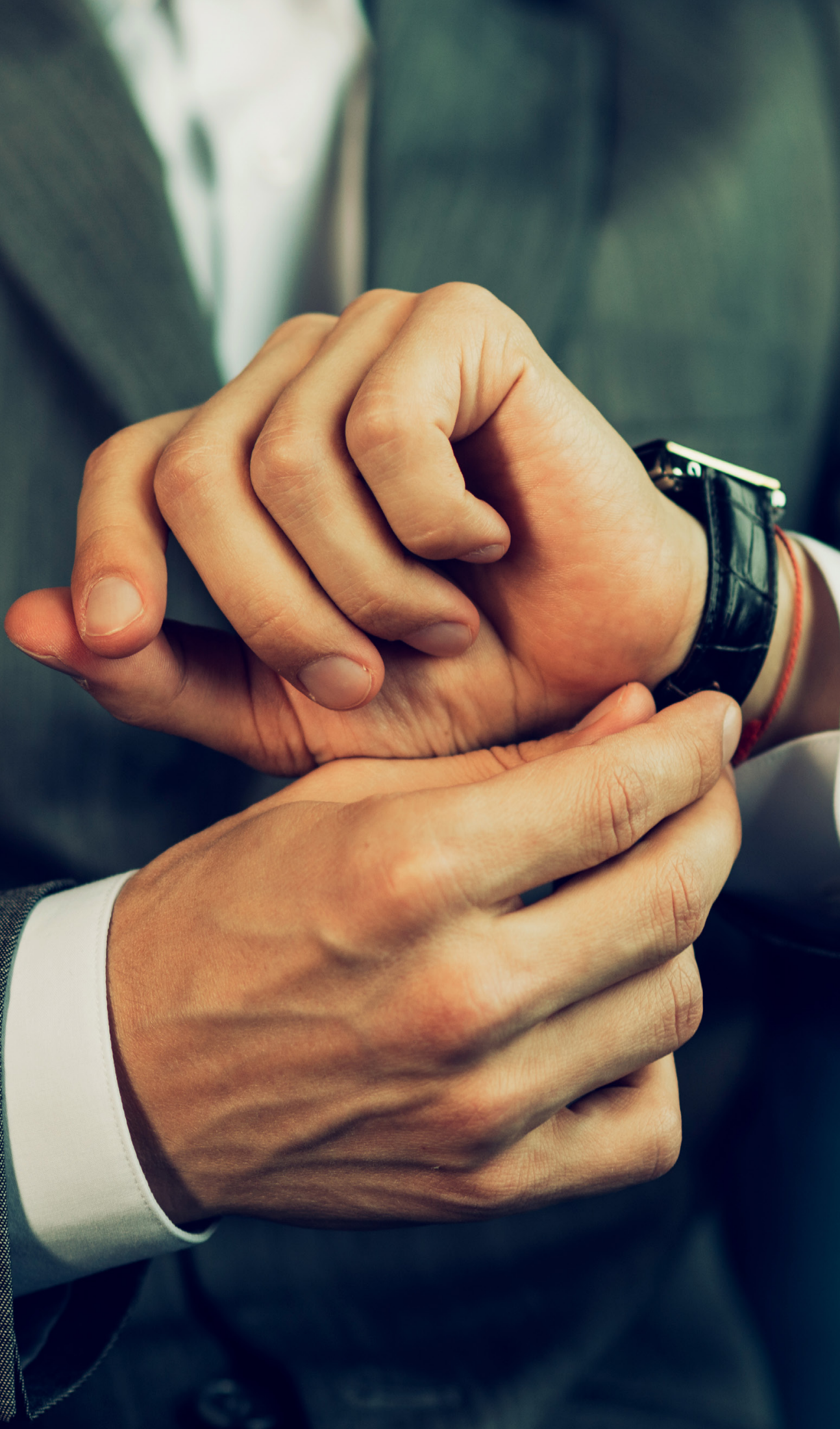




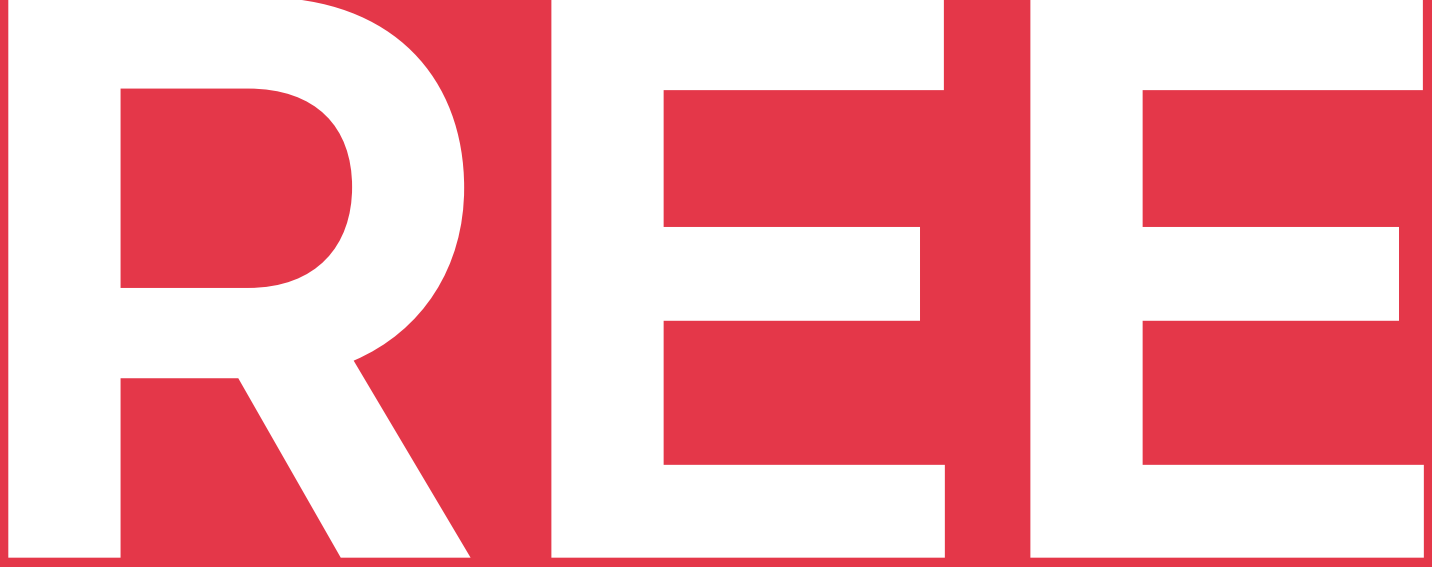

\section{CHAPTER 3: INTERNET MARKETING COMMUNICATIONS OF TRADE ENTERPRISES IN UKRAINE}

\section{Tetiana Dubovyk, Grand PhD (Economics)}

Professor, Department of Marketing and Advertising Kyiv National University of Trade and Economics

Kyiv, Ukraine 
It's necessary to make an accent that at the present stage of economic growth, the essential changes take place in the consciousness of the customer - customer became another one, his "market consciousness" increased. They have the higher level of goods and services quality expectations, strive for more convenient arrangement and working hours, better service, lower prices. Such situations were caused by the modern society development tends, changes in the way and style of people's life. Also the part of innovators, who endeavor to get goods, in which new ideas and technologies were embodied. It is also stipulated by the modern development temps and by implementation of information-communication technologies, and by the psychological factors.

Consumption of such goods becomes a symbol along with the buying of prestige goods; it demonstrates the high social status, shows progressiveness and contemporaneity of the customer. As the world experience shows the velocity of reaction on market changes is characteristic for small and midsize business, which are rather flexible to changes and opportunities of variable market conditions.

On today stage of economic development the majority of trade companies face with the market crisis, which is caused by globalizing processes, increasing competition, science-technology progress, consumer shift, his behavior and life style, the decrease of traditional marketing communications effectiveness, and also the increasing of society expectations about companies with great resources.

The information economy makes new demands on the formation of the internet-marketing communication that are able to continuously communicate with consumers, involve them in the process of interaction trade. The importance of internet-marketing communication (InMC) increases with increasing competition, and experts predict that over time they will play a leading role as the most progressive marketing system that is able to establish personal contacts with the target audience, offer individualized for each individual user. Ukraine ranks 34 among 201 countries in the number of Internet users [1].

Addressing the needs and wishes of potential and existing clients is indispensable in sustaining market success for a company; with increased international competition, companies must be focused to the individual specificities of consumers. With the increasing importance of online sales and the growing number of shoppers purchasing from online stores, it is imperative for marketers to develop a better understanding of Internet surfers and shoppers [2].

In international marketing activities, significant problems are often posed by differences in the characteristics and consumption behavior of consumers in different parts of the world. Certainly, some of these differences are becoming less important and some 
academics have the opinion that that they are no longer of great significance. However, there is also a lot of evidence that both cultural variance and differences in consumer behavior are still very important facts in many international markets $[2,3]$.

There is virtually a consensus that, to remain competitive, firms must continuously develop and adapt their business models [4]. However, it is believed that all users are equal and equally creative, particularly in relation to the so called Web 2.0 culture in which everyone is defined as being a participant in new Internet services [5,6]. However, several studies have demonstrated that people with similar levels of access engage the Internet in fundamentally different ways [7].

Kollmann, T., Kuckertz, A., \& Kayser, I. (2012) develop and empirically analyze a typology of customers to classify distinct segments of consumers, highlighting the associated interrelationship of individual shopping motives and cannibalization and synergetic effects [8].

S. Ghose and W. Dou (1998) have examined what the Web offers by doing a study of the impacts of web site design features on site quality [9]. Convenience in shopping is one of the most obvious advantages. Similarly, the ease with which information can be accessed is also strength of the online environment. Security of information is a primary worry for potential e-commerce consumers. Ph. Kotler (2002) also mentions that consumers have ethical concerns about Internet vendors [10]. Research results clearly show that attitudes towards the Internet and Internet shopping behavior differ from country to country $[2,11]$.

In this global environment, consumer typologies may prove an effective instrument for identifying and addressing different consumer clusters. A similar approach has been considered to be highly relevant for Internet marketing [12,13]. In trade articles, customer segmentation is described as crucial for the success of electronic commerce. R. Burke (2002) points out that an important unanswered research question relates to how retailers can segment online shoppers [14]. Only through an understanding of the different customer segments will marketers be able to develop strategies and tactics to attract and maintain these customers [2].

However, as yet, only a few typologies of Internet users exist, such as those of the Boston Consulting Group or McKinsey \& Co., and these have not been developed in accordance with academic standards of research $[2,15]$.

The paper uncovers issues of methodological, scientific and practical marketing investigations approaches basic target segments of consumers and proposes the possible use of the components of Internet marketing communication for these segments of consumers. 
The Internet occupies the basic position among all the information technologies, which growth leads to the necessity of trade enterprises products and services promotion, the search of information, customers and partners, and also the profit of internet-technologies application. All the mentioned need almost new means of internet-marketing, including marketing communications, which can give an opportunity to make a considerable reduce of marketing budget and provide more effective affairs of trade enterprise with consumers, competitors, intermediates, providers and other social circles.

\section{METHOD}

The author conducted a marketing research. The purpose of the study was to identify the factors that influence the management of online marketing communications of trade enterprises. The task of marketing research definition: the purpose of creating online stores; marketing communication goals of the site / online store; the activity of the company is strictly the work with consumers and their responses; evaluating Internet marketing activities of online stores; features used to monitor the effectiveness of Internet marketing communication activities; obstacles to rising costs for Internet marketing communications; information provided on the site / online store; the presence of online stires in social networks.

The general statistics on the number of online stores, their turnover and, moreover, the division of food and non-food by the State Statistics Service of Ukraine is not conducted. It should be noted that by the end of 2016 there were about 45 thousand representatives engaged in electronic commerce.

Of the general population, Internet stores that occupy less than $2 \%$ of the market share in the structure of the Internet trade market (textiles, cooking and eating, jewelry and art products etc.) and those with the smallest number of transactions and the number of visitors (less 500 per day). Also separately considered the online store "Rosetka", which occupies 35\% of the Internet market in the segment "Electronics and Appliances".

The survey was conducted in Kyiv, Ukraine (May-June 2017) on the basis of a quota sample representing online stores (food, non-food, mixed). The volume of the representative sample is 304 online-stores, which reflects the general population of this group. The statistical error of a random probabilistic sample of 304 units in the general population with a confidence probability of 0.945 does not exceed 0.055 (5.5\%). The sample interval was 33 . 
The appropriateness of the approach to the formation of the sample is substantiated: multi-stage, stratification, using the quota method of removing online stores at the last stage.

The study was conducted in 2 stages. In the first stage, 30 enterprises of the Ukrainian trade industry were analyzed and the main trends in the organization of Internet marketing communications were determined, the nature of which was analyzed in detail during the increase of the sample. At the second stage, the distribution of online stores - survey participants is the following data groups: goods for construction, repair and decoration of housing - 7.9\%; furniture - 5.6\%; electronics and appliances - 35.5\%; goods for storing, cooking and eating - 2,6\%; goods for sports and tourism - 13,5\%; clothing and shoes - 20,1\%; household and personal care - $2.3 \%$; goods for children 9.5\%; food and beverages $-3.0 \%$.

The results of the author's research revealed the factors that inhibit the use of Internet marketing communications for $35.20 \%$ of trading companies there is a budget constraint for all marketing activities, 34.87\% - legislative and regulatory restrictions, $33.55 \%$ - shortage of skilled workers for implementation of these measures.

It is worthwhile to point out that for all types of enterprises, the material and technical base of the enterprise is a significant limiting factor, and in cases with online stores that specialize in food product - this factor reaches 55.56\%. In almost this percentage, factors affecting the legislative and regulatory restrictions on online stores specializing in goods for construction, repair and decoration of housing - 50.0\% (table1).

The analysis of the instruments of the InMC of trade enterprises has shown that most online stores tend to use search engine optimization for keywords, banner and multimedia advertising (table 2).

The results of the marketing research conducted by the author show that $59.2 \%$ of enterprises considered the generation of incomes and growth of sales as the main objectives of the management of InMC. However, for online stores specializing in clothing and shoes, children's products, home and personal care, the main goal of Internet marketing communications was to form and maintain relationships with target audiences of the Internet community.

The establishment of public relations as the target of InMC has chosen only $8.3 \%$ of online stores selling goods for construction, repair and decoration of housing. More than half of respondents (54.2\%) believe that optimizing the presence of an online stores is the best way to use search engine optimization for keywords. Trade companies specializing in the sale of goods for children, buy domain names to improve online trading. 
Tab. 1: Factors that constrain the use of the Internet marketing communications by online stores in Ukraine, $\%$

\section{Specialization of online stores}

\begin{tabular}{|c|c|c|c|c|c|c|c|c|c|}
\hline 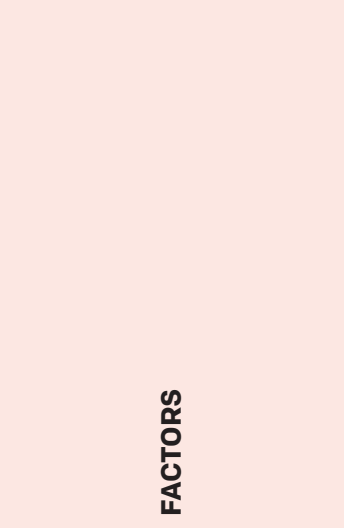 & 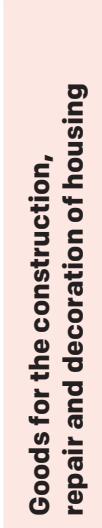 & 浐 & 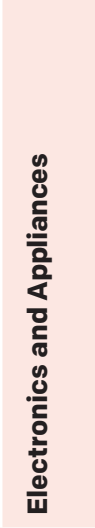 & 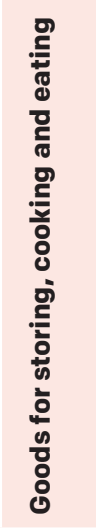 & 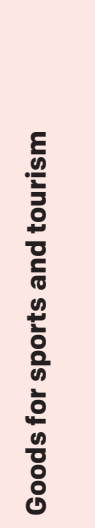 & 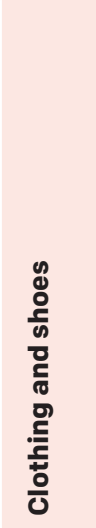 & 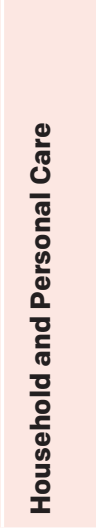 & 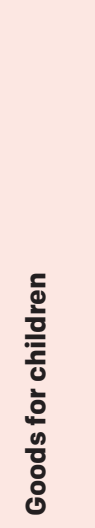 & 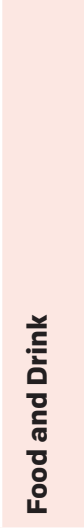 \\
\hline $\begin{array}{l}\text { Legislative and } \\
\text { regulatory constraints }\end{array}$ & 50,00 & 41,18 & 29,63 & 37,50 & 29,27 & 39,34 & 28,57 & 34,48 & 44,44 \\
\hline $\begin{array}{l}\text { Lack of the implementa- } \\
\text { tion of modern informa- } \\
\text { tion and communication } \\
\text { technologies into the } \\
\text { activity of the enterprise }\end{array}$ & 33,33 & 0,00 & 17,59 & 12,50 & 4,88 & 9,84 & 28,57 & 10,34 & 0,00 \\
\hline $\begin{array}{l}\text { Lack of special software } \\
\text { in the process of making } \\
\text { managerial decisions }\end{array}$ & 16,67 & 29,41 & 7,41 & 0,00 & 7,32 & 8,20 & 0,00 & 6,90 & 11,11 \\
\hline $\begin{array}{l}\text { Material and technical } \\
\text { base of the enterprise }\end{array}$ & 37,50 & 47,06 & 23,15 & 25,00 & 31,71 & 31,15 & 14,29 & 24,14 & 55,56 \\
\hline $\begin{array}{l}\text { Restriction of budget for } \\
\text { all marketing activities }\end{array}$ & 33,33 & 52,94 & 37,04 & 50,00 & 34,15 & 52,46 & 0,00 & 0,00 & 0,00 \\
\hline $\begin{array}{l}\text { Culture of entrepreneu- } \\
\text { rship }\end{array}$ & 0,00 & 0,00 & 7,41 & 0,00 & 0,00 & 0,00 & 0,00 & 3,45 & 0,00 \\
\hline $\begin{array}{l}\text { Insufficient skilled } \\
\text { workers to implement } \\
\text { these activities }\end{array}$ & 29,17 & 29,41 & 33,33 & 25,00 & 43,90 & 27,87 & 14,29 & 48,28 & 22,22 \\
\hline $\begin{array}{l}\text { Incompetence of emplo- } \\
\text { yees of the enterprise }\end{array}$ & 12,50 & 23,53 & 7,41 & 12,50 & 17,07 & 9,84 & 14,29 & 6,90 & 11,11 \\
\hline $\begin{array}{l}\text { Experience of conducting } \\
\text { InMC }\end{array}$ & 29,17 & 35,29 & 5,56 & 25,00 & 9,76 & 11,48 & 0,00 & 6,90 & 0,00 \\
\hline $\begin{array}{l}\text { Expecting an incredible } \\
\text { result after carrying out } \\
\text { these activities }\end{array}$ & 8,33 & 0,00 & 2,78 & 0,00 & 9,76 & 4,92 & 0,00 & 6,90 & 11,11 \\
\hline
\end{tabular}

Source: authors investigations, a national survey of 304 online-stores in Kiev, Ukraine, statistical error - 0,945doesn't exceed 0,055 (5,5\%). Investigations were provided in 2017. 
Tab. 2: Use instruments of InMC by online stores in Ukraine,\%

\begin{tabular}{|c|c|c|c|c|c|c|c|c|c|}
\hline \multicolumn{10}{|c|}{ Specialization of online stores } \\
\hline 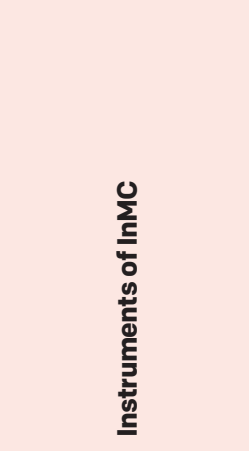 & 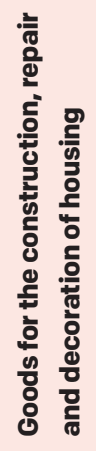 & $\begin{array}{l}\text { 올 } \\
\text { 론 } \\
\text { 녹 }\end{array}$ & 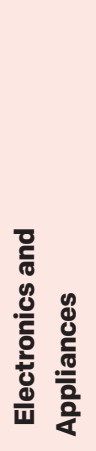 & 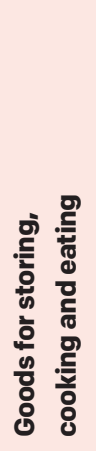 & 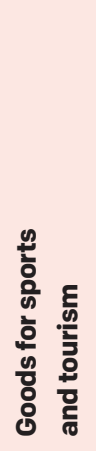 & 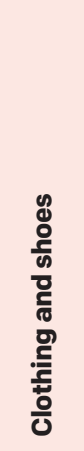 & 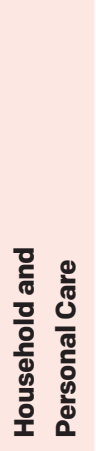 & $\begin{array}{l}\frac{5}{0} \\
\text { 흘 } \\
\frac{\bar{c}}{0} \\
\frac{2}{2} \\
\frac{0}{0} \\
\frac{0}{8} \\
8 \\
0\end{array}$ & 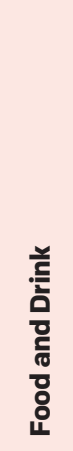 \\
\hline $\begin{array}{l}\text { Key words } \\
\text { search engine } \\
\text { optimization }\end{array}$ & 87,5 & 76,5 & 83,3 & 75,0 & 87,8 & 88,5 & 57,1 & 86,2 & 55,6 \\
\hline $\begin{array}{l}\text { InMC in social } \\
\text { networks }\end{array}$ & 37,5 & 64,7 & 32,4 & 15,6 & 61,0 & 77,1 & 28,6 & 72,4 & 33,3 \\
\hline $\begin{array}{l}\text { InMC appeal } \\
\text { content }\end{array}$ & 66,7 & 64,7 & 48,2 & 18,8 & 80,5 & 85,3 & 71,4 & 58,6 & 44,4 \\
\hline $\begin{array}{l}\text { E-mail of sending } \\
\text { inquiries to InMC }\end{array}$ & 12,5 & 17,7 & 70,4 & 6,3 & 70,7 & 52,5 & 42,9 & 55,2 & 44,4 \\
\hline $\begin{array}{l}\text { InMC on mobile } \\
\text { devices }\end{array}$ & 33,3 & 11,8 & 63,9 & 6,6 & 39,1 & 0,0 & 28,6 & 69,0 & 11,1 \\
\hline $\begin{array}{l}\text { Banners, } \\
\text { multimedia and } \\
\text { online advertising }\end{array}$ & 66,7 & 52,9 & 80,6 & 12,5 & 85,4 & 54,1 & 28,6 & 72,4 & 44,4 \\
\hline InMC in webinars & 0,0 & 0,0 & 2,8 & 0,0 & 0,0 & 0,0 & 0,0 & 0,0 & 0,0 \\
\hline $\begin{array}{l}\text { InMC in affiliate } \\
\text { programs }\end{array}$ & 12,5 & 5,9 & 17,6 & 0,0 & 0,0 & 19,7 & 14,3 & 17,2 & 11,1 \\
\hline $\begin{array}{l}\text { Price comparison } \\
\text { sites }\end{array}$ & 54,2 & 47,1 & 89,8 & 9,4 & 53,7 & 68,9 & 57,1 & 55,2 & 55,6 \\
\hline Forums / chats & 25,0 & 0,0 & 39,8 & 0,0 & 19,5 & 6,6 & 0,0 & 55,2 & 0,0 \\
\hline $\begin{array}{l}\text { PR in the Internet } \\
\text { (articles, video- } \\
\text { conferences) }\end{array}$ & 12,5 & 11,8 & 19,4 & 6,3 & 0,0 & 4,9 & 14,3 & 10,3 & 0,0 \\
\hline $\begin{array}{l}\text { Participation in } \\
\text { professional client } \\
\text { discussion clubs }\end{array}$ & 0,0 & 0,0 & 20,4 & 0,0 & 0,0 & 9,8 & 14,3 & 37,9 & 0,0 \\
\hline $\begin{array}{l}\text { Sponsorship } \\
\text { in Internet }\end{array}$ & 0,0 & 0,0 & 13,0 & 0,0 & 0,0 & 6,6 & 0,0 & 13,8 & 0,0 \\
\hline Virtual exhibitions & 0,0 & 5,9 & 4,6 & 0,0 & 0,0 & 4,9 & 0,0 & 3,5 & 0,0 \\
\hline $\begin{array}{l}\text { Promotions, sales, } \\
\text { the Internet prizes } \\
\text { raffling }\end{array}$ & 25,0 & 11,8 & 34,3 & 0,0 & 17,1 & 29,5 & 42,9 & 41,4 & 22,2 \\
\hline $\begin{array}{l}\text { Links to the site } \\
\text { for relevant tests / } \\
\text { reviews }\end{array}$ & 25,0 & 0,0 & 31,5 & 3,1 & 7,3 & 23,0 & 14,3 & 27,6 & 11,1 \\
\hline
\end{tabular}

Source: authors investigations, a national survey of 304 online-stores in Kiev, Ukraine, statistical error - 0,945doesn't exceed 0,055 (5,5\%). Investigations were provided in 2017. 
The results of the provided by authors marketing investigation, evidence that respondents indicated the most essential features of the internet-stores: the wide choice, price level, the ability to compare the products' characteristics, prices, promotions, sales, customers and experts reviews, forums discussions. The differences in the price range are actively tracked by customers of 30-39 years old - 85,7\%, and by customers of 40-55 years old $-83,7 \%$. For the customers $(86,5 \%)$ with the high income the most determinant option in choosing the internet-store is the rapidity of delivery. The available video review and receiving the supply information appeared less essential.

The Internet posts (experts' reviews, blogs, and forums), online-stores web-sites, comparison sites and social networks information are the most significant of all the information sources, which influence the decisions of customers - to buy or not to buy goods in online-stores.

\section{RESULTS}

The personalized approach to plan the internet-marketing communicative companies of trade enterprises, and also to define the perspectives of their improvement are based on the using of methodological approaches to the process of Internet users segmentation, so it provides the formation of integrated online-marketing communications considering the influence of online-marketing communications on the target customers segments.

There are models of consumer behavior VALS (based on hierarchical theory of needs Maslow), VALS-2 (consumers are based the choice on their beliefs, their perception, action) and financial, informational, physical, psychological resource consumers. Developed SRI International model iVALS (Internet VALS) (1997) helped to improve the efficiency and quality «online» - environment. Depending on the activity and the professional skills of the Internet users are divided into groups: wizard, pioneers, surfers, mainstreamers, upstreamers, workers, sociables, socialites - seekers, immigrants. However, these models do not take into consideration specific features and actions of domestic consumers in terms of extremely rapid development of the Internet in Ukraine. The segmentation process of the Internet users must be based on the monitoring of the activity in social networks, on the customers awareness of personal data value considering the forecast influence of online-marketing communications on customers target segments [16,17].

The approved expediency of specific consumer segments isolation - those, who constantly look for the sought-for information in the Internet; have an experience in information search, look for the conditions of purchase, look for the low prices, look for the information in the Internet for the first time.

The target groups of consumers were formed by the base segmentation criteria 
(a set of factors, which influence the consumers' decision making, the probability of Internet purchase, and the social networks as a communication mean, the personal data confidentiality management, the customers' awareness of personal data value). Motivated segmentation allows specialists make propositions of argumentative InMC instruments and main themes of online-marketing appeals.

For the results the target consumers segments were detected (Table 3). It is suggested to apply the customized approach to the defining of the most acceptable for the target audience forms of and methods of online advertising, the system of stimulating in the Internet, online merchandising, PR in the Internet, direct sales in the Internet; during the process of the Internet online-marketing communication program development; it is also suggested to apply the bench marketing methods for the InMC programs development. It is recommended to increase the competitiveness of enterprises by the implementation InMC means into the marketing activity, based on the "virus" online-marketing; consistent inner corporate coordination, which provides the coordinated work of all the departments, which take part in development or realization of InMC programs.

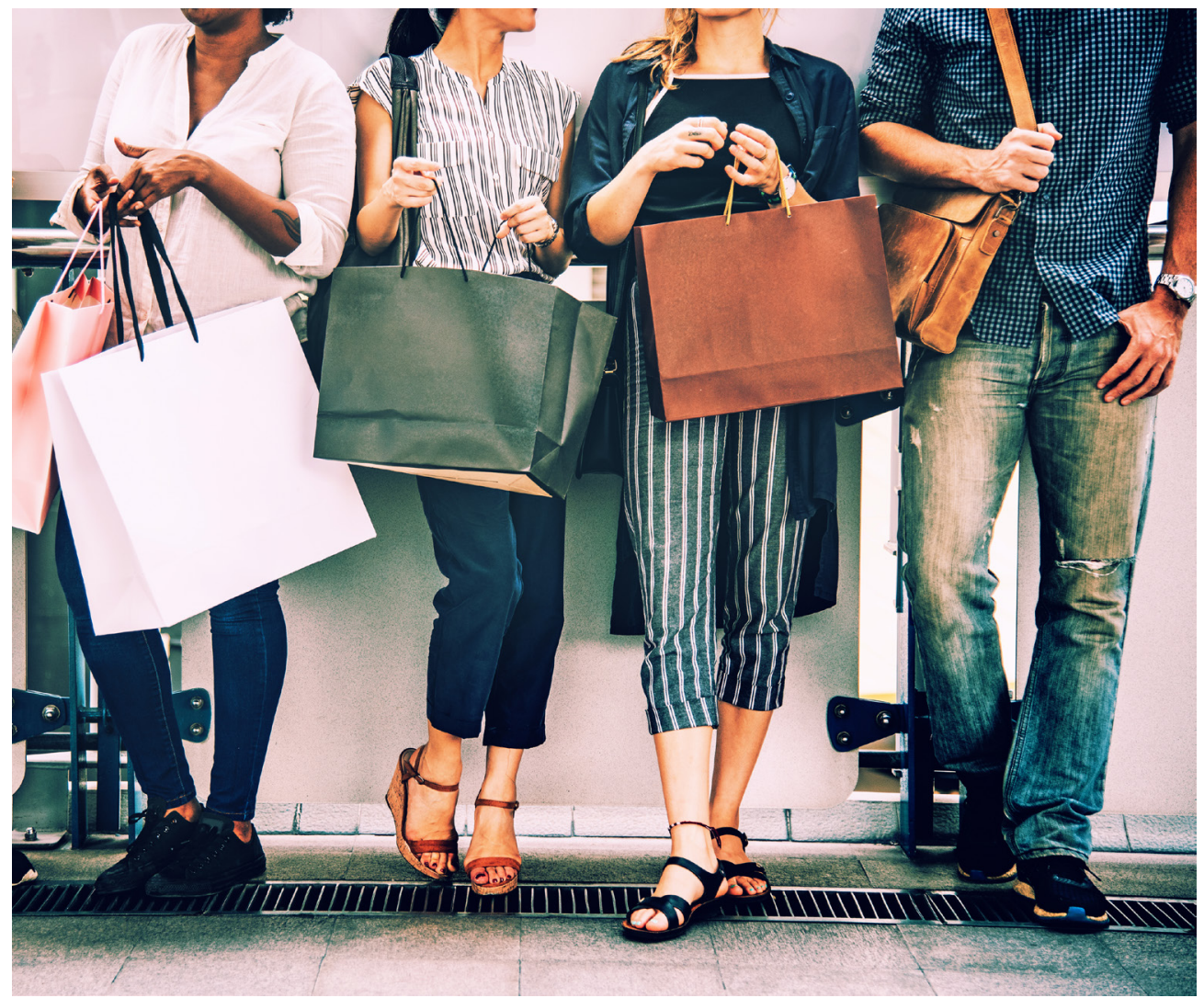


Tab. 3: Application of the internet-marketing communications to implicate Ukrainian consumers [The authors's development]

Target segments characteristics

Characteristics

Set of factors, which
influence the consumers
decision making concerning
buying products in the
Internet

Probability of the Internet purchase

Social networks for communication

Data privacy management

The customers' awareness of personal data value

\section{Price hunters}

- The wide range of products

- Competent and common style of product review

- The web site design (color, font, etc.)

- Product photo

- Video review

\section{High}

Very often

In comparison with other users they are more disposed to make purchases by means of mobile devices and to share personal data, but expect the future profits in return

Not enough recognition
Interested

- Information about the online-stores charts

- The wide range of products

- Clients, experts responds and forums discussions
They don't conceive the value of the personal data and don't express the concern about it

\section{Internet-marketing communications components}

\section{The main topic in InMC} content appeals
Technical and semantic logic
The expert support of specific information search
The most important instruments of InMC, which should be used by the trade enterprises
- Key words search engine optimization

- InMC appeal content

- $\quad$ InMC in social networks

- Price comparison sites

- InMC on mobile devices

- Banners, multimedia and online advertising
No recognition

\section{Seldom}

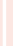

\section{Low}


Finders ("searchers")

- Conditions and different ways of payment

- The possibility to compare the product quality characteristics

- Easy order
Observers

- Price level

- The possibility to compare the product quality characteristics, prices, special offers

- $\quad$ Special offers, sales
Freshers ("tiros")

- The reputation and the popularity of online-store

- The safety level of the site

- The relevance of contacts

- Handy browsing

- $\quad$ The velocity of site uploading

- Friends advice

- The availability of reliable information
Middle

Often

They know that social networks can use the personal data to inform about the special deals
More recognition then its absence
Middle

Often

They share their personal data and expect the access and propositions profit in return

Recognition
Low

Seldom

They have protected personal settings and know, how to change the confidentiality settings on computer and mobile devices

Full recognition
Compliance with announced obligations

- $\quad$ Site navigation

- Banners, multimedia and online advertising

- InMC in partnership programs

- Price comparison sites

- Lead generation
Sales

\section{Protection of data privacy}

- $\quad$ Site navigation

- Professional club membership

- Links for the appropriate tests and reviews

- $\quad P R$ in the Internet (articles, video-conferences)

- Forum/chat

- Personal assistant 


\section{Discussions}

it is proved that in the future in Ukraine there will be an increase in e-commerce due to a number of factors: firstly, the activation of e-commerce in the regions of Ukraine; and secondly, the growth of online sales in Kyiv and in the cities of millions (with the emphasis shifted to commodity groups that were not previously in the top five - clothing and shoes, goods for childrens, cosmetics and perfumery, food products; thirdly, new players will enter the market (online retailers of chain retail trade stores) and, as a result, will increase competition, introduce new technologies, lower prices, and improve the quality of customer service.

According to the results of the research, typical problems of online stores of Ukraine were identified:

- Visitors leave the site in the first seconds without buying anything; users add items to the basket, but do not place orders;

- Customers execute orders but do not pay for it; visitors do not want to register in an online store;

- Contextual advertising does not work due to rigorous concurrency; price competition does not cover a significant portion of profits;

- $\quad$ Shares and discounts do not work properly or do not work at all;

- Mostly buyers make a purchase once on the site;

- Sales on the site are carried out without taking into account the specific features of the buyer;

- $\quad$ Standard pricing does not allow you to earn extra profit.

Thus, based on the systematization and synthesis of the literature and developments authors found that trading enterprises that operate offline and online have to respond to ongoing changes in consumer behavior, improving information and technological environments. Thesis there is determined consumer segments who, always in a constant search of information; has experience in information search; choose the easy way to buy; looking for the lowest prices; searches information for the first time. Target consumer group formed by the basic criteria for segmentation (a set of factors that influence the decision of consumers to purchase items online, chances shop online, use social networks for communication, privacy controls data, understanding consumer values personal data), there are tools InMC and the main topics of Internet marketing communication applications. 


\section{REFERENCES}

Internet Users by Country (2016). http://www.internetlivestats.com/internet-users-by-country/ Barnes, S. J., Bauer, H. H., Neumann, M. M., \& Huber, F. (2007). Segmenting cyberspace: a customer typology for the Internet. European Journal of Marketing, 41(1/2), 71-93.

Donthu, N. and Garcia, A., (1999) "The Internet Shopper", Journal of Advertising Research Vol. 39, No. 3 52-58.

Wirtz, B. W., Schilke, O., \& Ullrich, S. (2010). Strategic development of business models: implications of the Web 2.0 for creating value on the Internet. Long Range Planning, 43(2), 272-290.

Brandtzæg, P. B., Heim, J., \& Karahasanović, A. (2011). Understanding the new digital divide - A typology of Internet users in Europe. International journal of human-computer studies, 69(3), 123-138.

Van Dijck, J.D. (2009). Wikinomics and its discontents: a critical analysis of Web 2.0 business manifestos. New Media \& Society, 11 (5), 855-874.

Hargittai, E. (2010). Digital Na(t)ives? Variation in Internet skills and uses among members of the "Net Generation". Sociological Inquiry, 80 (1), 92-113.

Kollmann, T., Kuckertz, A., \& Kayser, I. (2012). Cannibalization or synergy? Consumers' channel selection in online-offline multichannel systems. Journal of Retailing and Consumer Services, 19(2), 186-194.

Ghose, S. and Dou, W. (1998). Interactive functions and their impacts on the appeal of Internet presence sites. Journal of Advertising Research, 38 (2), 29-43.

Kotler, Ph., Roberto, Lee, N. (2002). Social Marketing: Strategies for Changing Public Behavior. Thousand Oaks, CA: Sage Publications.

Hofstede, G. (1991) Cultures and Organizations: Software of the Mind. McGraw-Hill, London.

Lynch, P. D., Kent, R. J. and Srinivasan, S. S. (2001), "The global Internet shopper: evidence from shopping tasks in twelve countries", Journal of Advertising Research, Vol. 41 No. 3, pp.15-23.

Bhatnagar, A. and Ghose, S., (2004) "A Latent Class Segmentation Analysis of E-Shoppers," Journal of Business Research Vol. 57, 758-767.

Rohm, A. J. and Swaminathan, V. (2004) "A Typology of Online Shoppers Based on Shopping Motivations," Journal of Business Research Vol. 57, No. 7: 748-758.

Burke, Raymond R. (2002) "Technology and the Customer Interface: What Consumers Want in the Physical and Virtual Store," Journal of the Academy of Marketing Science, 30, 411-432.

Monsuwé, T.P.y., Dellaert, B.G.C. \& Ruyter, K.d. (2004) What drives consumers to shop online? A literature review. International Journal of Service Industry Management, 15(1), pp.102-21.

Dubovyk, T. (2014) Integreted internet-marketing communications. The economic annals $-X X I$, 116-119. (in Ukr.). 
Concepts are purely differential and defined not by their positive content but negatively by their relations with the other terms of the system" The "most precise characteristic" of these concepts "is in being what the others are not" (F. de Saussere, 1993 p.117) "Signs function, then, not through their intrinsic value but through their relative position" (F. de Saussere, 1993 p.118)

Ferdinand de Saussure, Course in General Linguistics

Typology: a system used for putting things into groups according to how they are similar: the study of how things can be divided into different types.

Merriam-Webster Dictionary

\section{INTRODUCTION}

Studying consumer lifestyles and ethnocentrism is a unique way of finding out buyer behavior and market segmentation. This chapter discusses two of the most popular marketing typologies, The Values, Attitudes and Lifestyles (VALS) 1 and 2 typology and the Claritas typology. The methodological issues include measure equivalence and sample equivalence of the segmentation(Lim, Yoo, \& Park, 2018; Maciejewski, Mokrysz, \& Wróblewski, 2019) basis, segmentation methods employed, and whether national sample sizes should be proportional to population sises (Steenkamp \& Ter Hofstede, 2002). It argues that these typologies have certain deficiencies and suggests a different typology, the Grid-Group typology which suggests there are four lifestyles (consumer cultures) that are all in opposition to one another but which shape consumer preferences for members of each culture.

If you think about it, marketers aren't terribly interested in individuals but have preferences are for groups of people who share certain characteristics and who can be targeted by advertising. This The written focuses on how to segment customers' lifestyles based on their consumption data and provides suggestions on which lifestyle groups can be good candidates for certain programs based on the segmentation result (Kwac, Flora, \& Rajagopal, 2018). This leads to marketers developing typologies to classify potential customers into different groups. In this essay I will deal with two wellknown and influential typologies, The VALS typology (of historic interest), the Claritas typology (still being used), and a third typology with which many marketers may not be familiar, the Grid-Group typology. I will begin with the VALS typology: VALS stands for Values and Life Styles according to the literature strongly approached by authors such as. de acuerdo a la literatura fuertemente abordados s por autores como (Barber \& Taylor, 2011; Bruwer, Li, \& Reid, 2002; Kesić \& Piri-Rajh, 2003; Kesić, Rajh, \& Kesić, 2008; Kucukusta \& Denizci Guillet, 2016; Pandey, Chawla, \& Venkatesh, 2015; Srihadi, Hartoyo, Sukandar, \& Soehadi, 2016; Vyncke, 2002; Wicker, Hallmann, Prinz, \& Weimar, 2012). In 
the markets studied here, these lifestyle segmentations clearly surpass the classic demographic segmentations in terms of obtaining significant differences in terms of evaluation of product attributes or benefits, and therefore the use of tools is indispensable for the achievement of the desired objective (Swenson, Bastian, \& Nembhard, 2018).

In previous publications I have already analyzed how consumer cultures place advertising in the communication process and consider the use of sexuality in advertising (Berger, 2011, 2016), political advertising and marketing theory. The marketing discussion deals with the Typology of Values and Lifestyle (VALS) and the typology of Claritas but on this occasion it deals with the following topics(Kahle, Beatty, Homer, Beatty, \& Homer, 2019).

Finally, it is important that marketing efforts focus on improving consumer knowledge, as well as ensuring adequate availability (Buitrago-Vera, Escribá-Pérez, BavieraPuig, \& Montero-Vicente, 2016; Choi \& Hong, 2017; Hrubá, 2018; Van Huy, Chi, Lobo, Nguyen, \& Long, 2019) of inputs for decision making by marketing managers.

\section{The vals (values and life styles) typology}

One of the most interesting and influential typologies, developed more than thirty years ago, was the Values and Life Styles Typology, created by SRI International (Levinson \& Barron, 2018), a think tank in Menlo Park, California. This typology focuses on values and lifestyles of consumers and argues that there are nine different and distinctive kinds or types of consumers in the United States. Knowing about each of these lifestyles enables advertisers to understand what motivates people and target their appeals to the values and lifestyles of members of each lifestyle/kind of consumer. On this type of interest analysis are referenced in the literature in (Bruwer \& Li, 2017; Choi \& Hong, 2017; Díaz, Gómez, Molina, \& Santos, 2018; Van Huy et al., 2019; Zwolinsky et al., 2016) .

In (1983), Arnold Mitchell, director of the Stanford Research Institute's Values and Lifestyles (VALS) program, published The Nine American Lifestyles: Who We Are \& Where We Are Going (Simpson, Bretherton, \& Vere, 2012). In his preface, he makes some interesting points (Kwac et al., 2018):

People's values and lifestyles say a good deal about where we are going, and they help explain such practical, diverse questions as (Bruwer, Roediger, \& Herbst, 2017; Ripoll, Alberti, \& Panea, 2015; Srihadi et al., 2016): why we support some issues and oppose others; why some people are strong leaders and others weak; why some people are economically brilliant and others gifted artistically_and a few are both; why we trust some people and are suspicious of others; why some products attract us and others don't; why revolutions occur (Jayasankaraprasad \& Kathyayani, 2014). 
Other studies investigate the psychographic segmentation of urban consumers (Kumar \& Sarkar, 2008), based on VALS, using cluster analysis to segment metropolitan consumers in India into six categories of behaviour, namely: Well Established, Fighting, Enjoying, Conservative, Self-Concerned and Realistic. The segments have been profiled in terms of product ownership, activities and interests, financial investment channels and media habits. Implications for marketing.

By the term "values" we mean the entire constellation of a person's attitudes, beliefs, opinions, hopes, fears, prejudices, needs, desires, and aspirations that, taken together, govern how one behaves. We now have powerful evidence that the classification of an individual based on a few dozen attitudes and demographics tells us a good deal about what to expect of that person in hundreds of other domains. Further, the approach often enables us to identify the decisive quality-of-life factor or factors in a person's life (Díaz et al., 2018; Iversen, Hem, \& Mehmetoglu, 2016; Jordan, 2006; Vyncke, 2002).

Mitchell (1983) developed what became known as the VALS typology based on a survey that he and his colleagues conducted in 1980. The typology argues that members of each lifestyle share similar values that shape their behaviour, especially as consumers (Abedniya \& Zaeim, 2011; Akgün \& Yalım, 2015; Verhoeven, Pieterse, \& Pruyn, 2006). The advertising industry was extremely interested in the VALS typology (Chang, 2011, 2013; Kumar \& Sarkar, 2008; Simpson et al., 2012) because advertisers thought it would help them be more successful in targeting groups of interest to them. It assumes people's values and beliefs shape their purchasing of goods and services.

The nine categories of consumers in the VALS 1 typology are as follows:

- Survivors: old, poor, and out of the cultural mainstream.

- Sustainers: young, crafty, and on the edge of poverty, want to get ahead in the world.

- Belongers: conservative and conventional in their tastes, sentimental, not experimental.

- Emulators: upwardly mobile, status conscious, competitive, and distrustful of the establishment. They want to make it big.

- Achievers: leaders of society, who have been successful in the professions, in business, and in the government. They have status, comfort, fame, and materialistic values.

- I-Am-Me's: young, narcissistic, exhibitionist, inventive, impulsive, and individualistic.

- Experientials: an older version of the I-Am-Me's and is concerned with inner growth.

- Societally Conscious Individuals: believe in simple living and smallness of scale, and support causes such as environmentalism, consumerism and conservation. This group made up around 28 percent of the adult population in the United States in 1990 and has, perhaps, grown considerably since then.

- Integrateds: characterized by psychological maturity, tolerance, assuredness, and a self-actualizing philosophy. Integrateds tend to ignore advertising, and relatively 
few advertisements are made to appeal to them. Integrateds make up only around 2 percent of the adult American population, but they are very influential and are disproportionately found among corporate and national leaders. While Integrateds may not be as susceptible to advertising as other groups, their taste in lifestyle products may be highly influential and they may function as what might be described as "taste" leaders.

An example of how VALS was used is a campaign by Merrill Lynch, which had a slogan, "Bullish on America," that showed a herd of bulls and was directed towards Belongers. Merrill Lynch switched its ads and slogan to "A Breed Apart," which showed a lone bull and was directed towards Achievers, who preferred the ad to the "Bullish on America" ones because Achievers see themselves as independent and leaders. In addition, Achievers have much more money to invest than Belongers (Simpson, Bretherton, \& De Vere, 2005; Simpson et al., 2012).

The problem with the VALS typology is that it assumes consumer rationality and that people will always purchase products that fit with their values and lifestyles and financial status, but we know that is not always the case. Sustainers may purchase products that one would expect Emulators to buy and Experientials may purchase things that Belongers buy (Tan, Chai, \& Min, 2017). That is, poor people sometimes "buy rich" and rich people sometimes "buy poor".

The VALS typologies were based on a survey that SRI conducted in 1980. As Mitchell explains:

The Values and Lifestyle (VALS) typology rests upon data obtained in a major mail survey conducted by VALS in 1980. The survey asked over 800 specific questions on a great range of topics. Sample size exceeded 1600. Respondents constituted a national probability sample of Americans aged eighteen or over living in the forty-eight contiguous states. Statistical analysis of survey results quantified and enriched the basic concepts of the VALS typology and enabled us to provide detailed quantitative and human portraits of the VALS types, together with their activities and consumption patterns (Berger, 2000; Novak, 2015).

It is people's consumption patterns and product preferences that are of most interest to marketers and advertisers but do people's values always, or even often, shape their decisions as consumers? It is doubtful that this is the case (Dees, 1998). Because of problems with the first VALS typology, SRI had to come up with a second VALS typology, but it had its problems as well (Douglas, 1997). 


\section{THE CLARITAS TYPOLOGY}

\section{These sixty-six categories and their subcategories are shown below:}

\section{Y1 Midlife Success}

03 Movers \& Shakers

08 Executive Suites

11 God's Country

12 Brite Lites, Li'l City

19 Home Sweet Home

25 Country Casuals

30 Suburban Sprawl

37 Mayberry-ville

\section{Y2 Young Achievers}

04 Young Digerati

16 Bohemian Mix

22 Young Influentials

23 Greenbelt Sports

24 Up-and-Comers

31 Urban Achievers

35 Boomtown Singles

Y3 Striving Singles

42 Red, White \& Blues

44 New Beginnings

45 Blue Highways

47 City Startups

48 Young \& Rustic

53 Mobility Blues

56 Crossroads Villagers Family Life

\section{M1 Affluent Empty Nests}

01 Upper Crust

07 Money \& Brains

09 Big Fish, Small Pond

10 Second City Elite

\section{M2 Conservative Classics}

14 New Empty Nests

15 Pools \& Patios

21 Gray Power

26 The Cosmopolitans

27 Middleburg Managers

28 Traditional Times

F1 Accumulated Wealth

02 Blue Blood Estates

05 Country Squires

06 Winner's Circle

\section{F2 Young Accumulators}

13 Upward Bound

17 Beltway Boomers

18 Kids \& Cul-de-Sacs

20 Fast-Track Families

29 American Dreams

\section{F3 Mainstream Families}

32 New Homesteaders

33 Big Sky Families

34 White Picket Fences

36 Blue-Chip Blues

50 Kid Country, USA

51 Shotguns \& Pickups

52 Suburban Pioneers

54 Multi-Culti Mosaic

\section{F4 Sustaining Families}

63 Family Thrifts

64 Bedrock America

65 Big City Blues

66 Low-Rise Living Years

\section{M3 Cautious Couples}

38 Simple Pleasures

39 Domestic Duos

40 Close-In Couples

41 Sunset City Blues

43 Heartlanders

46 Old Glories

49 American Classics

\section{M4 Sustaining Seniors}

55 Golden Ponds

57 Old Milltowns

58 Back Country Folks

59 Urban Elders

60 Park Bench Seniors

61 City Roots

62 Home 
Several years later, a new typology, the Claritas (formerly the Nielsen/Claritas) typology was developed which argues that there are not nine or eight different kinds of consumers in the United States but as many as sixty-six kinds of consumers. Claritas suggests that "birds of a feather flock together" which means that people with the same socio-economic (Chang, 2013; Rhyne, 2011, 2013; Shavitt, Jiang, \& Cho, 2016) status and taste level tend to live in areas with the same zip codes. Other categories of consumers may also be found in those zip codes, so a zip code isn't always an indication of a person's socio-economic status but it generally accurate. Claritas uses Zip codes in its research (Berger, 2011).

For example, I live in a zip code with the wealthiest category, the "upper crust," but I am not, by any means, a member of that category.

It is possible for people in the United States to look up their Zip Codes on the Claritas "My Best Segments" web site. The segments for my zip code, 94941, are:

1. Upper Crust

2. Networked Neighbors

3. 03: Movers and Shakers

4. Winner's Circle

5. Gray Power

The Claritas typology gives its sixty-six categories of consumers jazzy names and asserts that knowing about each of the different categories enables marketers and advertisers to target them better. Claritas has a considerable amount of data on members of each group, such as the brand of car they drive, the kind of food they eat, the magazines they read, and so on. In recent years Claritas added group categories, such as YI Midlife Success and F3 Mainstream Families, to the list of categories.

There are problems that arise with all typologies. How do we know whether someone fits in one category rather than another? Is an Urban Elder different from a member of Golden Ponds and does it make that much difference to marketers and advertisers? Claritas argues that it does.

We might ask ourselves, why did Claritas stop at sixty-six kinds of consumers? Where does the ability to categorize Americans into clusters, groupings or categories to generate interesting typologies end? There is an element of invention and imagination (and sometimes a touch of humor) involved in developing typologies and their classification systems and categories; they are intriguing but are they useful? We must remember that the two different VALS typologies came from information provided by one SRI survey. 
An study titled Domain-specific market segmentation: a wine-related lifestyle (WRL) approach (Bruwer et al., 2017) demonstrated that market segmentation based on psychographic (lifestyle) behaviour is strengthened when supported by two additional segmentation methods, namely, socio-demographics and product involvement (purchasing and consumption).

The next typology we will consider, Grid-Group theory, argues that its typology is based on social dimensions that generate categories, not imagination and invention, and thus is more useful (Barber \& Taylor, 2011; Kucukemiroglu, Harcar, \& Spillan, 2006; Spillan, Kucukemiroglu, \& de Mayolo, 2007).

\section{GRID-GROUP THEORY}

In their book Cultural Theory, Michael Thompson, Richard Ellis and Aaron Wildavsky help us understand what Grid-Group means. They write (Thompson, M., Ellis, R. \& Wildavsky, 1990):

Our theory has a specific point of departure: the grid-group typology proposed by Mary Douglas (Douglas, 1997). She argues that the variability of an individual's involvement in social life can be adequately captured by two dimensions of sociality: group and grid. Group refers to the extent to which an individual is incorporated into bounded units (Ozanne \& Brucoli, 2015). The greater the incorporation, the more individual choice is subject to group determination. Grid denotes the degree to which an individual's life is circumscribed by externally imposed prescriptions. The more binding and extensive the scope of the prescriptions, the less of life that open to individual negotiation (Kwac et al., 2018).

The authors also deal with the way typologies and classification systems work and the problems that typologies face. They write (Thompson, M., Ellis, R. \& Wildavsky, 1990 p.261):

Any system will organize data-will order terms in classes-but only some classifications will be scientifically useful. That is why we must insist that typologies be based on dimensions that form categories, not on categories themselves. The disadvantage of categories as designations rather than as compounds of at least two dimensions is a loss of explanatory power.

Grid-group theorists argue that unless there is some way to control classifying and category making, it can spin out of control and the categories won't be terribly valuable. And the way to control category-making, they suggest, is to base them on social dimensions which are behind grid-group theory (Li, Zhang, Xiao, \& Chen, 2015). 
Douglas's theory argues that human beings face two major problems: the first is identity and involves an answer to the question "who am I?" and the second involves behavior and involves an answer to the question "what should I do?"

- Identity: Who am I? Grid Group Boundaries

- Behavior: What should I do? Group, Rules and Prescriptions

Let me summarize where we are: We solve the first problem, involving our identities, by belonging to a group that has either weak or strong boundaries and we solve the second problem, involving our behavior, by belonging to a group that has either few or many prescriptions or rules. Douglas calls these groups "lifestyles" and Aaron Wildavsky (Thompson, M., Ellis, R. \& Wildavsky, 1990), a political scientist, called them "political cultures." The two dimensions yield four (and only four) categories based on weak or strong boundaries and few or many prescriptions in groups.

\begin{tabular}{l|l|l}
\hline Lifestyle & Group Boundares & Many or Few Prescriptions \\
\hline Elitists & Strong & Numerous and varied \\
\hline Egalitarians & Strong & Few \\
\hline Individualists & Weak & Few \\
\hline Fatalists & Weak & Numerous and varied \\
\hline
\end{tabular}

Different Grid-Group theorists use different names for the four lifestyles, such as "hierarchical elitists" or "competitive individualists," but the names for the four groups shown above are representative (Hoffmann, Fischer, Schwarz, \& Mai, 2013; Khare, 2014; Sarma, 2017; Wei, McIntyre, \& Taplade, 2013).

In their book Culture Theory, explain how the four lifestyles come about (Thompson, M., Ellis, R. \& Wildavsky, 1990 p.6-7): Strong group boundaries coupled with minimal prescriptions produce social relations that are egalitarian. When an individual's social environment is characterized by strong group boundaries and binding prescriptions, the resulting social relations are hierarchical [sometimes known as elitist]. Individuals who are bounded by neither group incorporation nor prescribed roles inhabit an individualistic social context. In such an environment all boundaries are provisional and subject to negotiation. ... People who find themselves subject to binding prescriptions and are excluded from group membership exemplify the fatalistic way of life. Fatalists are controlled from without.

Individualists and Elitists form the establishment and are the most dominant lifestyles in all modern societies. Egalitarians are essentially critics of the status quo. They stress the fact that everyone has certain needs and try to elevate Fatalists, who generally find themselves at the bottom of the economic ladder. What we must 
understand is that our membership in one of these lifestyles plays an all-important role in our lives as consumers. These four lifestyles can be seen as four different consumer cultures operating in the same society and always antagonistic toward one another.

\section{IN DEFENCE OF SHOPPING}

Douglas wrote a seminal article, "In Defence of Shopping," in which she argues that (Douglas, 1997 p.23) "cultural alignment is the strongest predictor of preferences in a wide variety of fields." It is membership in one of the four lifestyles, or our cultural alignment, not personal taste or "individual choice" that determines what we consume. The advertisements that lead us to buy certain goods and services must resonate, then, with our lifestyles. She explains how this works. Consumption is not based on personal taste but on our group affiliations. She writes (Douglas, 1997):

We have to make a radical shift away from thinking about consumption as a manifestation of individual choices. Culture itself is the result of myriad choices, not primarily between commodities but between kinds of relationships. The basic choice that a rational individual has to make is the choice of what kind of society to live in. According to that choice, the rest follows. Artefacts are selected to demonstrate that choice. Food is eaten, clothes are worn, cinema, books, music, holidays, all the rest are choices that conform with the initial choice for a form of society (Mccracken, 1986).

By "society" Douglas means lifestyle and once that decision is made, "the rest follows." (Douglas, 1997)

Using the Grid-Group organizing principle, Douglas argues that in every advanced country there are four distinct and mutually antagonistic lifestyles or consumer cultures, even though people who are members of each of the lifestyles may not be aware they belong to one of them. What they are aware of is that they don't like the foods, clothes, films, books, and so on of people from other lifestyles.

This would mean that it wouldn't be demographic/socioeconomic class and discretionary income that is basic in consumption decisions, but lifestyles or membership in one of the four mutually antagonistic consumer cultures. This suggests, then, that there are four publics for marketers to focus their attention on because the consumption decisions that members of a lifestyle make are not based on individual taste but on the hidden imperatives stemming from one's lifestyle. 
In principle, every one of the nine or eight VALS groups or sixty-six groups on which Claritas has information will fit into one of the four lifestyles. Shopping, Douglas says is a struggle to define not what one is but what one is not. She argues that we know who we are by knowing who we are not. This reminds us of Ferdinand de Saussure's dictum that concepts are differential whose most precise characteristic is in being what others are not. Saussure was one of the founding fathers of semiotics, the science of signs. Advertisements, then, must be designed to appeal to the taste cultures of the members of the different lifestyles and what people in one lifestyle purchase involves the implicit rejection of the tastes of the three other lifestyles. What Mary Douglas reminds us is that, as consumers, we find out who we are by discovering who we aren't and whose taste we don't like(Harvey, Stensaker, Harvey, \& Stensaker, 2019).

What this means is that marketers must figure out ways to determine which members of each lifestyle might be most interested in a product they are selling and which ones wouldn't. There are, then, four target audiences/lifestyles/kinds of customers and advertisements must appeal primarily to one of them. The four lifestyles typology is powerful because it rests of the two dimensions that form groups: weak or strong boundaries (think, here, of the difference between reform rabbis and Roman Catholic priests) and few or many rules and prescriptions (think, here, of Unitarians and Muslims or Orthodox Jews). Grid-group's four lifestyles are based on the two essential dimensions of social life and not the creative imagination of marketers and people from advertising agencies, who can spin jazzy names for groups endlessly but whose efforts may not, in the final analysis, be very helpful to marketers (Darroch, 2014; Tan et al., 2017; Verma, 2017).

Consumers seek to avoid dissonance (making choices that are not congruent with their lifestyle imperatives) and seek reinforcement (making choices that are affirmed by their lifestyles) and Grid-Group theory explains why this is the case and asserts that it is cultural alignments, as she puts it, that determines our preferences as consumers, not individual taste (Lamont, Lareau, Theory, \& Autumn, 1988). This theory may have the benefit of being scientifically valid, but whether it solves the problem of determining why people buy the things they buy better than other typologies is open to question (Kumar \& Sarkar, 2008). A friend of mine who works in marketing told me that all typologies are a waste of time and companies that want to sell things to people would do better to consult a semiotician, who can tell them how people find meaning in signs and symbols and create a campaign that will work. He is, I should add, a semiotician (Thompson, M., Ellis, R. \& Wildavsky, 1990).

It may be that nobody knows why people act the way they do, and that marketers and advertisers have to live with the fact that as one famous advertiser put it, "fifty percent of money spent on advertising is wasted, but we don't know which fifty percent is the money that is wasted." 


\section{REFERENCES}

Abedniya, A., \& Zaeim, M. N. (2011). The impact of country of origin and ethnocentrism as major dimensions in consumer purchasing behavior in fashion industry. European Journal of Economics, Finance and Administrative Sciences, (33), 222-232. Retrieved from https://www. scopus.com/inward/record.uri?eid=2-s2.0-79959705358\&partnerID=40\&md5=65d410c2f6dca85fc7aed3229438e6e0

Akgün, S., \& Yalım, F. (2015). The reasons of young consumers' choice on chain café stores: A research on Starbucks. International Review of Management and Marketing, 5(3), 129-134. Retrieved from http://www.scopus.com/inward/record.url?eid=2-s2.0-84941790920\&partnerID $=40 \& \mathrm{md} 5=1 \mathrm{~d} 1869 \mathrm{f5} 26716 \mathrm{~d} 6 \mathrm{f} 2 \mathrm{da} 8980251 \mathrm{~cd} 0 \mathrm{dc} 1$

Barber, N., \& Taylor, C. (2011). Equity benefits of smaller wine regions and lifestyle segmentation. Journal of Brand Management, 19(2), 158-175. https://doi.org/10.1057/bm.2011.18

Berger, A. A. (2000). Fads and Consumer Culture: Advertising's Impact on American Character and Society (Fifth Edit). ROWMAN 6 LITTLEFIELD PUBLISHERS, INC.

Berger, A. A. (2011). Ads, Fads, and Consumer Culture. Advertising's Impact on American Character and Society, p. 258. Retrieved from http://books.google.com/books?id=5B8yXtjEsbkC\&printsec $=$ frontcover $\& d q=$ intitle:Ads + Fads + and + Consumer+Culture \&hl=\&cd $=1 \&$ source $=$ gbs api\%5Cnpapers3://publication/uuid/D6565543-930B-4D13-BB83-AD8D404C6BED

Berger, A. A. (2016). A Discourse on Discourse Studies. Society, 53(6), 597-602. https://doi. org/10.1007/s12115-016-0071-z

Bruwer, J., \& Li, E. (2017). Domain-specific market segmentation using a latent class mixture modelling approach and wine-related lifestyle (WRL) algorithm. European Journal of Marketing, 51(9-10), 1552-1576. https://doi.org/10.1108/EJM-10-2016-0593

Bruwer, J., Li, E., \& Reid, M. (2002). Segmentation of the Australian wine market using a wine-related lifestyle approach. Journal of Wine Research, 13(3), 217-242. https://doi. org/10.1080/0957126022000046510

Bruwer, J., Roediger, B., \& Herbst, F. (2017). Domain-specific market segmentation: a wine-related lifestyle (WRL) approach. Asia Pacific Journal of Marketing and Logistics, 29(1), 4-26. https:// doi.org/10.1108/APJML-10-2015-0161

Buitrago-Vera, J., Escribá-Pérez, C., Baviera-Puig, A., \& Montero-Vicente, L. (2016). Consumer segmentation based on food-related lifestyles and analysis of rabbit meat consumption. World Rabbit Science, 24(3), 169-182. https://doi.org/10.4995/wrs.2016.4229

Chang, E. C. (2011). Consumer market segmentation in China. In HandbookofContemporary Marketing in China: Theories and Practices (pp. 185-208). Retrieved from https://www.scopus.com/ inward/record.uri?eid=2-s2.0-84896169791\&partnerID=40\&md5=f6ff991a5a6249797deae6dd5db631f5

Chang, E. C. (2013). Consumer market segmentation in China. In Handbook of Contemporary Marketing in China: Theories and Practices (pp. 185-208). Retrieved from https://www.scopus.com/inward/record.uri?eid=2-s2.0-84896234070\&partnerID=40\&md5=ea5826ccacca456128799f8c53b6b991 
Choi, H.-R., \& Hong, W.-S. (2017). Market segmentation analysis of natural carbonated drinks according to health improving lifestyle. Journal of the Korean Society of Food Science and Nutrition, 46(12), 1539-1549. https://doi.org/10.3746/jkfn.2017.46.12.1539

Darroch, J. (2014). Why marketing to women doesn't work: Using market segmentation to understand consumer needs. In Why Marketing to Women Doesn't Work: Using Market Segmentation to Understand Consumer Needs. https://doi.org/10.1057/9781137358172

Dees, J. G. J. E. (1998). Review : The Challenges of Combining Social and Commercial Enterprise Reviewed Work ( s ): University-Business Partnerships : An Assessment by Norman E. Bowie Review by : J . Gregory Dees and Jaan Elias Published by : Cambridge University Press Stable UR. Business Ethics Quarterly, 8(1), 165-178.

Díaz, A., Gómez, M., Molina, A., \& Santos, J. (2018). A segmentation study of cinema consumers based on values and lifestyle. Journal of Retailing and Consumer Services, 41, 79-89. https:// doi.org/10.1016/j.jretconser.2017.12.001

Douglas, M. (1997). In Defense of Shopping. In The Shopping Experience (Falk \& and C. Campbell, Eds.). London: Sage.

F. de Saussere. (1993). Saussure's Third Course of Lectures on General Linghuistics (1910-1911) (E. K. \& R. Harris, Ed.). Oxford: Pergamon Press.

Harvey, L., Stensaker, B., Harvey, L. E. E., \& Stensaker, B. (2019). Quality Culture : Understandings, Boundaries and Linkages Quality Culture : understandings, boundaries and linkages. 43(4), 427-442.

Hoffmann, S., Fischer, S., Schwarz, U., \& Mai, R. (2013). State of the art of cross-cultural consumer research. An analysis of the literature from 2005 to 2010 . Journal fur Betriebswirtschaft, 63(1), 45-86. https://doi.org/10.1007/s11301-012-0090-9

Hrubá, R. (2018). Lifestyle segmentation of Czech food shoppers: How sustainability and corporate social responsibility correspond to consumers' lifestyles. In S. K.S. (Ed.), 32nd International Business Information Management Association Conference, IBIMA 2018 (pp. 6364-6374). Retrieved from https://www.scopus.com/inward/record.uri?eid=2-s2.0-85063034975\&partnerID=40\&md5=f78c36f83ae12656eeb1c24254323162

Iversen, N. M., Hem, L. E., \& Mehmetoglu, M. (2016). Lifestyle segmentation of tourists seeking nature-based experiences: The role of cultural values and travel motives. Journal of Travel and Tourism Marketing, 33, S38-S66. https://doi.org/10.1080/10548408.2014.998359

Jayasankaraprasad, C., \& Kathyayani, G. (2014). Cross-format shopping motives and shopper typologies for grocery shopping: a multivariate approach. International Review of Retail, Distribution and Consumer Research, 24(1), 79-115. https://doi.org/10.1080/09593969.2013.801358

Jordan, P. W. (2006). Lifestyles and values of older users - A segmentation. Annual Conference of the Ergonomics Society on Contemporary Ergonomics 2006, 414-418. Retrieved from https:// www.scopus.com/inward/record.uri?eid=2-s2.0-84857701052\&partnerID=40\&md5=e0d60b5af9de92a886361a6b3d9e4d13

Kahle, L. R., Beatty, S. E., Homer, P., Beatty, S. E., \& Homer, P. (2019). Research in Brief. 13(3), 405-409. Kesić, T., \& Piri-Rajh, S. (2003). Market segmentation on the basis of food-related lifestyles of Croatian families. British Food Journal, 105(3), 162-174. https://doi. org/10.1108/00070700310477112 
Kesić, T., Rajh, S. P., \& Kesić, H. (2008). Market segmentation in the republic of Croatia according to food-related lifestyle. Ekonomski Pregled, 59(9-10), 503-522. Retrieved from https:// www.scopus.com/inward/record.uri?eid=2-s2.0-55849142982\&partnerID=40\&md5 $=38702555$ a993e695e7e3ad0a540cb6d8

Khare, A. (2014). Consumers' susceptibility to interpersonal influence as a determining factor of ecologically conscious behaviour. Marketing Intelligence and Planning, 32(1), 2-20. https:// doi.org/10.1108/MIP-04-2013-0062

Kucukemiroglu, O., Harcar, T., \& Spillan, J. E. (2006). Market segmentation by exploring buyer lifestyle dimensions and ethnocentrism among Vietnamese consumers: An empirical study. Journal of Asia-Pacific Business, 7(4), 55-76. https://doi.org/10.1300/J098v07n04_04

Kucukusta, D., \& Denizci Guillet, B. (2016). Lifestyle Segmentation of Spa Users: A Study of Inbound Travelers to Hong Kong. Asia Pacific Journal of Tourism Research, 21(3), 239-258. https://doi. org/10.1080/10941665.2015.1025087

Kumar, R. V, \& Sarkar, A. (2008). Psychographic segmentation of Indian urban consumers. Journal of the Asia Pacific Economy, 13(2), 204-226. https://doi.org/10.1080/13547860801923590

Kwac, J., Flora, J., \& Rajagopal, R. (2018). Lifestyle Segmentation Based on Energy Consumption Data. IEEE Transactions on Smart Grid, 9(4), 2409-2418. https://doi.org/10.1109/ TSG.2016.2611600

Lamont, M., Lareau, A., Theory, S., \& Autumn, N. (1988). Cultural Capital : Allusions , Gaps and Glissandos in Recent Theoretical Developments Cultural Capital : Allusions , Gaps and Glissandos in Recent Theoretical Developments. Sociological Theory, 6(2), 153-169. https://doi. org/10.2307/202113

Levinson, A. M., \& Barron, B. (2018). Latino immigrant families learning with digital media across settings and generations. Digital Education Review, (33), 150-169. Retrieved from https://www.scopus.com/inward/record.uri?eid=2-s2.0-85049333674\&partnerID=40\&md5=357012cc631192bbb0117d6a46a4ead8

Li, M., Zhang, H., Xiao, H., \& Chen, Y. (2015). A grid-group analysis of tourism motivation. International Journal of Tourism Research, 17(1), 35-44. https://doi.org/10.1002/jtr.1963

Lim, H., Yoo, E.-H., \& Park, M. (2018). Warehouse rental market segmentation using spatial profile regression. Journal of Transport Geography, 73, 64-74. https://doi.org/10.1016/j.jtrangeo.2018.10.007

Maciejewski, G., Mokrysz, S., \& Wróblewski, Ł. (2019). Segmentation of coffee consumers using sustainable values: Cluster analysis on the Polish coffee market. Sustainability (Switzerland), 11(3). https://doi.org/10.3390/su11030613

Mccracken, G. (1986). Culture and Consumption : A Theoretical Account of the Structure and Movement of the Cultural Meaning of Consumer Goods MEANING : THE CULTURALLY. 13(June).

Mitchell, A. (1983). The nine American lifestyles.

Novak, T. P. (2015). On comparing alternative segmentation schemes : The List of Values ( LOV) and Values and Life Styles (VALS ). (August). https://doi.org/10.1086/208541

Ozanne, M., \& Brucoli, M. (2015). Holistic masterplanning for resilient mini-grids: A case study methodology analysis applied to rural communities in Palestine. 2nd IEEE Canada In- 
ternational Humanitarian Technology Conference, IHTC 2015. https://doi.org/10.1109/ IHTC.2015.7238063

Pandey, S., Chawla, D., \& Venkatesh, U. (2015). Online Shopper Segmentation Based on Lifestyles: An Exploratory Study in India. Journal of Internet Commerce, 14(1), 21-41. https://doi.org/1 $0.1080 / 15332861.2015 .1006516$

Rhyne, W. (2011). The China wine market: A case for segmentation, promotion, distribution, pricing, and mode of entry decisions. In Handbook of Contemporary Marketing in China: Theories and Practices (pp. 263-271). Retrieved from https://www.scopus.com/inward/record. uri?eid=2-s2.0-84896150206\&partnerID=40\&md5=6b5990bb68dd9143b013133b5f65e835

Rhyne, W. (2013). The China wine market: A case for segmentation, promotion distribution, pricing, and mode of entry decisions. In Handbook of Contemporary Marketing in China: Theories and Practices (pp. 263-272). Retrieved from https://www.scopus.com/inward/record. uri?eid=2-s2.0-84896205235\&partnerID=40\&md5=ddbf0b3671c0e10adb48cd3596102f3a

Ripoll, G., Alberti, P., \& Panea, B. (2015). Consumer segmentation based on food-related lifestyles and perception of chicken breast. International Journal of Poultry Science, 14(5), 262-275. https://doi.org/10.3923/ijps.2015.262.275

Sarma, S. (2017). Cultural nuances in changing consumer behavior: Lessons for cultural positioning. In Global Observations of the Influence of Culture on Consumer Buying Behavior (pp. 279293). https://doi.org/10.4018/978-1-5225-2727-5.ch016

Shavitt, S., Jiang, D., \& Cho, H. (2016). Stratification and segmentation: Social class in consumer behavior. Journal of Consumer Psychology, 26(4), 583-593. https://doi.org/10.1016/j. jcps.2016.08.005

Simpson, K., Bretherton, P., \& De Vere, G. (2005). Lifestyle market segmentation, small business entrepreneurs, and the new zealand wine tourism industry. Journal of Quality Assurance in Hospitality and Tourism, 5(2-4), 157-188. https://doi.org/10.1300/J162v05n02_09

Simpson, K., Bretherton, P., \& Vere, G. D. (2012). Lifestyle market segmentation, small business entrepreneurs, and the New Zealand wine tourism industry. In Hospitality, Tourism, and Lifestyle Concepts: Implications for Quality Management and Customer Satisfaction (pp. 157-188). https://doi.org/10.1300/J162v05n02_09

Spillan, J. E., Kucukemiroglu, O., \& de Mayolo, C. A. (2007). Profiling peruvian consumers' lifestyles, market segmentation, and ethnocentrism. Latin American Business Review, 8(4), 38-59. https://doi.org/10.1080/10978520802114573

Srihadi, T. F., Hartoyo, Sukandar, D., \& Soehadi, A. W. (2016). Segmentation of the tourism market for Jakarta: Classification of foreign visitors' lifestyle typologies. Tourism Management Perspectives, 19, 32-39. https://doi.org/10.1016/j.tmp.2016.03.005

Steenkamp, J.-B. E. M., \& Ter Hofstede, F. (2002). International market segmentation: Issues and perspective. International Journal of Research in Marketing, 19(3), 185-213. https://doi. org/10.1016/S0167-8116(02)00076-9

Swenson, E. R., Bastian, N. D., \& Nembhard, H. B. (2018). Healthcare market segmentation and data mining: A systematic review. Health Marketing Quarterly, 35(3), 186-208. https://doi.org/10 $.1080 / 07359683.2018 .1514734$ 
Tan, B. C., Chai, L. T., \& Min, P. S. (2017). Attitude towards eating "green": Do consumer consciousness, healthy lifestyle, and value orientation matter? In A. K.Ab. (Ed.), 5th International Conference on Innovation and Entrepreneurship, ICIE 2017 (pp. 153-160). Retrieved from https:// www.scopus.com/inward/record.uri?eid=2-s2.0-85054251418\&partnerID=40\& $\mathrm{md5}=-$ d92027ad867b55eea111ae13a8e72363

Thompson, M., Ellis, R. \& Wildavsky, A. (1990). Cultural Theory. In Boulder \& W. Press (Eds.), Cultural Theory. San Francisco.

Van Huy, L., Chi, M. T. T., Lobo, A., Nguyen, N., \& Long, P. H. (2019). Effective segmentation of organic food consumers in Vietnam using food-related lifestyles. Sustainability (Switzerland), 11(5). https://doi.org/10.3390/su11051237

Verhoeven, J. W. M., Pieterse, M. E., \& Pruyn, A. T. H. (2006). Effects of interior color on healthcare consumers: A 360 degree photo simulation experiment. Advances in Consumer Research, 33, 292-293.

Verma, S. (2017). Niche level segmentation of green consumers: A key for psychographic or demographic predicament. South Asian Journal of Business Studies, 6(3), 274-290. https://doi. org/10.1108/SAJBS-05-2016-0040

Vyncke, P. (2002). Lifestyle segmentation: From attitudes, interests and opinions, to values, aesthetic styles, life visions and media preferences. European Journal of Communication, 17(4), 445-463. https://doi.org/10.1177/02673231020170040301

Wei, Y., McIntyre, F. S., \& Taplade, S. (2013). A cross-cultural study of relationship proneness and its implications for relationship marketing. In Managing Customer Trust, Satisfaction, and Loyalty through Information Communication Technologies (pp. 235-257). https://doi. org/10.4018/978-1-4666-3631-6.ch014

Wicker, P., Hallmann, K., Prinz, J., \& Weimar, D. (2012). Who takes part in triathlon? An application of lifestyle segmentation to triathlon participants. International Journal of Sport Management and Marketing, 12(1-2), 1-24. https://doi.org/10.1504/IJSMM.2012.051246

Zwolinsky, S., McKenna, J., Pringle, A., Widdop, P., Griffiths, C., Mellis, M., ... Collins, P. (2016). Physical activity and sedentary behavior clustering: Segmentation to optimize active lifestyles. Journal of Physical Activity and Health, 13(9), 921-928. https://doi.org/10.1123/jpah.2015-0307 


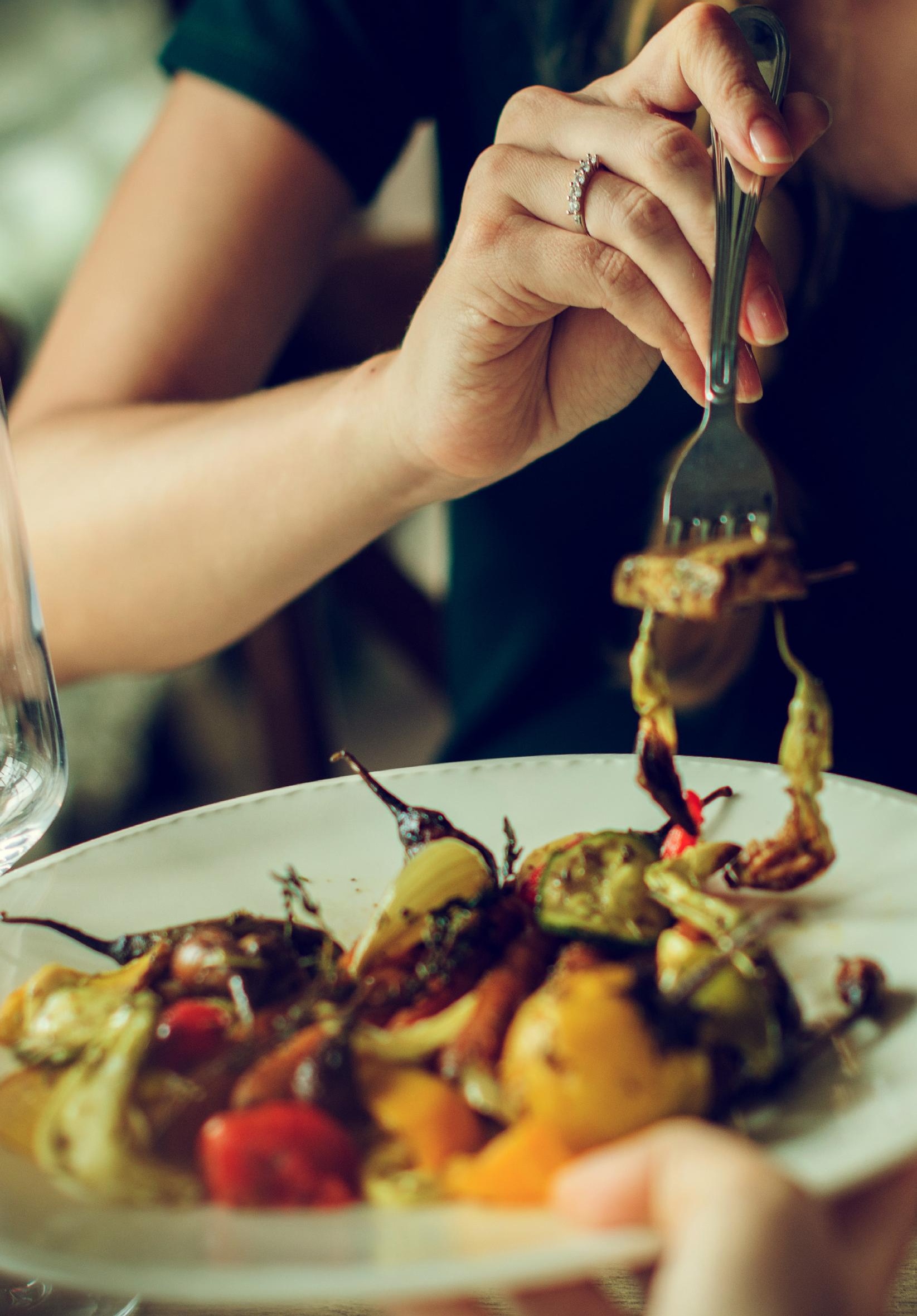




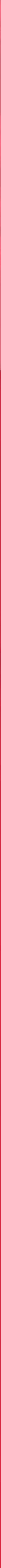




\section{MEANS-END THEORY IN CROSS-CULTURAL CONTEXTS}

Means-end chain (MEC) theory is grounded in a cognitive approach emphasizing connections between the attributes of the product, the consequences of consumption, and the corresponding instrumentality of satisfying consumer values (Gutman, 1982). Taking this hierarchical cognitive structure into account in cross-cultural contexts can lead to deeper understanding of international consumer behavior concerning product choice and consumption decisions. To date, however, international and cross-cultural applications of MEC theory have been conducted primarily by Western researchers with Anglo-Saxon consumers as subjects (e.g., Grunert et al., 2001; Hofstede, Steenkamp, and Wedel, 1999; Mort \& Rose, 2004; Overby, Gardial, and Woodruff, 2004; Russel et al., 2004; Valette-Florence et al., 2000). In addition, little attention has been paid to consumers' cognitive processing styles, which determine different patterns of thinking, in comparative analyses of MECs among consumers from different cultural backgrounds, particularly Western and Eastern cultures. This is despite the fact that a growing corpus of cross-cultural psychology studies confirms cultural differences in styles of thinking, with Western societies characterized by analytic thinking and Eastern societies characterized by holistic thinking (Nisbett et al., 2001). We suggest that this cultural orientation in the different styles of thinking influences the hierarchical cognitive structure on which consumers from Eastern versus Western cultures base their purchase decision-making process. Thus, the question we address in this research is whether analytic versus holistic thinking affects the manner in which consumers cognitively link product attributes to different consequences and values. More precisely, this research aims to contribute to recent MEC research by examining the relation between cultural differences in cognition between Western (French) and Eastern (Korean) cultural members and their MEC linkages underlying wine purchase decision. Our research was undertaken at two different levels of cross-cultural analysis: a chronic cultural difference level and an experimental level in which either the analytic or the holistic thinking tendency is primed.

\section{DYNAMIC APPROACH TO CULTURAL ORIENTATION IN STYLES OF THINKING}

Different development of self-view between Westerners and Easterners has implications for fundamental differences in styles of thinking used for their intellectual and perceptual activities: An interdependent view of self is related to a tendency to perceive an object within a part of a whole, whereas an independent view of self refers to the ability to mentally isolate focal or distinctive object from its context (Markus \& Kitayama, 1991; Kühnen et al., 2001). As such, cognitive psychologists have demon- 
strated the potential impact of self-view on cognitive processing style by describing the dichotomy between cultural perspectives-holistic (analytic) thinking encouraged in Eastern (Western) cultures. More specifically, analytic thinking involves a tendency to separate the object from a given environment and context by ignoring situational variance to focus on a salient object and its attributes, whereas holistic thinking involves an orientation to the context or field as a whole, including attention to relationships between a focal object and the field, and a preference for explaining and predicting events on the basis of such relationships (Nisbett et al., 2001). It is widely acknowledged that Easterners possess relatively more holistic ideas about the universe in general and more complex beliefs about causal reasoning in particular than do Westerners (Morris, Nisbett, and Peng, 1995; Hong et al., 2000). Likewise, the more holistic reasoners tend to consider a more diverse set of information as potentially relevant to causal analysis and thereby assume the presence of complex causality (Choi et al., 2003). Consequently, it would seem to follow that such different cognitive activity affects the way in which consumers cognitively connect perceptual MEC elements to each other across the range of attributes, consequences, and values. That is, this research attempts to clarify whether cultural differences in styles of thinking cause cultural differences in the number of MEC linkages underlying wine consumers' decision processes. It is suggested that holistic consumers, compared to analytic consumers, will be likely to generate a greater number of relationships between MEC constitutive elements, and then to develop more complex cognitive structures when selecting wine.

Although a culture determines a particular style of thinking that tends to be chronically accessible, this dominant cultural orientation is malleable in response to situational accessibility through cultural priming (Hong et al., 2000, 2003; Kühnen \& Oyserman, 2002). It is believed that the assumption that Easterners are born to be holistic and Westerners are primarily analytic may be too simplistic, and that contextual cues (cultural priming) will determine the activated cultural self-view, thereby resulting in culture-specific cognitive processing styles. We suggest, therefore, that the relative salience of analytic versus holistic thinking can be manipulated experimentally by means of priming, in which the activation level of the specific mode of thinking is increased through the presentation of a stimulus semantically related to corresponding self-view. To conclude, we propose that:

H1: Consumers from Eastern cultures will make a greater number of MEC linkages considered in purchase decision making than consumers from Western cultures.

H2: Priming holistic thinking among Western consumers will increase the number of MEC linkages considered in purchase decision making, whereas priming analytic thinking among Eastern consumers will reduce the number of MEC linkages considered. 


\section{METHODOLOGY}

\section{General Study Design}

To demonstrate the robustness of the effects of priming analytic and holistic thinking, we conducted our experiment in two cultural settings-in France and also in Korea. The hypotheses were tested through an experimental design employing a 2 (culture: French, Korean) x 3 (priming: no priming, analytic priming, holistic priming) between-subjects factor analysis. Participants in both cultural groups were randomly assigned to one of the three experimental conditions. A non-priming control condition was included to compare the results of "chronic activation" of analytic or holistic thinking encouraged by each culture and "situational activation" by priming selected cognitive modes within a cultural group. Following the priming activity, participants were given the stimulus materials-measures of MEC linkages in a wine purchasing context. We explained both the priming task and measurement of the dependent variable beforehand to minimize the temporal interval between the two phases of our experimental procedure, which were presented as two independent studies.

\section{Participants}

The research participants were 157 French undergraduates (66\% female, Mage = 20.95 years, SD $=2.39$ years; home language $=100 \%$ French) from a university in Paris and 171 Korean undergraduates (59\% female, Mage = 22.07 years, SD = 3.21 years; home language $=100 \%$ Korean) from a university in Seoul. All French (Korean) students who participated in the study identified themselves as being of French (Korean) descent, having lived in France (Korea) for their entire lives. All participants reported both consuming and purchasing wine at least once per month. Our experimental design was administered in exactly the same way at the two universities for both cultural groups.

\section{Priming Manipulations}

Participants' analytic or holistic thinking styles were made temporarily more accessible via self-view priming manipulation adapted from Aaker and Williams (1998). Participants were exposed to a fictitious advertisement representing the independent self or interdependent self, or a neutral prime. The assignment of the participants to the two experimental conditions and the control condition was random. Participants in the analytic condition were shown an advertisement featuring an individual alone accompanied by the caption:

"I remember a day by myself at the beach. I hear the sound of the surf crashing on the beach. I feel joy and happiness in the bright light of the sun shining on me. I would like to extend these precious moments for myself without being disturbed by other people!" (See Appendix 1.) 
Participants in the holistic condition received an advertisement featuring a group of friends or family accompanied by the caption:

"I remember a day with my family and friends at the beach. We hear the sound of the surf crashing on the beach. We feel joy and happiness in the bright light of the sun shining on us. We would like to extend these precious moments for ourselves without being disturbed by other people!" (See Appendix 2.)

Participants were then asked to form an impression of the given advertisement. Recent studies suggest that priming a self-view effectively activates a different cognitive style in one's mind, making information congruent with the primed self temporarily more accessible (Kühnen et al., 2001; Kühnen \& Oyserman, 2002; Ng \& Huston, 2006). We thus expect that increasing the accessibility of a particular aspect of the self can promote related networks of cultural thinking styles. In our research, priming the independent (interdependent) self was intended to increase the level of activation of the analytic (holistic) cognitive processing style.

\section{Measurement of MEC Linkages}

Immediately after the cultural priming procedure, participants were introduced to the quantitative measurement for assessing hierarchical MEC relationships and were shown the association pattern matrix (APM) technique designed by Hofstede et al. (1998). APM is a quantitatively oriented method for uncovering MEC linkages, suitable for large-scale samples of consumers, particularly in international marketing research. In APM, the MEC is conceived as a string of connected matrices, an (attribute-consequence) A-C matrix and a (consequence-value) $\mathrm{C}-\mathrm{V}$ matrix, which are independent of each other and are measured separately. Applying the structured APM method requires exploratory research to identify the main concepts to be included in the two matrices (Hofstede et al., 1998). Accordingly, our predefined set of attributes, consequences, and values that constitute the content of wine consumer's MEC were transferred to the matrices and presented as a paper-and-pencil test in a questionnaire format. Figure 1 gives an example of a section of the $\mathrm{A}-\mathrm{C}$ and $\mathrm{C}-\mathrm{V}$ matrices used in our experimental study. In the A-C $(\mathrm{C}-\mathrm{V})$ matrix, participants were presented with the attributes (consequences) and consequences (values), respectively listed in the columns and rows. Thus each matrix includes all possible association networks between the elements provided. Participants simply checked the corresponding cell in the given matrix to indicate MEC connections they value when selecting wine. To ensure that the priming and APM materials correctly conveyed the same meaning in both cultures, we performed the standard technique of back translation (Hui \& Triandis, 1989). 

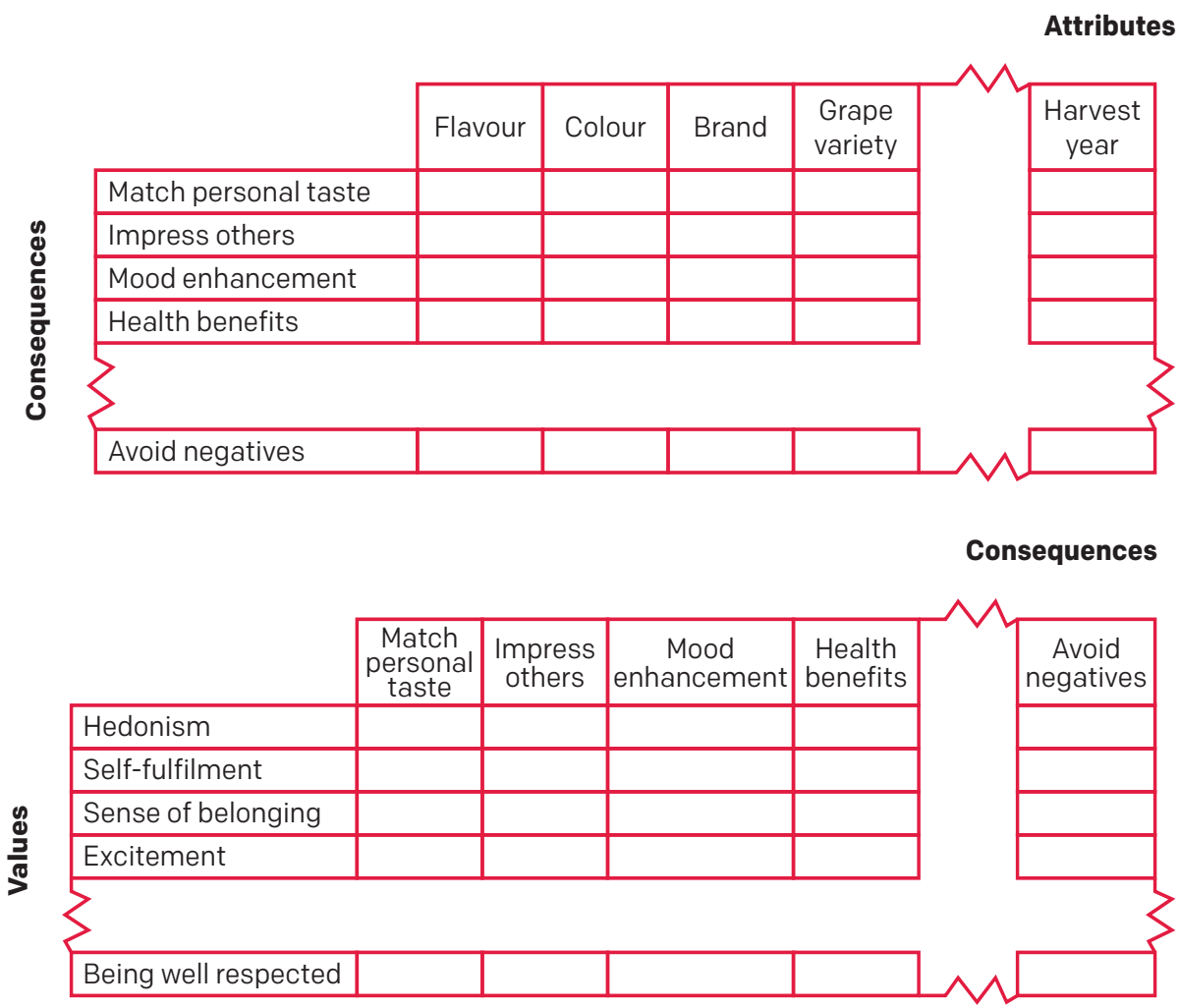

Figure 1. Example of the $\mathrm{A}-\mathrm{C}$ and $\mathrm{C}-\mathrm{V}$ matrices for wine purchase decisions

\section{RESULTS}

\section{Quantitative Variations in A-C and C-V Linkages}

We examined the relationship between cultural differences in wine consumers' thinking styles and cultural differences in the number of MEC linkages they consider. The aggregate numbers of $\mathrm{A}-\mathrm{C}$ and $\mathrm{C}-\mathrm{V}$ linkages for our control and experimental groups were calculated by averaging all the cognitive linkages each participant indicated in the corresponding matrices. The $\mathrm{A}-\mathrm{C}$ and $\mathrm{C}-\mathrm{V}$ linkages generated were subjected to a 2 (culture) x 3 (prime) ANOVA with, culture and priming mechanism as a between-subjects factor. We first explored whether Korean participants considered a greater number of cognitive linkages when buying wine than French participants. Planned comparisons confirmed that there were significant differences between the two cultural groups (in the non-priming condition) in the means of A-C linkages (F(1, $322)=12.31 ; \mathrm{p}=<.001)$ and $\mathrm{C}-\mathrm{V}$ linkages $(\mathrm{F}(1,322)=7.92 ; \mathrm{p}<.01$; see Table 1 for means and standard deviations). Consistent with $\mathrm{H} 1$, we found that a greater num- 
ber of MEC linkages emerged in Korean consumers' cognitive structures compared to their French counterparts.

Table 1. Mean numbers of $\mathrm{A}-\mathrm{C}$ and $\mathrm{C}-\mathrm{V}$ linkages

\begin{tabular}{l|c|c|c|}
\hline \multicolumn{4}{|c}{ French consumers } \\
\hline $\begin{array}{l}\text { MEC } \\
\text { linkages }\end{array}$ & $\begin{array}{c}\text { No priming } \\
(n=52)\end{array}$ & $\begin{array}{c}\text { Analytic } \\
\text { priming } \\
(n=50)\end{array}$ & $\begin{array}{c}\text { Holistic } \\
\text { priming } \\
(n=55)\end{array}$ \\
\hline \multirow{2}{*}{ A-C } & 12.53 & 12.27 & 14.86 \\
\hline & $(1.94)$ & $(2.31)$ & $(2.01)$ \\
\hline C-V & 10.77 & 11.03 & 13.12 \\
\hline
\end{tabular}

\begin{tabular}{|c|c|c|}
\hline \multicolumn{3}{|c|}{ Korean consumers } \\
\hline $\begin{array}{c}\text { No priming } \\
(n=53)\end{array}$ & $\begin{array}{c}\text { Analytic } \\
\text { priming } \\
(n=58)\end{array}$ & $\begin{array}{c}\text { Holistic } \\
\text { priming } \\
(n=60)\end{array}$ \\
\hline 16.15 & 13.62 & 16.93 \\
\hline$(2.56)$ & $(1.54)$ & $(2.09)$ \\
\hline 13.58 & 10.19 & 14.07 \\
\hline$(2.18)$ & $(1.89)$ & $(1.61)$ \\
\hline
\end{tabular}

Note. Standard deviations shown in parentheses; A-C = attributes-consequences linkages; $\mathrm{C}-\mathrm{V}=$ consequences-values linkages.

In addition, we examined whether the number of linkages considered by wine consumers varied at an individual level after being primed for analytic versus holistic thinking within each culture. As predicted, the interaction effects were found to be significant between culture and priming for $\mathrm{A}-\mathrm{C}$ linkages $(\mathrm{F}(2,322)=3.97$; $\mathrm{p}<.05)$ and $\mathrm{C}-\mathrm{V}$ linkages $(F(2,322)=6.12 ; p<.01)$, as shown in Table 2 (means and standard deviations). More specifically, while the holistic priming induced more cognitive linkages among French participants, the analytic priming induced fewer cognitive linkages among Korean participants. The results of our planned comparisons indicated that the French A-C linkages were significantly more numerous in the holistic prime than in the non-priming condition $(F(1,214)=6.93, p<.01)$; the Korean A-C linkages were significantly fewer in the analytic priming condition than in the non-priming condition $(F(1,214)=8.75, p<$ .01). We further verified that French consumers primed with holistic thinking tended to consider a greater number of $\mathrm{C}-\mathrm{V}$ linkages than when in the neutral priming condition $(\mathrm{F}(1,214)=5.18, \mathrm{p}<.01)$; Korean consumers accessed fewer $\mathrm{C}-\mathrm{V}$ linkages when analytic thinking was primed in contrast to the neutral priming condition $(F(1,214)=14.23$, $p$ $<$.001). In short, a visual summary of the means of MEC linkages (see Figures 2 and 3) highlights that quantitative variation in the number of cognitive linkages appeared in accordance with culturally relevant priming frames, broadly consistent with $\mathrm{H} 2$. These priming results thus provide evidence that a shift in thinking styles among French and Korean consumers plays a crucial role in the modulation of the cognitive approach guiding the $\mathrm{A}-\mathrm{C}-\mathrm{V}$ hierarchy structures involved in their wine choice. 


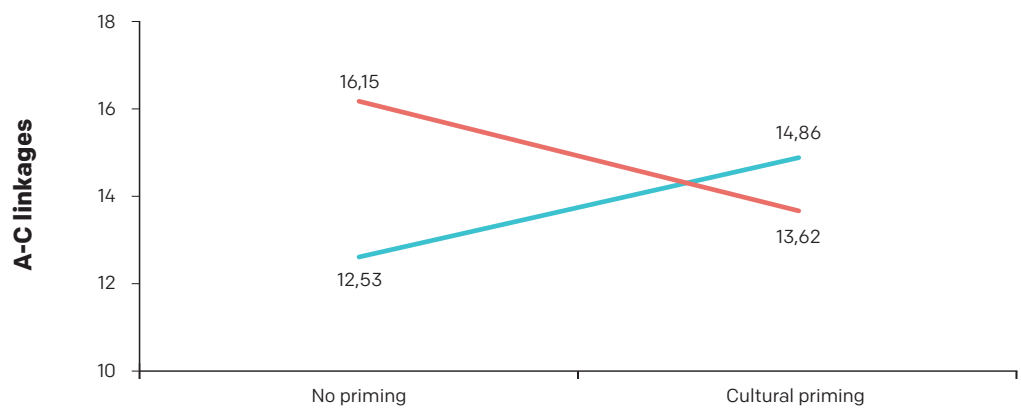

Priming conditions

French consumers Korean consumers

Figure 2. Effect of cultural primes on the number of A-C linkages considered by wine consumers

Note. $\mathrm{A}-\mathrm{C}=$ attributes-consequences linkages; cultural priming $=$ holistic priming for French wine consumers and analytic priming for Korean wine consumers.

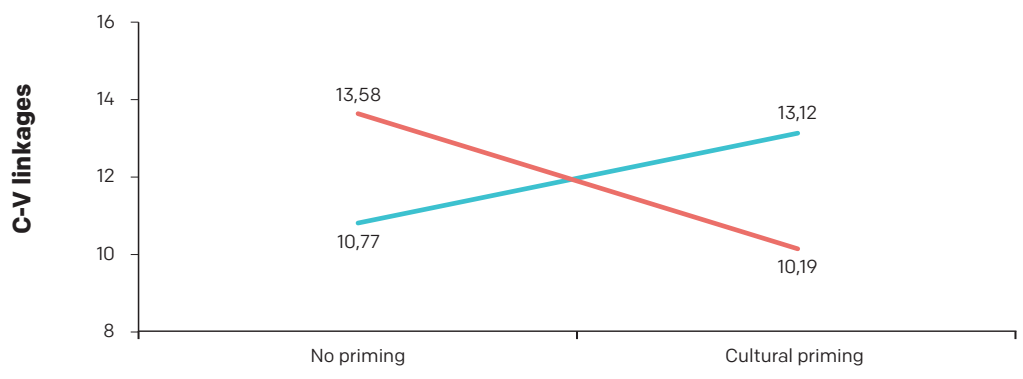

Priming conditions

French consumers $\quad$ Korean consumers

Figure 3. Effect of cultural primes on the number of $\mathrm{C}-\mathrm{V}$ linkages considered by wine consumers Note. $\mathrm{C}-\mathrm{V}=$ consequences-values linkages; cultural priming = holistic priming for French wine consumers and analytic priming for Korean wine consumers 


\section{MEC Linkage Complexity}

To reveal the cognitive structures in participants' minds, we aggregated all the linkages evoked in the form of a graphical representation, that is to say, we visualized the set formed by various relationships between all the attributes, consequences, and values related to wine purchases. The forms of $\mathrm{A}-\mathrm{C}-\mathrm{V}$ sequences are represented in hierarchical value maps (HVMs; Reynolds \& Gutman, 1988) of the consumer decision-making process based on the frequencies of linkages. Specifically, the construction of the HVMs enabled us to compare all possible combinations for the hierarchical relations made by two separate groups of wine consumers; all participants primed with analytic (holistic) thinking were taken as analytic (holistic) consumers, irrespective of their own cultural background. The entire contents of the MEC were presented in order of their assigned numbers across the range of three different levels of abstraction. A visual comparison of two HVMs (see Figures 4 and 5) demonstrates that the linkages between each element of content are considerably more numerous in the holistic consumers' MEC network than in the analytic consumers' one. We find that holistic consumers consider a large pool of hierarchical MEC relationships, such that they form more complex, even confusing, cognitive structures. Indeed, a given attribute (consequence) is associated with a greater number of consequences (values) in the holistic priming condition than in the analytic priming condition.

Overall, in line with the results of the statistical analysis, the global observation of the HVMs reinforces the argument that the salience of analytic versus holistic thinking creates different complexity in the MEC with regard to consumers' decision-making processes concerning the purchase of wine.

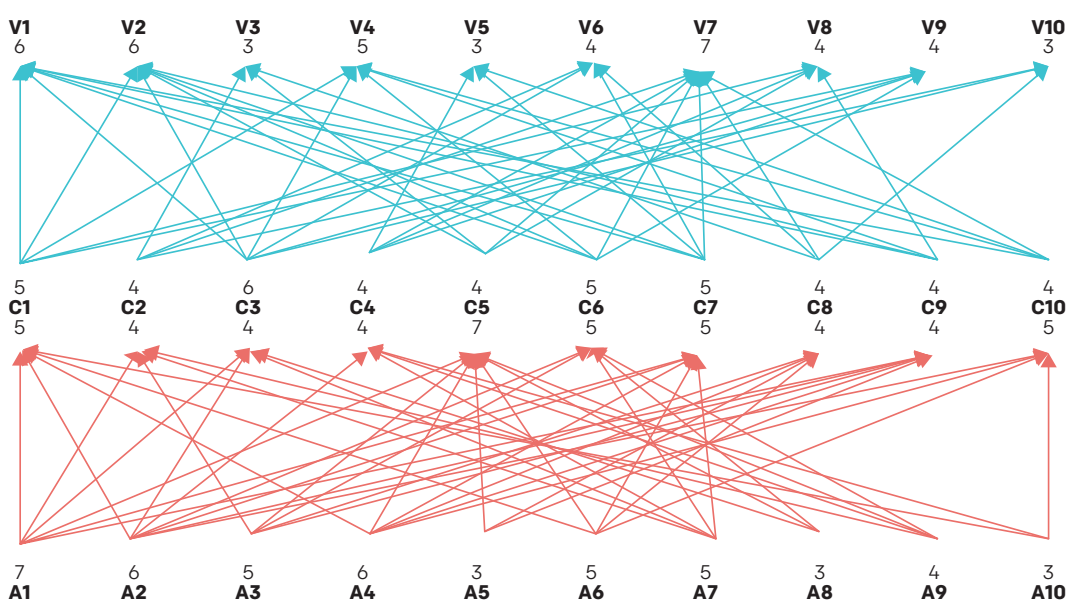

Figure 4. MEC network of wine consumers primed with holistic thinking 
Note. The number shown above (below) each MEC content indicates the number of elements connected upstream (downstream) of MEC network.

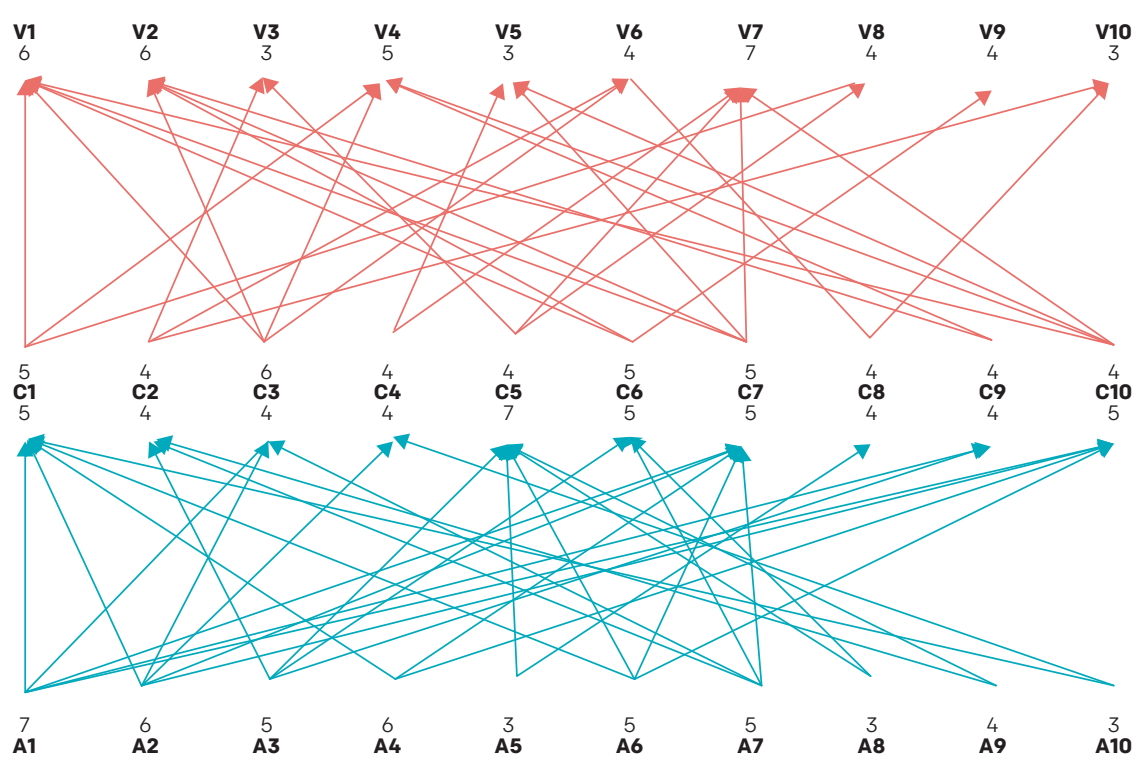

Figure 5. MEC network of wine consumers primed with analytic thinking

Note. The number shown above (below) each MEC content indicates the number of elements connected upstream (downstream) of MEC network.

\section{DISCUSSION}

The MEC approach has been particularly successful in exploring cross-cultural consumer mindsets and behavior in the food domain (e.g., Hofstede et al., 1999; Nielsen, Bech-Larsen, \& Grunert, 1998; Overby et al., 2004; Russel et al., 2004; Valette-Florence et al., 2000). Until now, MEC-related research has not explicitly considered the influence of consumers' cognitive processing styles on their hierarchical cognitive structures, although recent research from cross-cultural psychology has revealed that modes of thinking are different between Westerners with a dependent self-view and Easterners with an interdependent self-view. The primary purpose of this study was to examine whether consumers exhibited different cognitive complexity in consumption decisions, depending on which thinking style was salient. This idea was investigated in the context of wine consumers' purchases with two different cultural groups, French and Korean, 
believed to be analytic and holistic respectively within their own cultures. This study, using a priming paradigm in a cultural analysis of wine consumers' MEC linkages, has provided some clarification on the role of analytic versus holistic thinking in the consumer decision-making process. Thus, it contributes to recent research in food marketing by clarifying the different styles of thinking as a driving force for the potential cultural variation in the number of hierarchical relationships linking attributes, consequences, and values consumers consider in making a decisión.

As holistic thinkers have a tendency to focus on relationships among objects and events, while analytic thinkers are inclined to focus on the attributes of a focal object divorced from its context (Choi et al., 2003; Nisbett et al. 2001), we hypothesized and confirmed that Korean wine consumers, compared to French wine consumers, would consider broader connections between the key perceptual elements of the MEC, resulting in more complex structures of interconnected motives. Specifically, drawing upon previous research validating that the two ways of viewing the self affect human cognition (Gardner et al., 1999; Kühnen et al., 2001; Markus \& Kitayama, 1991), we have demonstrated the effects of thinking style on MEC linkages after priming consumers with independent versus interdependent self-view prompts. In an experimental setting, we found that self-view priming differentially influences the number of $\mathrm{A}-\mathrm{C}$ and $\mathrm{C}-\mathrm{V}$ linkages engendered by two cultural groups, such that French (Korean) consumers exposed to contexts fostering an interdependent (independent) orientation, when compared to those in the non-priming condition, considered more (fewer) hierarchical MEC relationships. Thus, these findings suggest that different cognitive processing styles among French and Korean wine consumers can be induced through priming an independent or interdependent self-view, and that the thinking style consistent with situationally activated self-view can in turn affect the process by which they form sets of cognitive linkages between the product's attributes and their motivations to consume.

Furthermore, wine consumers' hierarchical cognitive structures are graphically represented in HVMs constructed based on individual A-C and C-V matrices to observe their mental images and networks related to wine purchase decisions. Splitting the total sample into analytic versus holistic consumers, regardless of culture, results in parallel patterns of cognitive complexity for French versus Korean consumers. The holistic thinking-primed consumers draw a highly complex MEC network containing a larger number of perceived connections across the range of attributes, consequences, and values than the analytic thinking-primed consumers. These consistent prime effects show that the thinking style associated with a particular self-view, even when temporarily activated, plays an important role in determining the structure of the A-C-V hierarchy underlying the consumer decision process. As a whole, the results provide support for our basic premise that cultural differences in the relative complexity of MEC linkages underlying consumers' wine-buying decision making are due to cultural differences in 
holistic tendency: Easterners take more complex relationships into consideration in the causal reasoning of the world than Westerners.

Consistent with the idea of analytic versus holistic thinking (Choi et al., 2003), and the perspective of culture as a dynamic construct (Hong et al., 2000), our overall findings may shed light on the variation in cognitive processing styles as a function of the shift in self-concept styles induced by self-view priming manipulation. What is particularly notable is the fact that our research presents a pattern of results consistent with those of Kühnen and Oyserman (2002), who demonstrated that the independent (interdependent) self is stored in a semantic network-autonomous (social) semantic knowledge of the self-which is connected to cognitive procedures of analytic (holistic) thinking, and that priming these different views of the self brings about an associated thinking mode influencing judgment and decision making. Therefore, our results also contribute to the dynamic understanding of culture-specific thinking styles by supporting the argument that the activation of a particular cognitive process depends on culture-priming cues encountered in a given situation (Hong et al., 2003; Morris \& Peng, 1994; Ng \& Huston, 2006). Interestingly, in comparison to prior research with Western participants, we believe that this is one of the first cross-cultural studies of consumer behavior to include both Western and Eastern participants who are thought to be dominated respectively by independent and interdependent self-views, as analytic and holistic thinkers. More importantly, what is unique about this study is the identification of consumers' cognitive styles as a determinant of cultural differences in the number of cognitive linkages between the attributes, consequences, and values that serve as a basis for decision making. Considering culturally encouraged versus situationally primed self-view, this cross-cultural investigation of MECs contributes to a better understanding of the flexibility of thinking styles in consumers, thereby emphasizing the importance of the accessibility of cultural mindsets in making product choice decisions. As such, these findings suggest the possibility of applying a dynamic perspective to culture and cognition in research on cross-cultural consumer behavior toward food. We hope that our experimental study of wine consumers' hierarchical cognitive structures will stimulate international food marketing researchers to explore the fundamental mechanisms that underlie cultural differences in consumer cognition and decision making in the food consumption context.

The possible limitation of this research is that the divergent thinking styles were not actually measured. We inferred consumers' analytic or holistic tendency from experimental manipulations of the independent and interdependent self, based on previous priming studies on culture and cognition. Recently, Choi et al. (2007) constructed the analysis-holism scale for cross-cultural research to measure analytic versus holistic reasoning, such as locus of attention (parts versus whole) and causal theory (dispositional versus contextual). Administering this convenient measure of thinking 
style after priming may open up new possibilities for the direct examination of the various antecedents and consequences of consumers' cognitive differences. Potentially, future experiments can thus find which aspect of the analytic-holistic thinking dimension comes to be particularly salient due to priming independence or interdependence. Further research would help broaden our knowledge of the causal role of the consumer's self-view in determining cultural cognitive styles by using the analysis-holism scale as complementary tool for manipulation checking.

In summary, our findings may fruitfully be extended to naturalistic environments, such as retail food stores and restaurants. It would be worth trying to explore whether drawing on congruent contextual cues in real-world purchase situations also facilitates relevant cognitive processing styles, thereby giving rise to the cross-cultural variations in decision makers' hierarchical cognitive structures. We hope that this study linking chronic or activated thinking styles to the MEC framework will provide fresh avenues for much more international research on the relationships between analytic-holistic cognition and consumer decision making regarding food products.

\section{REFERENCES}

Aaker, J., \& Williams, P. (1998). Empathy versus Pride: The influence of emotional appeals across cultures. Journal of Consumer Research, 25, 241-261.

Choi, I., Koo, M., \& Choi, J. A. (2007). Individual differences in analytic versus holistic thinking. Personality and Social Psychology Bulletin, 33, 691-705.

Choi, I., Park, H., Dalal, R., \& Kim-Prieto, C. (2003). Culture and judgment of causal relevance. Journal of Personality and Social Psychology, 84, 46-59.

Gardner, W. L., Gabriel, S., \& Lee, A. Y. (1999). I value freedom, but We value relationships: self-construal priming mirrors cultural differences in judgment. Psychological Science, 10, 321-326.

Grunert, K., Lähteenmäki, L., Nielsen, N., Poulsen, J., Ueland, O., \& Åström, A. (2001). Consumer perceptions of food products involving genetic modification-results from a qualitative study in four Nordic countries. Food Quality and Preference, 12, 527-542.

Gutman, J. (1982). A means-end chain model based on consumer categorization processes. Journal of Marketing, 46, 60-72.

Hofstede, F., Aubenaert, J. B., Steenkamp, E. M., \& Wedel, M. (1998). An investigation into the association pattern technique as a quantitative approach to measuring means-end chains. International Journal of Research in Marketing, 15, 37-50.

Hofstede, F., Steenkamp, E. M., \& Wedel, M. (1999). International market segmentation based on consumer-product relations. Journal of Marketing Research, 36, 1-17.

Hong, Y., Benet-Martinez, V., Chiu, C. Y., \& Morris, M. W. (2003). Boundaries of cultural influence: Construct activation as a mechanism for cultural differences in social perception. Journal of Cross-Cultural Psychology, 34, 453-464. 
Kühnen, U., Hannover, B., \& Schubert, B. (2001). The semantic-procedural interface model of the self: The role of self-knowledge for context-dependent versus context-independent modes of thinking. Journal of Personality and Social Psychology, 80, 397-409.

Kühnen, U., \& Oyserman, D. (2002). Thinking about the self influences thinking in general: cognitive consequences of salient self-concept. Journal of Experimental Social Psychology, 38, 492499.

Markus, H. R., \& Kitayama, S. (1991). Culture and self: implications for cognition, emotion and motivation. Psychological Review, 98, 224-253.

Morris, M., Nisbett, R. E., \& Peng, K. (1995). Causal understanding across domains and cultures. In D. Sperber, D. Premack, \& A. J. Premack (Eds.), Causal cognition: A multidisciplinary debate (pp. 577-612). Oxford, England: Oxford University Press.

Morris, M., \& Peng, K. (1994). Culture and cause: American and Chinese attributions for social and physical events. Journal of Personality and Social Psychology, 67, 949-971.

Ng, S., \& Houston, M. J. (2006). Exemplars or beliefs? The impact of self-view on the nature and relative influence of brand associations. Journal of Consumer Research, 32, 519-529.

Nisbett, R. E., Peng, K., Choi, I., \& Norenzayan, A. (2001). Culture and systems of thought: Holistic vs. analytic cognition. Psychological Review, 108, 291-310.

Norenzayan, A., Choi, I., \& Nisbett, R. E. (2002). Cultural similarities and differences in social inference: Evidence from behavioral predictions and lay theories of behavior. Personality and Social Psychology Bulletin, 28, 109-120.

Olson, J. C., \& Reynolds, T. J. (1983). Understanding consumer's cognitive structures: implications for advertising strategy. Advertising and Consumer Psychology, 1, 77-90.

Overby, J. W., Gardial, S. F., \& Woodruff, R. B. (2004). French versus American consumers' attachment of value to a product in a common consumption context: a cross-national comparison. Journal of the Academy of Marketing Science, 32, 437-460.

Peter, P. J., \& Olson, J. C. (2005). Consumer Behaviour and Marketing Strategy. New York, NY: McGraw Hill.

Reynolds, T.J. (1985). Implications for value research: A micro versus macro perspective. Psychology and Marketing, 2, 297-305.

Reynolds, T. J., \& Gutman, J. (1988). Laddering theory, method, analysis and interpretation. Journal of Advertising Research, 28, 11-31.

Russell, C., Busson, A., Flight, I., Bryan, J., van Lawick van Pabst, J., \& Cox, D. (2004). Comparison of three laddering techniques applied to an example of a complex food choice. Food Quality and Preference, 15, 569-583.

Valette-Florence, P., Sirieix, L., Grunert, K., \& Nielsen N. (2000). Means-end chain analyses of fish consumption in Denmark and France: A multidimensional perspective. Journal of Euromarketing, 8, 15-27. 


\section{APPENDIX A.}

Analytic priming condition for French and Korean wine consumers

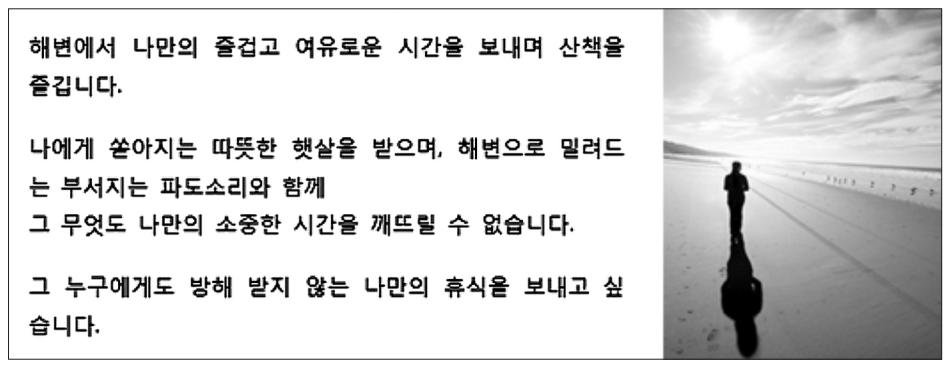

Je me balade le long de la plage en passant mon temps à relaxer et à jouir du beau temps.

Je sens avec délice les rayons du soleil qui me caressent les joues, et $j$ 'entends le bruit que font les vagues qui déferlent sur la plage.

J'aimerais prolonger ces moments précieux pour moi sans être gênés par personne.

\section{APPENDIX B.}

Holistic priming condition for French and Korean wine consumers

Nous nous baladons le long de la plage en passant notre temps à relaxer et à jouir du beau temps.

Nous sentons avec délice les rayons du soleil qui nous caressent les joues, et nous entendons le bruit que font les vagues qui déferlent sur la plage.

Nous aimerions prolonger ces moments précieux pour nous sans être gênés par personne.

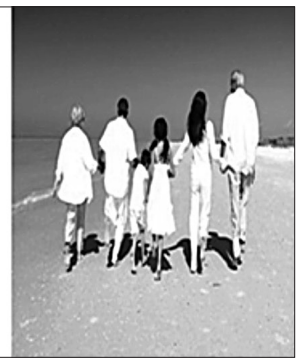

해변에서 우리만의 즐겁고 여유로운 시간을 보내며 산책 을 즐깁니다.

우리에게 쏟아지는 따뜻한 햇살을 받으며, 해변으로 일려 드는 부서지는 파도소리와 함께

그 무엇도 우리들의 소중한 시간을 깨뜨릴 수 없습니다.

그 누구에게도 방해 받지 않는 우리만의 휴식을 보내고 싶습니다.

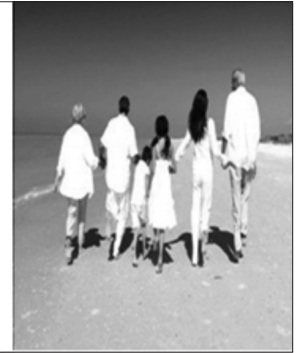




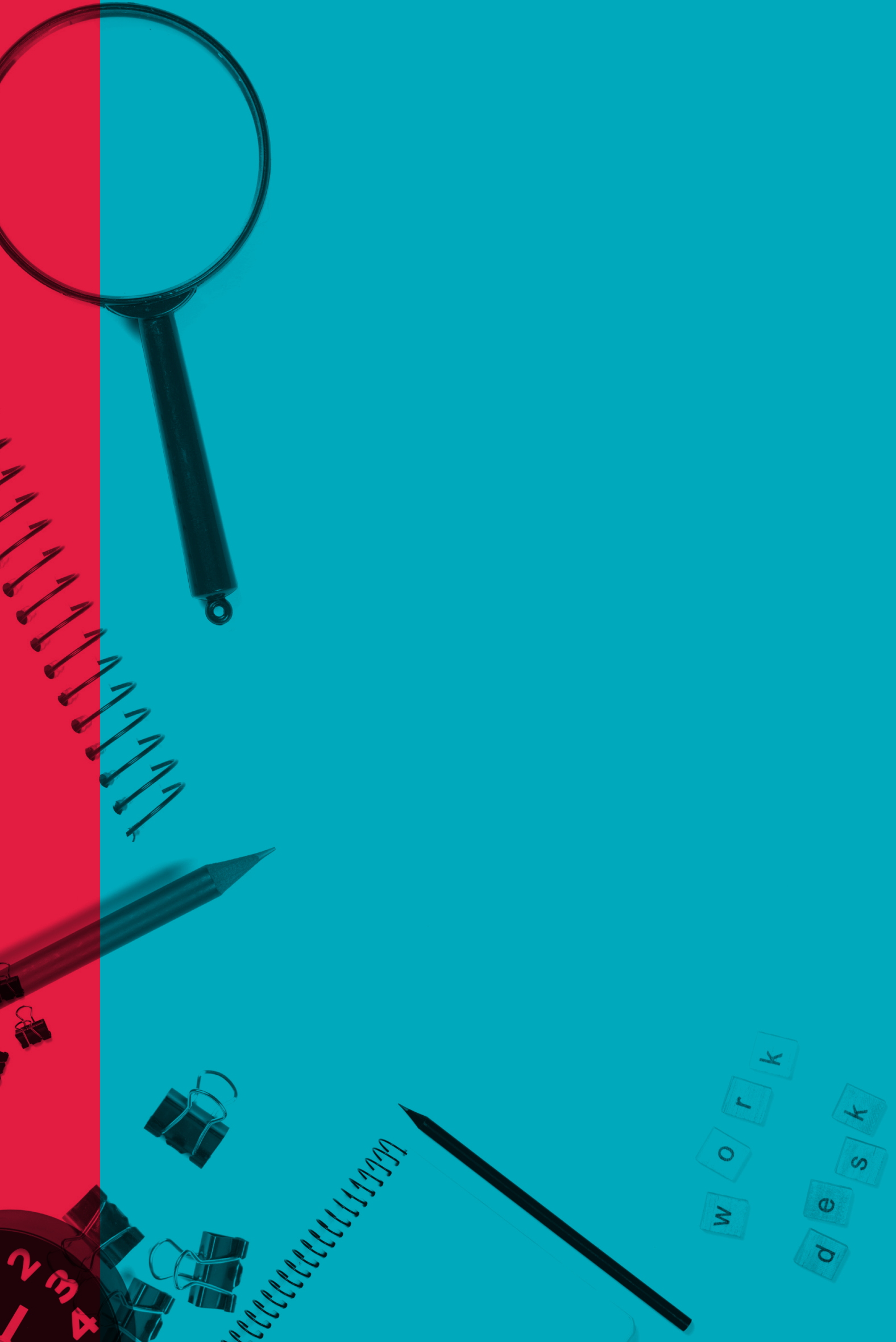




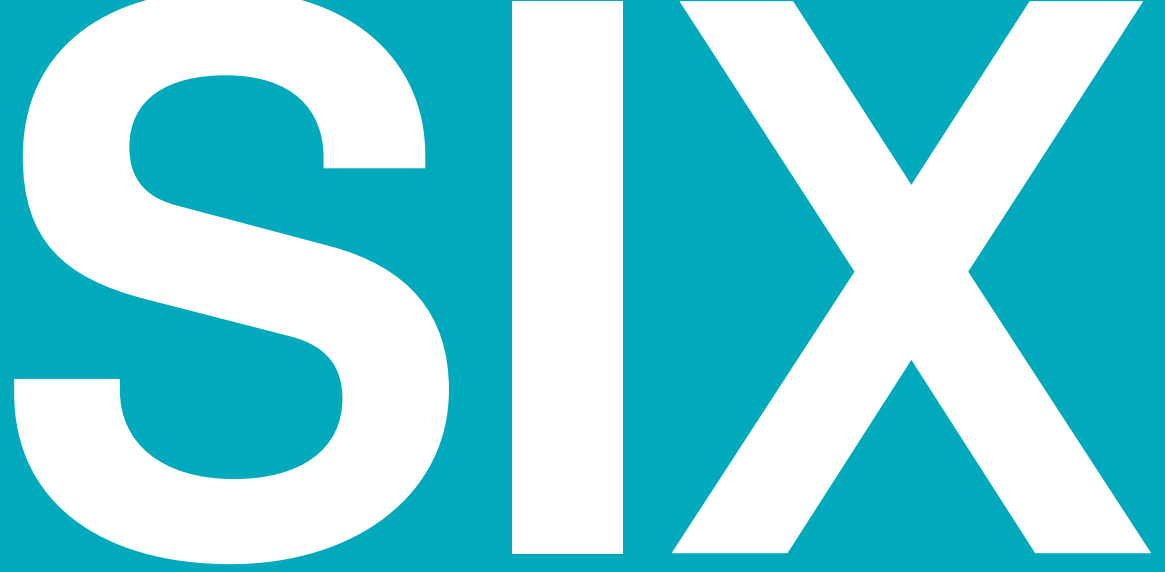

MARKETING RESEARCH PROCESSES. A PERSPECTIVE OF THE FUTURE FROM A QUALITATIVE VIEW

AUTHORS:

Luz Alexandra Montoya-Restrepo, PhD. Associate Professor, School of Mining, National University of Colombia.

Iván Alonso Montoya Restrepo, PhD. Associate Professor, School of Agricultural Sciences, National University of Colombia

Sandra Rojas-Berrío, PhD. Assistant Professor, School of Economic Sciences, National University of Colombia. 


\section{INTRODUCTION}

The objective of this document is to resume the increasing importance of qualitative market research, which has shown growth not just in scientific journals but also has larger numbers compared to quantitative research. The first step was reflecting on research in marketing and the possibilities it offers to get to know consumers and purchasing habits. The methodology applied is divided in two moments: the first moment is based on bibliometrics, which reviews trends in publications, and in the second moment, different scenarios from marketing research are proposed based on experts' opinions and prospective methods (Smic Prob-Expert method). The conclusion is that in the future, research will become a discipline that is largely associated to sensory and neurological studies, operated with social networking strategies and oriented to the description of specific phenomena, all of which will lead to a new scientific anthropo-marketing.

Research and development processes in marketing are very significant due to its impact on organizations: they are a liaison between the market and the company, thus connecting the company's internal and external processes.

Both types of marketing strategies, internal (which allow employees to understand their organizational function, plan their professional future and get aligned with the company's strategic objectives with action between HR and marketing aimed at organizational commitment (Bohnenberger, M. 2017)) and external, also known as rational marketing (which allow a connection and the generation of added value relationships to reach permanence and growth goals through brand loyalty (Cano, A. 2015)) are the daily tasks of organizations, forcing them to be updated in order to improve organizational performance (Farris, et al. 2015).

In order to conduct this task properly, it is necessary to acknowledge many aspects of the company and its surroundings, this requires constant research of all kinds to feed the marketing information system, known as MKIS (Lopez et al, 2015).

This system is a set of structured information and relations that provide reliable, accurate and timely information to make decisions within marketing areas (Layton, R. \& Duan, Z. 2015). It must ensure information reliability; therefore its collection must be subject to quality criteria, and it has to be current and reality-adjusted, it must also provide information that is relevant for the organizational needs (Rowley, J. 2016).

The aforementioned requires obtaining information centers at micro and macro environment scale (Smith, L. \& Wong, M. 2016, Leonidou et al, 2018).

The main functions of the marketing area directors are to analyze, plan, execute and control, which will attest the needs of the information and how it may be better 
used to implement the marketing strategy for the target audience and in terms of competitors, stakeholders and all macro environment forces (summarized in the acronym PESTEL Political, Economic, Social, Technological, Environmental and Legal) (Grünig, R., \& Kühn, R. (2015).

The environment search that comprises this marketing intelligence may have different types of sources:

- Informal: unstructured effort with the function of providing a general idea,

- Conditioned: when specific information is required, and

- Formal: planned and systematic search (Arias et al, 2016). Depending on the requirements, management may choose one or the other, or a mix of both.

Another additional element is competitors' research (Arnett, D. \& Wittmann, C. 2014) as a surveillance system, which is key to feed the MKIS, to observe changes taking place in companies in the same sector and to face the same changes and challenges offered by the environment to the company (Lopez et al, 2016).

Aside from the external elements, there are others that are directly related to the company's capacity to fulfill the consumers' needs, wishes and interests (East, R. el al, 2016, Barahona, et al, 2018), for which consumer behavior will try to identify:

- New needs

- Unfulfilled needs or needs that may be managed better

- Changes in the purchasing process

- Decision-making mechanisms in shopping

- Use or usage of products and services

- Impact of price changes

- Client satisfaction processes

- Brand positioning

- New distribution and communication channels with the clients

- Impact of social and environmental campaigns

- Regulation changes, among others.

All of the environment information will be entered by this area to be taken into account by the organizational strategic management (Solomon, M. 2014), this is precisely where market research as primary source of information becomes essential in the MKIS (Rani, P. 2014).

It may be said that market research as a scientific research process (Sekaran, U., \& Bougie, R. 2016) must abide by methodological requisites to guarantee objectivity and rigor. 
This enables information collection to solve questions formulated as part of the research process initiation, allowing it to recognize trends and relations in the system's understanding (Gutierrez, 2007).

Table No. 1 contains the main definitions of this process.

Table No. 1 Definitions of Market Research

\begin{tabular}{l|l} 
Author, year & Definition \\
\hline Malhotra, 2008 & $\begin{array}{l}\text { Market research is the "identification, compilation, analysis and } \\
\text { dissemination of information in a systematic and objective way, } \\
\text { with the purpose of improving decision-making processes that } \\
\text { relate to the identification and solution of marketing problems } \\
\text { and opportunities" p. 2 }\end{array}$ \\
\hline Kotler, Keller, 2009 & $\begin{array}{l}\text { It } \\
\text { presentation of data and findings that are pertinent to a specific } \\
\text { marketing situation faced by the company" p. 23 }\end{array}$ \\
\hline Sandhusen, 2005 & $\begin{array}{l}\text { "A systematic compilation, record, analysis and distribution of } \\
\text { data and information on marketing problems and opportunities. } \\
\text { P. 33 }\end{array}$ \\
\hline $\begin{array}{l}\text { "Market research is the function that connects the consumer, } \\
\text { client and trader through information. This information is used } \\
\text { to identify and define marketing opportunities and problems; as } \\
\text { well as to generate, perfect and assess marketing actions, and } \\
\text { improve the understanding of marketing as a process"ç }\end{array}$ \\
\hline $\begin{array}{l}\text { American Marketing } \\
\text { Association, 2017 }\end{array}$ & $\begin{array}{l}\text { "Market research is a comprehensive part of marketing, in charge } \\
\text { of collecting and analyzing key information related to a specific } \\
\text { situation in the market. This information is used to identify and } \\
\text { define opportunities and to support decision-making processes. } \\
\text { Therefore, it is of the utmost importance in business decision- } \\
\text { making since it steers the development of business strategies". }\end{array}$ \\
\hline
\end{tabular}

Source: research

These processes may take two routes: quantitative and qualitative (Brannen, J. 2017, Hanssens, 2018). The first methodological route (qualitative) searches for the why and the how, based on hermeneutics, phenomenology and social interaction: social applications such as ethnography, action-participation and using history research. It is based on direct methods, such as group sessions and in-depth interviews, or on indirect methods, applying techniques such as association, termination, construction and expression (Hussein, A. 2015, Burke, R. 2018). 
The quantitative route examines the analytical, experimental or descriptive with a mathematical lens. It allows a generalization of results due to its statistical and probative development (Figure No. 1).

Figure No. 1 Types of Research

\begin{tabular}{|l|l|}
\hline \multicolumn{2}{|c|}{ Qualitative Qualitative } \\
\hline $\begin{array}{l}\text { - Hermeneutics } \\
\text { - Phernomenology }\end{array}$ & - Analytical \\
- Social interaction & - Experimental \\
& - Descriptive \\
\hline
\end{tabular}

Source: the research

The differences among both research alternatives are very appealing (Lipowski, eta al, 2018), nonetheless, mixed analyses allow a complete observation of the outlook. Table No. 2 shows the limitations of each method.

\begin{tabular}{|l|l|}
\hline Qualitative & Quantitative \\
\hline $\begin{array}{l}\text { Focuses on phenomenology and } \\
\text { comprehension }\end{array}$ & Probabilistic induction of logical positivism \\
\hline Subjectivity & Permanent and controlled measurement \\
\hline Data inference & Inference that is posterior to the data \\
\hline Exploratory, inductive and descriptive & Confirmatory, inferential, deductive. \\
\hline Process-oriented & Result-oriented \\
\hline Does not allow generalizations & Repeatable data that may be generalized \\
\hline Changing and dynamic reality & Static reality \\
\hline
\end{tabular}

Table No. 2 Differentiation of the Research Methodologies. Source: Delgado, 2017. P. 1

With this environment in mind, this chapter aims at elucidating the main trends in research, highlighting the advantages of each through the analysis of secondary sources and prospective analysis. 


\section{METHODOLOGY}

In order to achieve the objective of establishing the main trends in qualitative marketing research, this document combines a methodology of analyzing the main academic contributions, especially those related to a quantitative analysis, followed by the qualitative analysis. With this purpose, the methodology throughout the analysis stages consisted in establishing which of the academic contributions had qualitative and which had quantitative characteristics, as illustrated in Figure No. 1.

Figure No.1 Stages of the Analysis

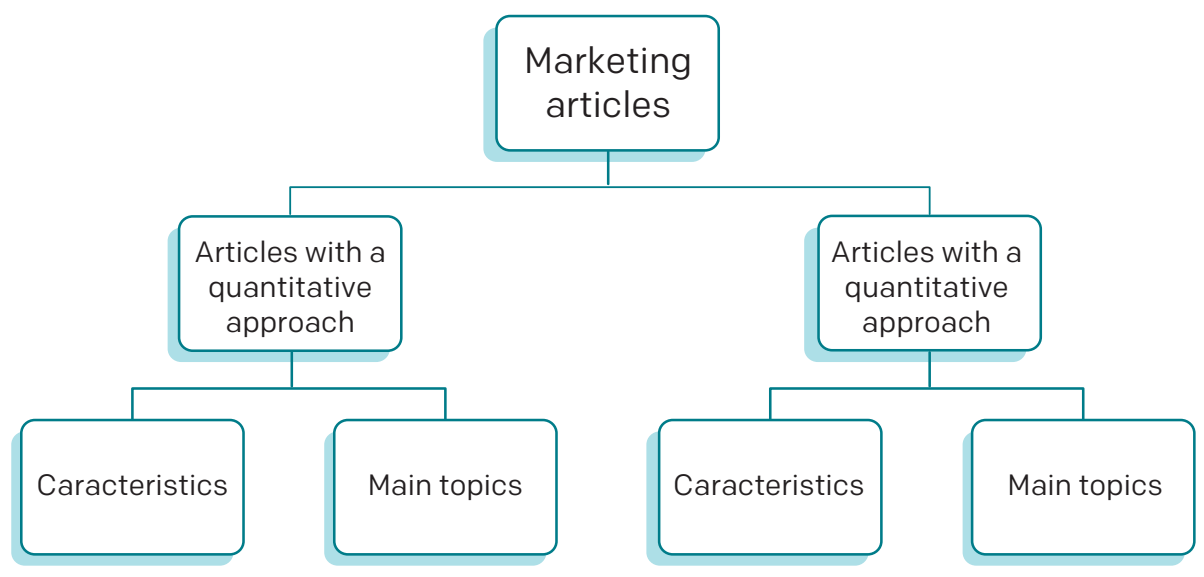

Source: the research

Likewise, 4 article typologies were found in the academic material, which were useful to conduct this type of research, one focuses on quantitative analysis and three others are specifically related to the qualitative approach, as explained in Table No. 3 
Table No. 3 Characteristics of the Research Approaches in Marketing

\begin{tabular}{|c|c|c|}
\hline Type of document & Characteristics & Approach \\
\hline Empirical-quantitative & $\begin{array}{l}\text { Articles based on real data, whe- } \\
\text { ther exploratory, descriptive or } \\
\text { explanatory, that analyze rela- } \\
\text { tions between different variables } \\
\text { through quantitative analysis } \\
\text { techniques. }\end{array}$ & $\begin{array}{l}\text { Statistical, descriptive } \\
\text { and inferential analysis, } \\
\text { parametric and non-para- } \\
\text { metric tests, multi-vari- } \\
\text { able analysis. } \\
\text { Experiments are also } \\
\text { included. }\end{array}$ \\
\hline Empirical-qualitative & $\begin{array}{l}\text { Articles based on real data, } \\
\text { whether exploratory, descriptive } \\
\text { or explanatory, that analyze real } \\
\text { organizational phenomenon } \\
\text { without resorting to quantitative } \\
\text { analysis techniques. }\end{array}$ & $\begin{array}{l}\text { Descriptions of histories, } \\
\text { case studies and narra- } \\
\text { tives take precedence, } \\
\text { methodologies such as } \\
\text { grounded theory may be } \\
\text { considered. Overall, this } \\
\text { theory may be sum- } \\
\text { marized in observation, } \\
\text { interviews / surveys, } \\
\text { document compilation } \\
\text { and research action. }\end{array}$ \\
\hline Conceptual-applied & $\begin{array}{l}\text { Articles that analyze theories or } \\
\text { concepts and models suggesting } \\
\text { models, approaches or recipes } \\
\text { as practical guides to be used by } \\
\text { management professionals. }\end{array}$ & $\begin{array}{l}\text { Suggest new alterna- } \\
\text { tives for reality analysis } \\
\text { through analytical deduc- } \\
\text { tive methodologies. }\end{array}$ \\
\hline Conceptual-theoretical & $\begin{array}{l}\text { Articles centered on theoretical } \\
\text { knowledge dissemination of exis- } \\
\text { ting theories or models or based } \\
\text { on criticism or magnification. }\end{array}$ & $\begin{array}{l}\text { Conceptual develop- } \\
\text { ments of analyzed real- } \\
\text { ities that show alterna- } \\
\text { tives. }\end{array}$ \\
\hline
\end{tabular}

Source: Adapted from Gantman, E. R., \& Rodriguez, C. J. F. (2017) p. 5)

In Colombia, there is an association of companies that conduct market research and that are certified with UNE-ISO 20252:2012 Market, social and opinion research to guarantee product quality. These companies also divide their research in different typologies, and in qualitative and quantitative research, as seen in Figure No. 2. This proves that the methods are widely used in any of the research's typologies required. 
Figure No. 2 Business Approaches
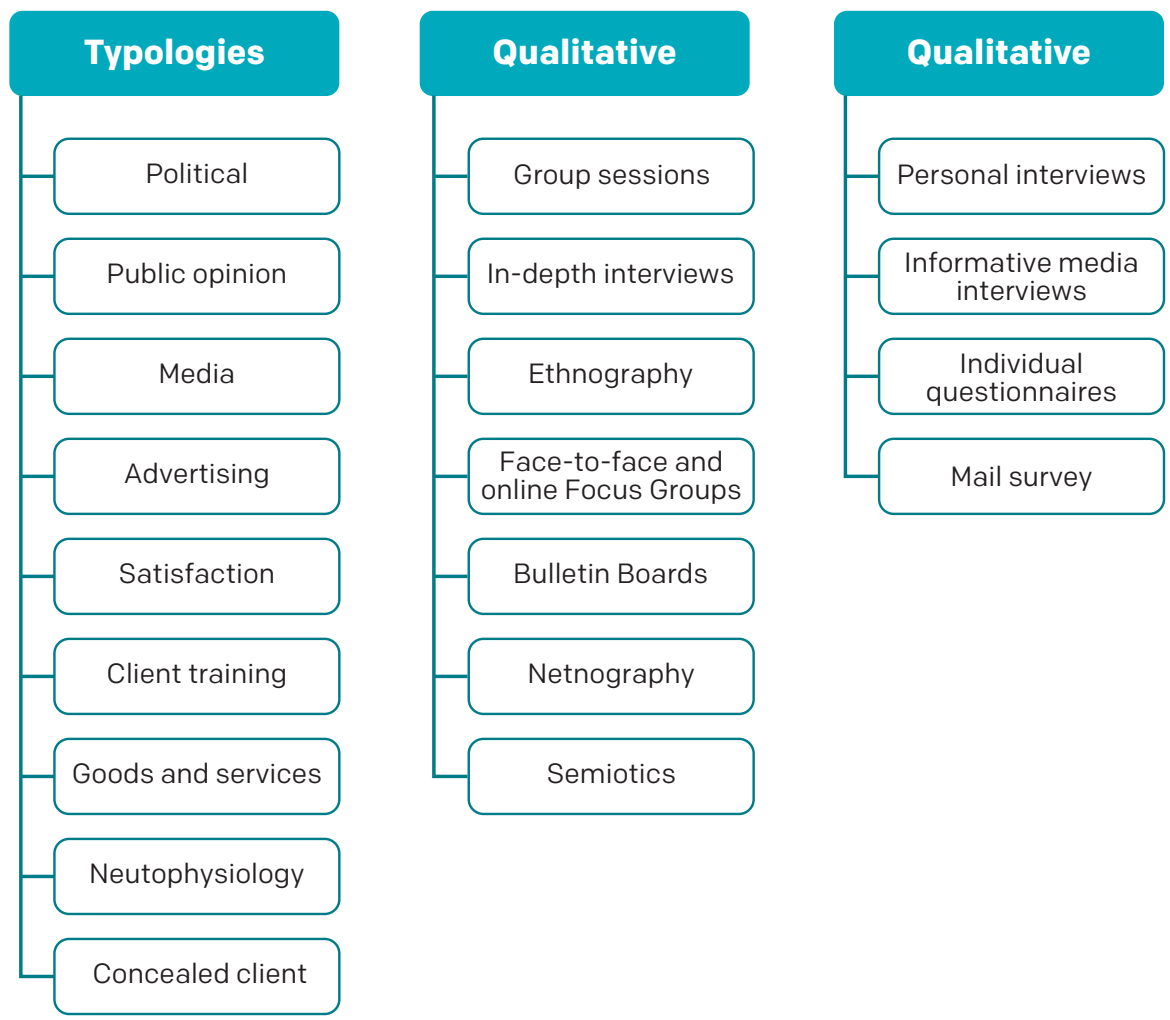

Source: adapted from ACEI, 2017

With the probabilistic findings, a probabilistic cross-reference impact matrix was created based on the contributions of a panel of 10 marketing management experts, 5 of them from the academic sector (McBride, et al, 2017). These results "were oriented towards determining simple and conditional probabilities of hypotheses and/or events, as well as the combination probabilities of the latter, taking into account the interactions between events and/or hypotheses" (Godet, 2017). This method, denominated SmicProb-Expert® was developed in 1974 by Michel Godet regarding nuclear power topics (Godet, 1997), the objective of the methodology is to determine probabilities to develop more likely scenarios and to evaluate low-impact combinations. Thanks to the methodology suggested by Godet, M., \& Durance, P. (2007), Amer et al, 2013, variable prioritization is achieved in decision-making processes, as observed in Figure No. 2. The analysis herein is intended to achieve strategic architecture as a future project (Stratigea, A., \& Papadopoulou, C. A. (2013). 
Figure No. 2 Smic Prob-Expert ${ }^{\circledR}$ Method

SMIC PROB-EXPERT Method

Probabilistic cross-referenced impact

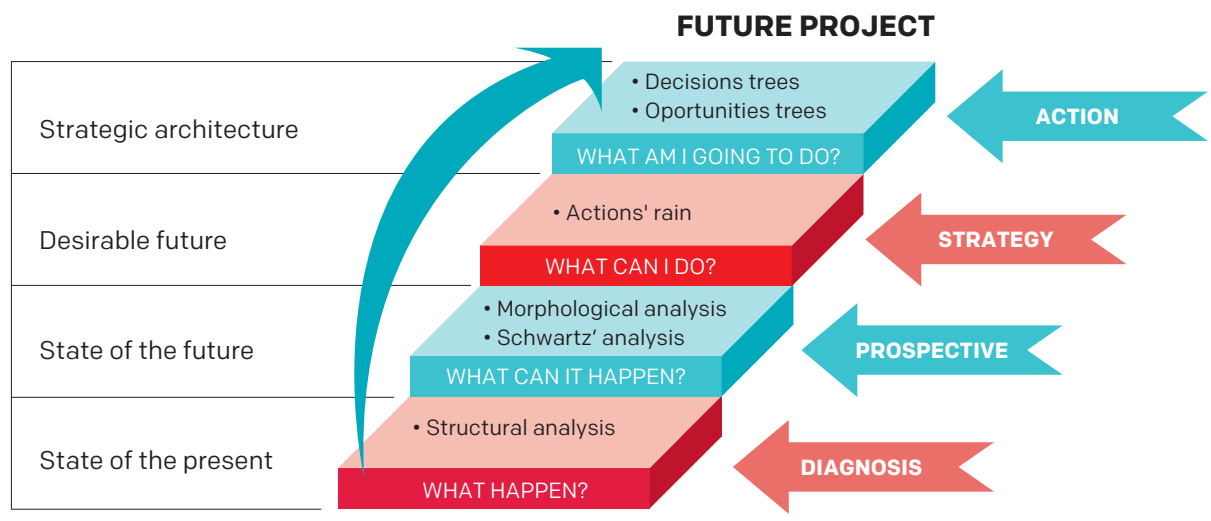

Source: Gill Bolivar Fabio, Prospectiva estratégica t, UNAD, 2001, pág. 10

The methodology focuses on 3 stages (Figure No. 3), the first is where hypotheses are formulated and experts are selected, it is followed by a probabilization of scenarios in order to proceed with the suggested strategy to obtain the expected results.

Figure No. 3 Smic-Prob-Expert® Methodology

Stage 1: formulation of hypotheses and expert selection

- A SMIC survey begins with 5 or 6 fundamental hypotheses and some complementary hypotheses.

- An expert panel requests an evaluation of the simple fulfillment probability of one hypothesis from a probability of 1 (very weak) to a probability of 5 (very likely)

- The fulfillment is evaluated under the conditional probability of one hypotheses in relation to all of them.
Stage 3: Strategic proposal

- Based on the selected scenarios, alternatives are proposed to achieve the best scenario. 
The Smic-Prob-Expert@ program (a classic minimization program of a quadratic form with linear limits) allows the experts to conduct the analysis, eliminating opinions by experts that are not coherent or that affect the probability of each of the $2 \mathrm{~N}$ possible combinations of the $\mathrm{N}$ hypotheses (Sarpong, et al, 2013).

\section{RESULTS}

\section{Marketing Bibliometrics Analysis According to Research Focus}

Marketing research has grown both ways in the fields of qualitative and quantitative research; overall in the marketing field, publications in the Scopus ${ }^{\circledR}$ database in 1980 amounted to 858 per year and by 2016 to 10,456 (Figure No. 4), however, a decrease was experimented, which it shall be analyzed in years to come.

Figure No. 4 Documents Found in the Marketing Formula

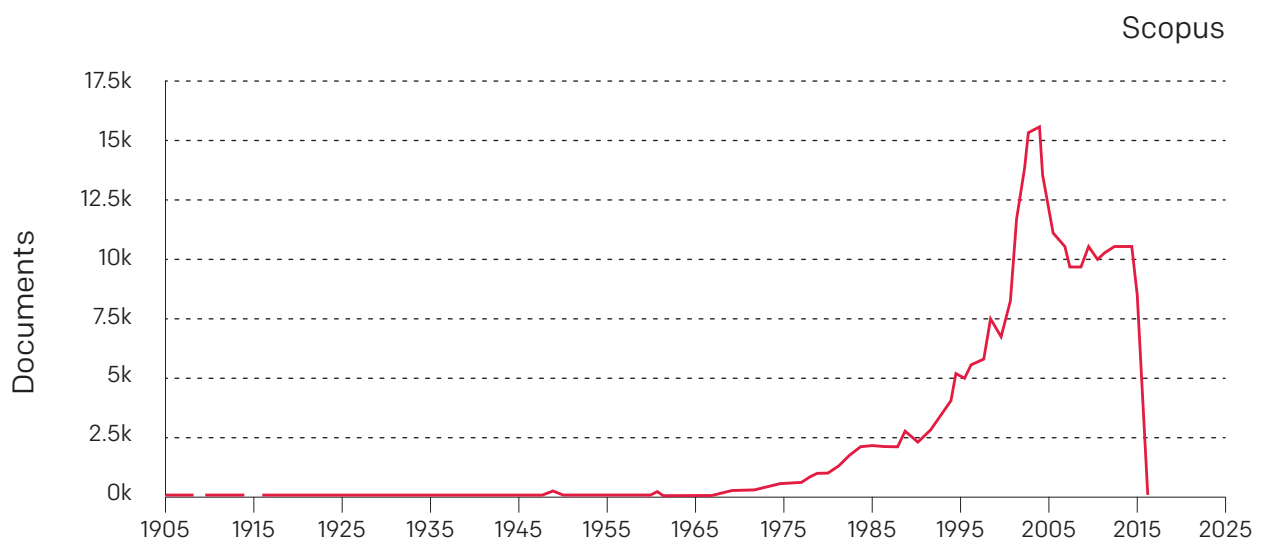

Source: Scopus® Date: November $7^{\text {th }}, 2017$

From these articles, Figure No. 5 shows a comparison between the two large methodologies, articles with quantitative methodology have a significant increase between 20002015, with an approximate peak of 345 articles in 2015, the qualitative methodology shows a similar growth rate but with a higher number of publications, its peak exceeded 500 in 2017. 
Figure No. 5 Comparison Between Qualitative Marketing Articles vs. Quantitative Marketing Articles

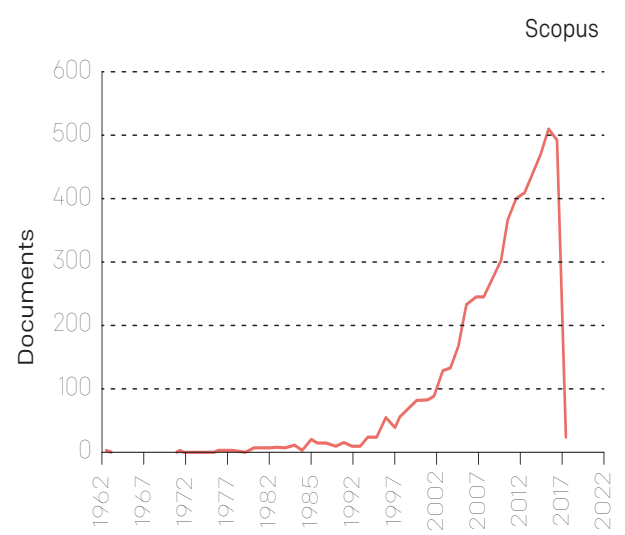

Qualitative and marketing

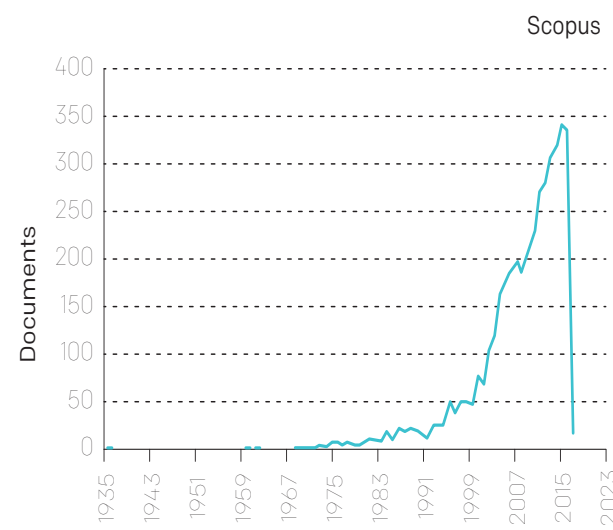

Qualitative and marketing

Source: Scopus® Date: January $17^{\text {th }}, 2018$

By observing the Figures, it is clear that both cases present a trend of growth, the difference lies in the number of publications: quantitative had peak of 344 in 2016 out of a total 4,079 since 1936, qualitative had a peak of 513 in the same year out of a total of 5,547 since 1962. There are more publications with qualitative analysis.

\section{Analysis of the Experts' Results}

When the experts were inquired regarding the development and research possibilities in the fields of qualitative research, they identified 5 research fields that are expected to lead marketing research.

Focusing on the qualitative type of research, different variables may arise in the research (Gutierrez, J., \& Delgado, J. M. (1999), with the fields proposed, Bibliometrics were reviewed, the findings appear in Figure No. 6, reflecting special growth in ethnography, networks, neuromarketing, and sensory marketing research, interest in the aforementioned has grown (elected by the experts), the case of research related to interactive surveys (Hulland, et al (2018) has had increase and decrease intervals, but it was taken into account due to its importance in the future. 
Figure No. 6 Main Articles in Qualitative Research

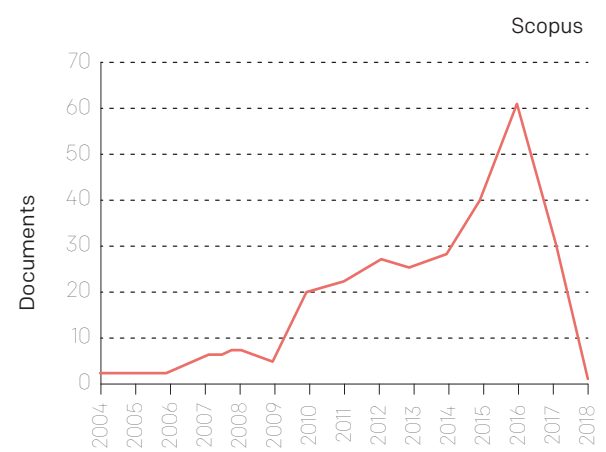

Neuromarketing

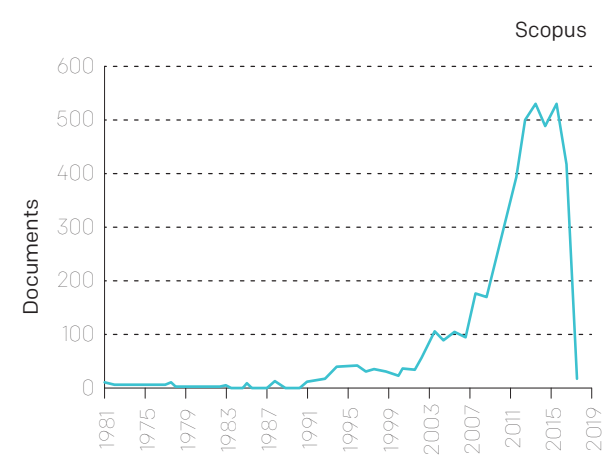

Marketing and Network

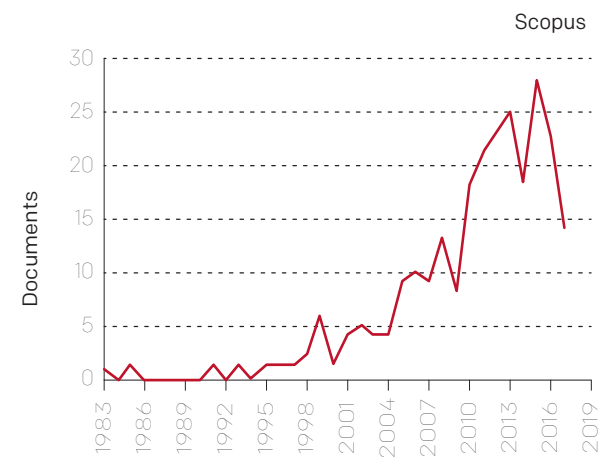

Etnography

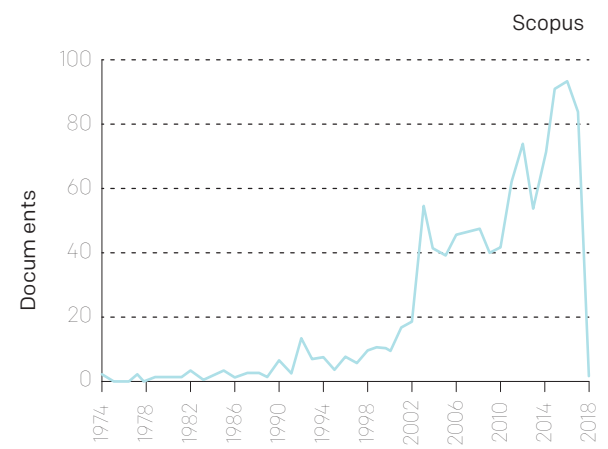

Marketing and sensory

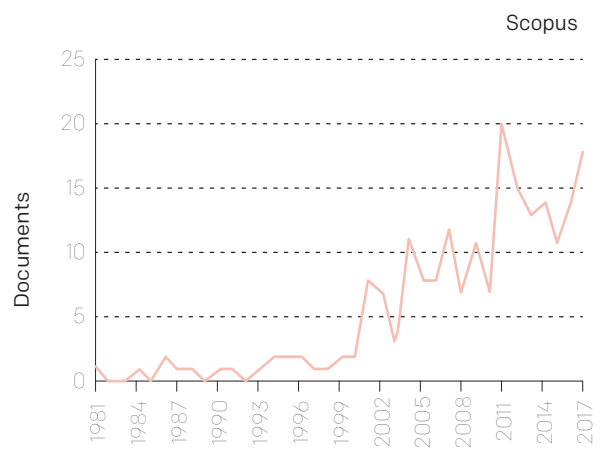

Marketing and intractive surveys 
Once these 5 research fields were decided, the experts were asked for the definition of each one by outlining a future hypotheses describing the expectations in a 15-year horizon. These hypotheses indicate the way each research approach is expected to be oriented towards the future. The descriptions describing the hypotheses are summarized in Table No. 4.

Table No. 4 Description of the Qualitative Research Fields

\begin{tabular}{|l|l|l|l|}
\hline$N^{\circ}$ & Long title & Short title & Description \\
\hline 1 & $\begin{array}{l}\text { Research on social } \\
\text { networks }\end{array}$ & SocialN & $\begin{array}{l}\text { More automatic social networks in devices } \\
\text { of contextual use, so as not to interrupt } \\
\text { the interrelation of the consumer with the } \\
\text { environment. Not only generators of data } \\
\text { and likes, but of identification of patterns of } \\
\text { tendencies of repurchase. }\end{array}$ \\
\hline 2 & $\begin{array}{l}\text { Research on } \\
\text { ethnographic studies }\end{array}$ & Ethno & $\begin{array}{l}\text { Ethnographies focused on fictional designs } \\
\text { to explore not only learning from experience } \\
\text { but also from the imagination. }\end{array}$ \\
\hline 3 & $\begin{array}{l}\text { Research in } \\
\text { neurophysiology for } \\
\text { marketing }\end{array}$ & Neuro & $\begin{array}{l}\text { Consumer evaluation technology less } \\
\text { invasive and at the time of decision-making. }\end{array}$ \\
\hline 4 & $\begin{array}{l}\text { Sensory research in } \\
\text { marketing }\end{array}$ & Sens & $\begin{array}{l}\text { Development of interfaces for better use of } \\
\text { the human senses (consumers). }\end{array}$ \\
\hline 5 & $\begin{array}{l}\text { Development of } \\
\text { interactive surveys }\end{array}$ & Survey & $\begin{array}{l}\text { Everyday applications of surveys with virtual } \\
\text { and applied reality. }\end{array}$ \\
\hline
\end{tabular}

Source: the research

The experts were explained that the Smic-prob-expert $\AA$ method would be applied (cross-reference impact analysis), intended to inquire the experts about their opinion regarding the occurrence of some future hypotheses or events in a defined timeline and its mutual influences. The hypotheses turned out to be descriptions or explanations that seek to foretell the future state of a process.

Once the hypotheses were outlined, the panel members were asked to express their opinion regarding the probability of occurrence of each hypotheses $(\mathrm{Hi}=\mathrm{H} 1, \mathrm{H} 2$, $\mathrm{H} 3, \mathrm{H} 4, \mathrm{H} 5$ ) in the timeline. They were asked to score each one as very likely, likely, uncertain, unlikely or very unlikely $(0.9,0.7,0.5,0.3,0.1$ respectively).

The probabilities of each hypothesis are known as $\mathrm{P}(\mathrm{i})$ of the hypotheses or simple scores. Afterwards, the experts proceeded to score the positive and negative conditioned probabilities as a structural analysis through the cross-reference matrix evaluation, in order to appreciate their opinion regarding the probability of occurrence of a hypothesis, if another hypothesis were probable (positive) or not (negative). Conditional probabilities are taken against each other, as follows: 


\section{$P(i / j)$ probability of $i$ if $j$ were to take place}

\section{$P(i / j)$ probability of $i$ if $j$ were not to take place}

According to the help manual of the SMIC application, the following conditions have to be fulfilled:

"These raw opinions must be such that the net results respect the following conditions:

a) $0<P($ i $)<1$

b) $P(i / j) \cdot P(j)=P(j / i) \cdot P(i)=P(i \cdot j)$

c) $P(i / j) \cdot P(j)+P(i / n o j) \cdot P($ noj $)=P(i)$

The principle of the Smic method consists of correcting the raw opinions expressed by the experts in a way that obtains coherent net results (meaning, satisfying the classic problems on probabilities), the closest to the initial estimates" (Smic-probexpert ${ }^{\circledR}$ help)

With this strategy, the application obtains net probabilities on the hypotheses with a median of probability distribution. The solution is obtained with a quadratic minimization; this way, the application classifies the possible scenarios based on the experts' scores.

Figure No. 7 shows the future scenarios for a 15 -year horizon, it can be observed that only a few scenarios turn out to be very likely based on the scores allocated by the panel of experts: 
Figure No. 7 Future Scenarios by the Experts' Panel

\section{Histogram of Probability of the Scenarios (Expert)}

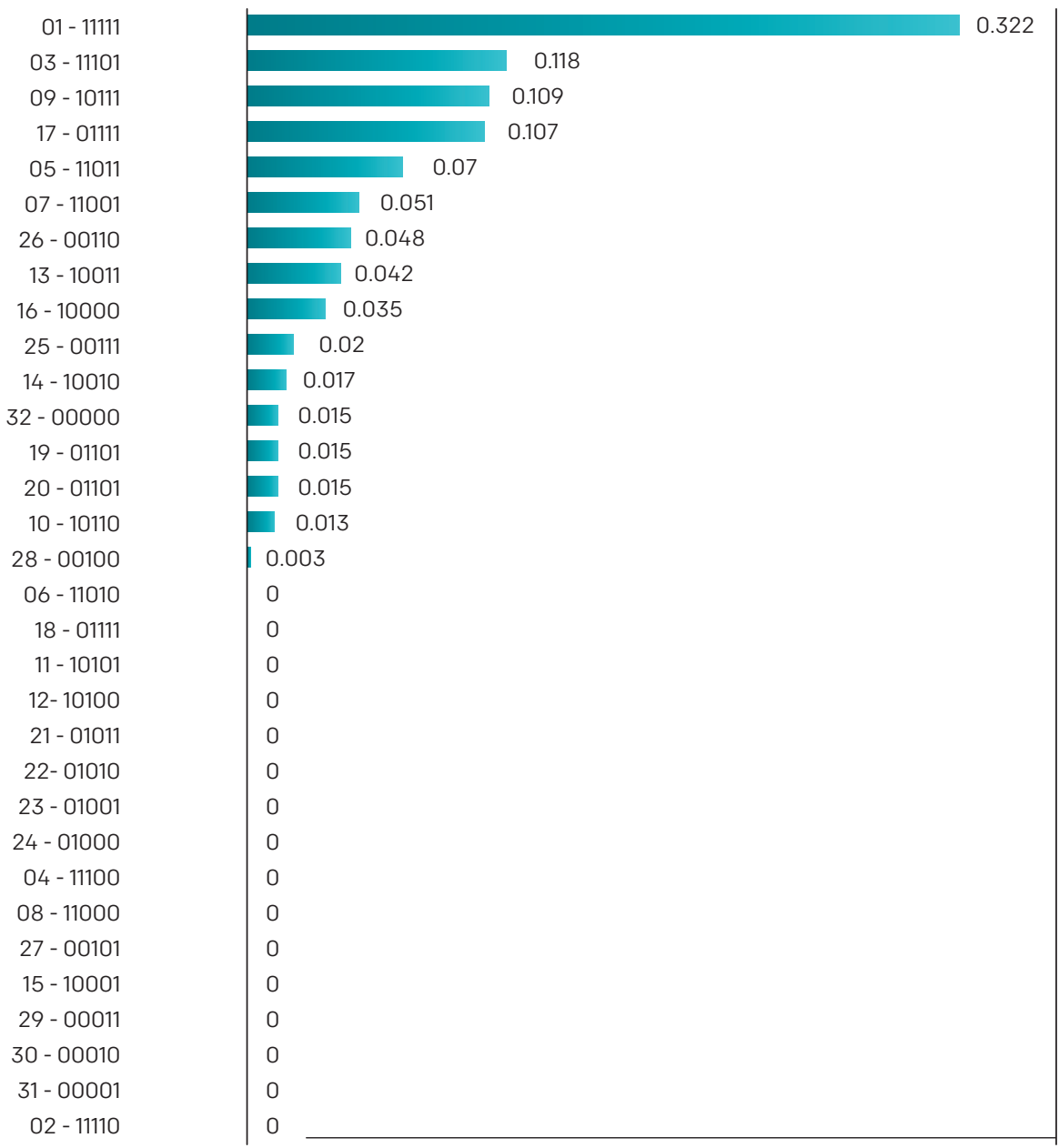

Source: Smic-prob-expert $\AA$

These scenarios present different alternatives:

Scenario 11111 is the one perceived as most likely, in which it is expected that in 15 years, all of the hypotheses take place and synergies between the hypotheses acknowledged for each research field are generated. Marketing will be a discipline that is highly associated with sensory and neurological studies, operated with social networking strategies and oriented towards the description of specific phenomena with an ethnographic approach. 
The second most likely scenario is 11101 , which acknowledges that almost all the proposed hypotheses will take place, but challenges may arise in fulfilling the sensory research field hypothesis due to difficulty of having sophisticated functional interfaces that are articulated to the human sensory system. This scenario acknowledges a future challenge in the research agenda associated with the development of science and technology that enables communication and control processes between the human brain, the nervous system, devices, the sensory system and its organs, and its connections, as well with the ethical and engineering aspects involved in an agenda such as this one. It could result in consumers rejecting the use of prosthetics and/or relatively invasive additions to enhance the human sensory experience.

10111 is the third most likely scenario. In the future, all of the hypotheses take place except the one regarding ethnographic studies research. This specific difficulty may be associated with the strong trend of social groups' diversification, it could be particularly difficult to recognize homogeneous groups within the investigation and for them to keep stable patterns in time, or for studies to result in possible adaptations to a dominant vision in an indepth neoliberal consumption model. Progress in the neurological and sensory fields may lead to group experiences becoming significantly particular to the individual consumption experience.

The fourth likely scenario is 01111. It acknowledges the difficulty of having more automated social networks in devices of contextual use. As well as the difficulty of being able to identify patterns of tendencies of repurchase with these networks. Aspects such as ethical and respectful usage of consumers' personal data in highly automated networks, the exhaustion of the technological addiction model based on gratification deriving from social networks and the perception of time loss or lack or reality could affect this research field. The scenario could show that the development of better networking requires identifiable group consumption, and that limitations in the sensory agenda or neuromarketing studies could affect novel ways of social network interaction, its contextual use and automation.

A fifth relevant scenario implies all the hypotheses taking place in 15 years, except for marketing neurophysiology. It is unclear if accessible and affordable evaluation technology that is not extremely invasive for consumers can be in place. It is also difficult to appreciate the power of understanding the consumer better, as well as the aspect related to the moment of decision-making. This scenario acknowledges that a future challenge for the development of the research agenda is the field of neurophysiology for marketing, seeing as its absence will determine the diversified or successful development of the other hypotheses.

After the scenarios are differentiated, it is possible to conduct a sensitivity analysis to appreciate how, as a result of the scores, the $\Delta \mathrm{Pj}$ variation of a $\mathrm{Pj}$ probability of the $\mathrm{j}$ event, as a result of a variation in the $\Delta \mathrm{Pj}$ probability of the i event. The results are in the form of an elasticity matrix in the eij form. 


$$
e(i j)=((P(i) \cdot \Delta P(j)) /(P(j) \cdot \Delta P(i)))
$$

The additions that accumulate effects on each hypotheses, measured with the eij coefficient, may make up a matrix in which the additions of the absolute value generate a measure of the influence of hypothesis i on the others. Consequently, additions per column account for the dependence of the hypotheses. (Source: Smic-prob-expert $\AA^{\circledR}$ help)

The values are seen in Figures No. 8 and 9 (Histograms of sensitivity of influences and dependences):

Figure No. 8 Histogram of Sensibility of Influences

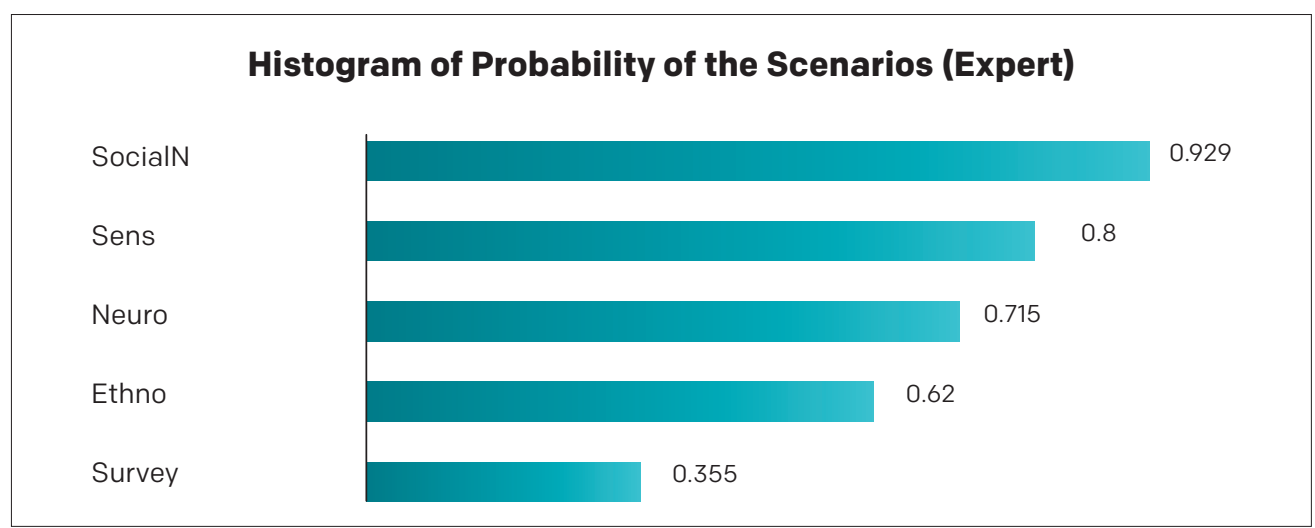

Source: Smic-prob-expert ${ }^{\circledR}$

Figure No. 9 Histogram of Sensibilities of Dependences

\section{Histogram of Sensitivity of Dependences (Expert)}

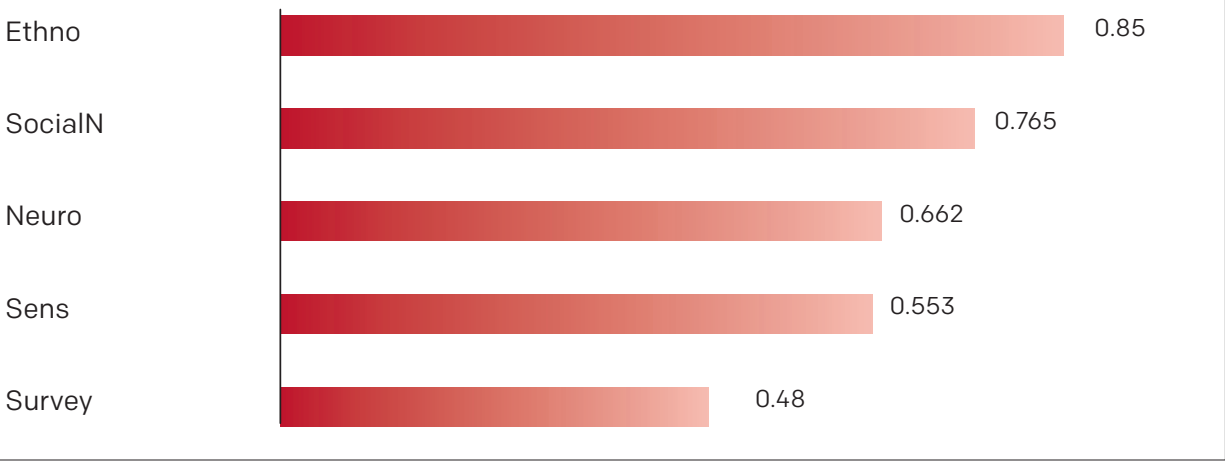

Source: Smic-prob-expert $®$ 
This way, a table to summarize the scores of the influences and dependences was compiled, determining the location of each trend, as follows:

Table No. 5 Matrix of Dependence and Influence of Described Trends

\begin{tabular}{|l|l|l|l|} 
& Dependence & Influence & Zone \\
\hline Socialnet & 0.765 & 0.929 & Strategic \\
\hline Sens & 0.653 & 0.8 & Challenge \\
\hline Neuro & 0.662 & 0.715 & Challenge \\
\hline Ethno & 0.86 & 0.62 & Effect \\
\hline Survey & 0.48 & 0.355 & Autonomous \\
\hline Average & 0.684 & 0.6838 & \\
\hline
\end{tabular}

Source: the research

Scores can be placed in a graph in a plane of dependences and influences ( $\mathrm{x}$ and y axes, respectively). Therefore, it is possible to have 4 areas or regions, as follows:

- An area with major influence hypotheses and minor dependences, configurating future challenges, it is the power area of the graph and the most influential.

- An area with major influence hypotheses and major dependences. This is known as an area of conflict, and it usually includes strategic aspects on others.

- An area with major dependences and minor influences, known as exit or effects area.

- An area with minor influences and minor dependences, leading to an area of autonomous hypotheses.

In Figure No. 10 of dependences and influences, the values adding the sensibility analysis are placed in the graph, and the hypotheses are classified in four areas:

The hypotheses of the sensory and neurological fields are in the power area, meaning these will be the most relevant fields in the future, the ones with the capacity to influence on the others and, relatively, the most independent.

Social networking is in the conflict area, it is influenced by the sensory and neurophysiology fields. This area also influences others, especially ethnographic studies.

The ethnographies hypothesis is the most dependent, while the surveys hypothesis is relatively autonomous. 
Figure No. 10 Dependences and Influences

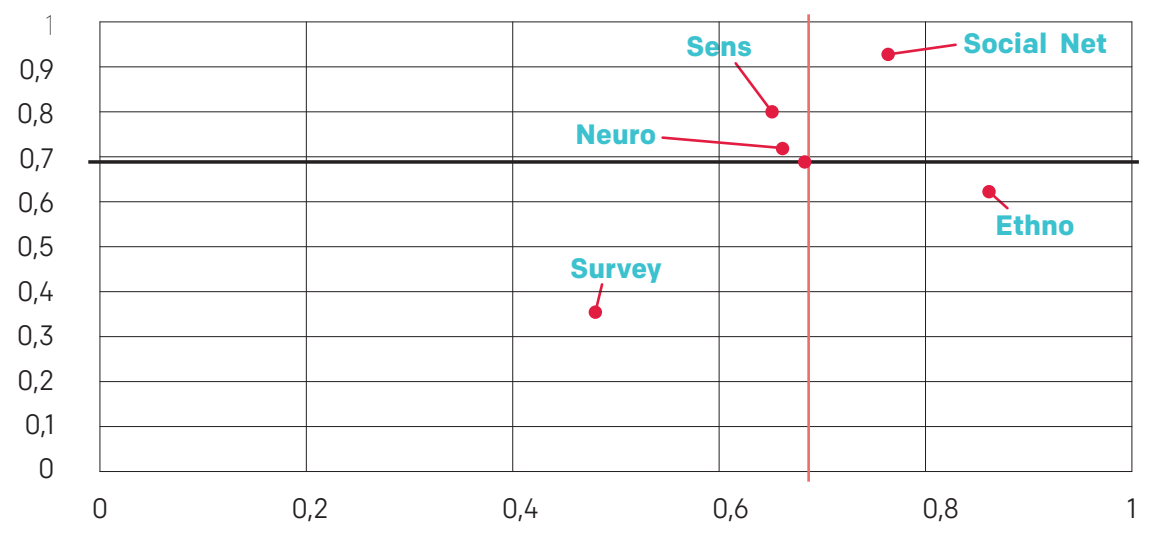

Source: the research

\section{CONCLUSIONS}

Analyzing the types of marketing research, it is found that qualitative research has been developing with more intensity than the quantitative research; although an indepth review may reveal one phenomenon being studied using a mixed tactic: first, a qualitative analysis to approach the problem, followed by a quantitative analysis to determine the true relations and be more accurate in the studies conducted.

Five important development areas are found when focusing on qualitative research: neuromarketing and nano-marketing research, sensory marketing research, social networks and Internet analysis, ethnographies and different ways of interactive interviews.

When experts were asked about these 5 trends, and having to score them with the Smic-prob-expert $®$ prospective method, it was found that marketing research will be a discipline that is highly related to sensory and neurological studies, operated with social networking strategies and oriented to the description of specific phenomena with an ethnographic approach, which may be called scientific anthropo-marketing, meaning the study of the most social and human behaviors from the perspective of sociology and anthropology, but grounded on results obtained by neurosciences. After the hypotheses were located in a matrix, it was clear that the sensory and neurological fields are in the power zone and will lead research without leaving social and fundamentally human approaches behind. More and more, there is a need to corroborate social and impact analyses on others in consumption with scientific and technological advances. 


\section{REFERENCES}

Amer, M., Daim, T. U., \& Jetter, A. (2013). A review of scenario planning. Futures, 46, 23-40.

Aranda Ogayar, M. (2001). Método de los escenarios: apuntes teóricos. Obtenido en línea el 7 de abril de 2010. Disponible en: www4.ujaen.es/ egarcia/programadedirest05-06.doc

Arias, Á., Durango, A., \& Navarro, M. S. (2016). Curso de Marketing Online: $2^{a}$ Edición. IT Campus Academy.

Arnett, D. B., \& Wittmann, C. M. (2014). Improving marketing success: The role of tacit knowledge exchange between sales and marketing. Journal of Business Research, 67(3), 324-331.

Barahona, I., Hernández, D. M., Pérez-Villarreal, H. H., \& del Pilar Martínez-Ruíz, M. (2018). Identifying research topics in marketing science along the past decade: a content analysis. Scientometrics, 117(1), 293-312.consumi

Bohnenberger, M. C. (2017). Marketing interno: la actuación conjunta entre recursos humanos y marketing en busca del compromiso organizacional.

Brannen, J. (Ed.). (2017). Mixing methods: Qualitative and quantitative research. Routledge.

Burke, R. (2018). Virtual Reality for Marketing Research. In Innovative Research Methodologies in Management (pp. 63-82). Palgrave Macmillan, Cham.

Cano, A. M. Á. (2015). Las relaciones sociales entre el proveedor y el comprador. Aplicación empírica del Marketing Relacional: un caso de estudio/The Social Relations Between the Supplier and the Buyer. Empirical Application of Relationship Marketing: a Case of Study. Revista Internacional de Ciencias Sociales, 4(1).

Dávila, G. G., \& Davila, M. C. G. (2014). Metodología de la Investigación. Grupo Editorial Patria.

Delgado. M. 2017. Método y metodología de la investigación cientifica. Disponible en: http://fti500marceladelgado.blogspot.com.co/2010/05/taller-5-metodo-y-metodologia.html

East, R., Singh, J., Wright, M., \& Vanhuele, M. (2016). Consumer behaviour: applications in marketing. Sage.

Farris, P., Bendle, N., Pfeifer, P., \& Reibstein, D. (2015). Marketing metrics: The manager's guide to measuring marketing performance. FT Press.s be combined?. Journal of Comparative Social Work, 4(1).

Gantman, E. R., \& Rodríguez, C. J. F. (2017). Literatura académica de administración en países de habla hispana: Análisis bibliométrico de la producción en revistas de la base Latindex Catálogo (2000-2010). Investigación Bibliotecológica. Archivonomía, Bibliotecología e Información, 31(72), 39-61.

Godet M., 1997.Manuel de prospective stratégique, tome 2: L’art et la méthode, Dunod, Paris.

Godet, M., \& Durance, P. (2007). Prospectiva Estratégica: problemas y métodos. Cuadernos de LIPSOR, 104.

Gómez Gonzales, W., Gonzales Santos, E., \& Rosales Rojas, R. (2015). Metodología de la Investigación.

Grünig, R., \& Kühn, R. (2015). Global Environmental Analysis. In The Strategy Planning Process (pp. 89-96). Springer Berlin Heidelberg.

Gutiérrez, J. (coord.) (2007) La investigación social del turismo : perspectivas y aplicaciones. Madrid : Paraninfo, 
Gutiérrez, J., \& Delgado, J. M. (1999). Métodos y técnicas cualitativas de investigación en ciencias sociales. España. Síntesis.

Hanssens, D. M. (2018). The value of empirical generalizations in marketing. J. of the Acad. Mark. Sci. (2018) 46: 6. https://doi.org/10.1007/s11747-017-0567-0

Hernández J. (2013) Escenarios y prospectiva política , Michoacan, disponible en: https://es.slideshare.net/ICADEP/escenarios-y-prospe-abelardo-23418874

Hulland, J., Baumgartner, H., \& Smith, K. M. (2018). Marketing survey research best practices: evidence and recommendations from a review of JAMS articles. Journal of the Academy of Marketing Science, 46(1), 92-108.

Hussein, A. (2015). The use of triangulation in social sciences research: Can qualitative and quantitative methods be combined?. Journal of Comparative Social Work, 4(1).

Kotler, P., \& Keller, K. L. (2009). Dirección de marketing. Pearson educación.

Layton, R. A., \& Duan, Z. (2015). Diversity in Marketing System Assortments. Journal of Macromarketing, 35(3), 320-333.

Leonidou, L. C., Katsikeas, C. S., Samiee, S., \& Aykol, B. (2018). International marketing research: A state-of-the-art review and the way forward. In Advances in Global Marketing (pp. 3-33). Springer, Cham.

Lipowski, M., Pastuszak, Z., \& Bondos, I. (2018). Synergy of Quantitative and Qualitative Marketing Research- Capi and Observation Diary. Econometrics, 22(1), 58-67.

López, C. A. G., Sossa, J. W. Z., Zarta, R. H., Reveiz, R. E., Gómez, C. A. G., Uribe, J. H. D., \& Garcés, J. G. (2016). Vigilancia Tecnológica y Análisis del Ciclo de Vida de la Tecnología: Revisión de herramientas para el diagnóstico empresarial y la aplicación del ciclo de vida del producto en el sector turismo. Espacios, 37(36).

López-Bonilla, J. M., López-Bonilla, L. M., \& Peña-Vinces, J. C. (2015). Marketing Information Systems: An integrative view. Tourism \& Management Studies, 11(2), 197-203.

Malhotra, N. K. (2008). Marketing research: An applied orientation, 5/e. Pearson Education India.

McBride, M., Lambert, K., Huff, E., Theoharides, K., Field, P., \& Thompson, J. (2017). Increasing the effectiveness of participatory scenario development through codesign. Ecology and Society, 22(3).

Rani, P. (2014). Factors influencing consumer behaviour. International journal of current research and academic review, 2(9), 52-61.

Rowley, J. (2016). Information marketing. Routledge.

Sandhusen, R. L. (2005). Mercadotecnia Internacional. 2a . Edición, Editorial. Grupo Patricia Cultural SA de CV, México.

Sarpong, D., Maclean, M., \& Davies, C. (2013). A matter of foresight: How practices enable (or impede) organizational foresightfulness. European Management Journal, 31(6), 613-625.

Sekaran, U., \& Bougie, R. (2016). Research methods for business: A skill building approach. John Wiley \& Sons.

Smith, L. C., \& Wong, M. A. (Eds.). (2016). Reference and Information Services: An Introduction: An Introduction. ABC-CLIO.

Solomon, M. R. (2014). Consumer behavior: Buying, having, and being (Vol. 10). Upper Saddle River, NJ: Prentice Hall.

Stratigea, A., \& Papadopoulou, C. A. (2013). Foresight analysis at the regional level-a participatory methodological framework. Journal of Management and Strategy, 4(2), 1 
